\title{
TRANSITION METAL-MEDIATED SYNTHESIS OF OXAZOLES
}

\section{Stefano Bresciani and Nicholas C. O. Tomkinson*}

WestCHEM, Department of Pure and Applied Chemistry, Thomas Graham Building, University of Strathclyde, 295 Cathedral Street, Glasgow, G1 1XL, UK. E-mail: Nicholas.Tomkinson@strath.ac.uk

\begin{abstract}
Among the synthetic methods for the formation of the oxazole ring, transition metal-mediated protocols are the most attractive in terms of selectivity, efficiency and mildness of reaction conditions. In this review we discuss methods for the preparation of oxazoles using transition metal complexes highlighting the key bonds being formed. This reveals critical gaps in the existing literature for the construction of this biologically significant ring system highlighting exciting opportunities for further research.
\end{abstract}

\section{INTRODUCTION}

Oxazoles represent an important class of heterocyclic compound, which are found in numerous natural and synthetic bioactive molecules as well as in a number of organic building blocks. ${ }^{1}$ While many methods for assembly of the oxazole ring have been reported to date, the development of efficient, selective and mild synthetic methods for the construction of this important aromatic ring system remains an important contemporary research topic. This is especially the case for multicomponent methods where the potential for array synthesis exists. Protocols employing transition metals play a major role in this context, since the transformations involved in these methods frequently proceed through catalytic domino and/or multicomponent cascades with key bond construction processes being mediated by unique properties of the metal.

This review describes synthetic protocols in which transition metal complexes mediate formation of the oxazole ring. The majority of these transformations, driven by the transition metal complexes, involve nucleophilic additions to activated $\mathrm{C}-\mathrm{C}$ multiple bonds, cycloaddition reactions and $\mathrm{N}-\mathrm{H}$ insertion reactions of carbenoids, $\mathrm{C}-\mathrm{H}$ activation processes, cross-coupling reactions and ring enlargement processes are also operative in a number of protocols. The transition metal can be involved in the synthesis of a key intermediate and/or in the cyclisation of such a species, which leads to assembly of the oxazole core. These protocols employ both catalytic and stoichiometric amounts of either a single or a combination 
of transition metals with salts of zinc and mercury being included for completeness. The sections in this review are organised based on the specific bond(s) being formed and transition metal employed. A brief mechanistic discussion, if provided in the original manuscript, is also included. Transition metal-mediated protocols for the synthesis of benzoxazoles and for the functionalisation of oxazoles are not described.

Oxazole (Figure 1) is a weakly basic aromatic compound with three potential points of substitution, C2, C4 and C5. Throughout this review key bonds for the disconnection of this molecule are used within the division of sections. The order of presentation reflects the number of publications describing each specific strategy.

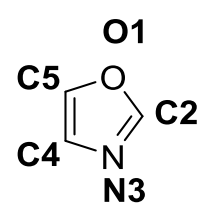

Figure 1. The oxazole unit

\section{O1-C2 AND N3-C4 BOND DISCONNECTIONS}

\section{RHODIUM(II)}

By far the most explored method for the preparation of oxazoles using transition metal catalysis involves the reaction of a diazo compound and a nitrile substrate in the presence of a $\mathrm{Rh}(\mathrm{II})$ species. In 1986, Helquist described the preparation of trisubstituted oxazoles 3 through the $\mathrm{Rh}(\mathrm{II})$-catalysed decomposition of dimethyl diazomalonate 1 in the presence of a nitrile 2 (Scheme 1). ${ }^{2-4}$ The majority of nitriles 2 reacted with 1 to deliver 3 in good to excellent yields apart from nitriles containing $\mathrm{C}=\mathrm{C}$ double bonds or free hydroxyl groups which resulted in competitive insertion products lowering the yield of oxazole. Despite these limitations this overall strategy has evolved to provide a robust and efficient method to construct oxazoles.

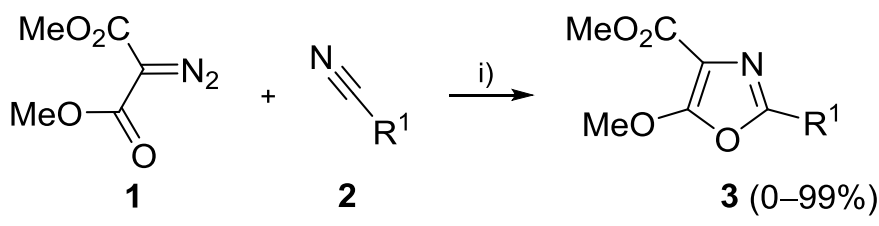

$\mathrm{R}^{1}=\mathrm{Ph}, 4-\mathrm{ClC}_{6} \mathrm{H}_{4}, 4-\mathrm{MeC}_{6} \mathrm{H}_{4}, 4-\mathrm{MeOC}_{6} \mathrm{H}_{4}, 4-\mathrm{NO}_{2} \mathrm{C}_{6} \mathrm{H}_{4}, 3-\mathrm{ClC}_{6} \mathrm{H}_{4}, \mathrm{PhCH}_{2}, \mathrm{PhCH}=\mathrm{CH}$, $\mathrm{Me}, n-\mathrm{Pr}, \mathrm{Me}\left(\mathrm{CH}_{2}\right)_{7} \mathrm{CH}_{2}, i-\mathrm{Pr}, t-\mathrm{Bu}, \mathrm{MeCH}=\mathrm{CH}, \mathrm{CH}_{2}=\mathrm{CHCH}_{2}, \mathrm{HOCH}_{2} \mathrm{CH}_{2}, \mathrm{EtOCH}=\mathrm{CH}$

i) 1 (1.0-2.0 eq), 2 (3.6-8.0 eq), $\mathrm{Rh}_{2}(\mathrm{OAc})_{4}(0.5-1.0 \mathrm{~mol} \%), \mathrm{CHCl}_{3}$ or $\mathrm{C}_{2} \mathrm{H}_{4} \mathrm{Cl}_{2}$ or neat, rt then reflux, 8-29 $\mathrm{h}$.

Scheme 1. Rh(II)-catalysed synthesis of oxazoles 3

The applicability of this transformation was extended by Helquist, who described the regioselective preparation of 2,4-disubstituted oxazoles 5 through the $\mathrm{Rh}(\mathrm{II})$-catalysed decomposition of ethyl 
formyldiazomalonate $\mathbf{4}$ in the presence of nitrile $\mathbf{2}$ as the solvent (Scheme 2). ${ }^{3,5}$ The reaction proceeds via the 1,3-dipolar cycloaddition of a metal carbenoid $\mathbf{7}$ and a nitrile $\mathbf{2}$ to give $\mathbf{5}$ (Scheme 2, Pathway A) or more plausibly, via the formation of a carbene complex $\mathbf{8}$, which reacts with $\mathbf{2}$ to generate a nitrile ylide $\mathbf{9}$ followed by cyclisation to give $\mathbf{5}$ (Scheme 2, Pathway B). This protocol provides a convenient method for the rapid synthesis of a range of 2,4-disubstituted oxazoles in good yield. A limitation of this work was the competing dimerization of $\mathbf{4}$ leading to $\mathbf{6}$.

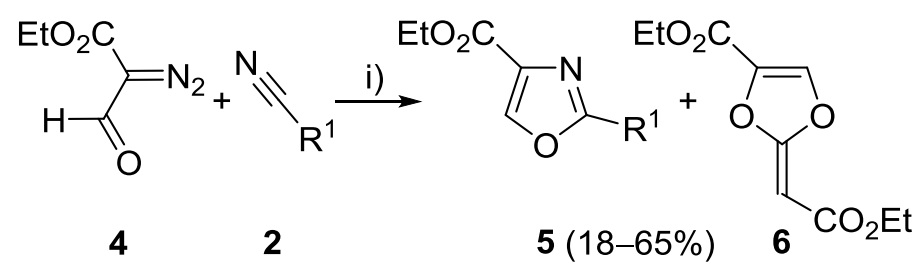

$\mathrm{R}^{1}=\mathrm{Ph}, 4-\mathrm{MeC}_{6} \mathrm{H}_{4}, \mathrm{MeCH}=\mathrm{CH}, \mathrm{EtOCH}=\mathrm{CH}, \mathrm{PhCH}=\mathrm{CH}, \mathrm{Me}, \mathrm{BrCH}_{2}$

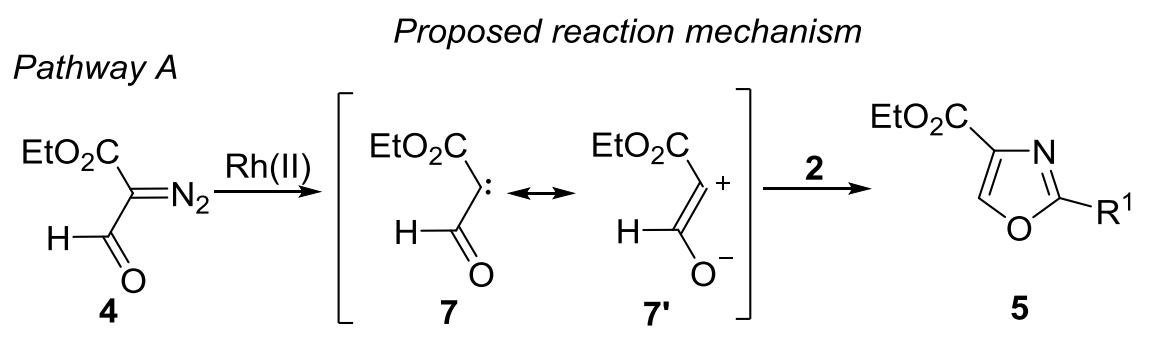

Pathway B

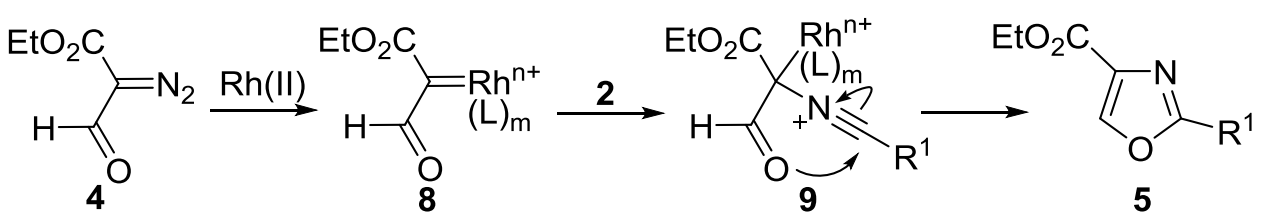

i) 4 (1.0 eq), 2 (solvent), $\mathrm{Rh}_{2}(\mathrm{OAc})_{4}(1.5 \mathrm{~mol} \%), 65-95^{\circ} \mathrm{C}, 10 \mathrm{~h}$.

Scheme 2. Rh(II)-catalysed synthesis of oxazoles 5

To introduce functionality at the 4-position of the oxazole ring, Moody reported the synthesis of trisubstituted oxazoles $\mathbf{1 1}$ through the $\mathrm{Rh}(\mathrm{II})$-catalysed reaction of diazo compounds $\mathbf{1 0}$ with a nitrile $\mathbf{2}$ (Scheme 3). ${ }^{6,7}$ In some cases, Rh(II) trifluoroacetamide proved to be a more efficient catalysts than Rh(II) acetate. Application of this method to the synthesis of bisoxazoles 15 through two consecutive $\mathrm{Rh}(\mathrm{II})$-catalysed cycloaddition reactions provided an important extension to this methodology with application in natural product synthesis (Scheme 4). ${ }^{6,7}$ 


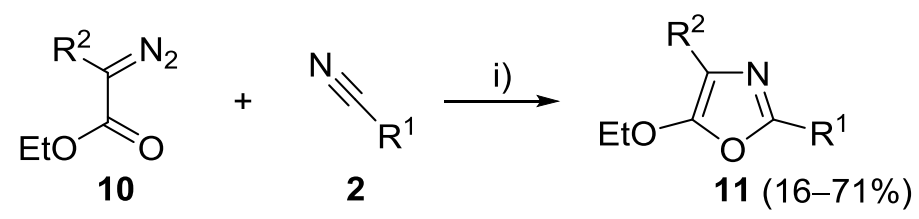

$\mathrm{R}^{1}=\mathrm{Et}, \mathrm{Ph}, 2-\mathrm{ClC}_{6} \mathrm{H}_{4}, 4-\mathrm{ClC}_{6} \mathrm{H}_{4}, 3-\mathrm{MeOC}_{6} \mathrm{H}_{4}, 4-\mathrm{MeOC}_{6} \mathrm{H}_{4}$, thiophen-2-yl;

$\mathrm{R}^{2}=\mathrm{SO}_{2} \mathrm{Ph}, \mathrm{PO}(\mathrm{OEt})_{2}, \mathrm{CN}$

i) 10 (1.0 eq), 2 (1.5-5.0 eq), $\mathrm{Rh}_{2}(\mathrm{OAc})_{4}(1 \mathrm{~mol} \%), \mathrm{CHCl}_{3}, \mathrm{rt}, 6-10 \mathrm{~h}$ then reflux $1 \mathrm{~h}$.

Scheme 3. Rh(II)-catalysed syntheses of oxazoles 11

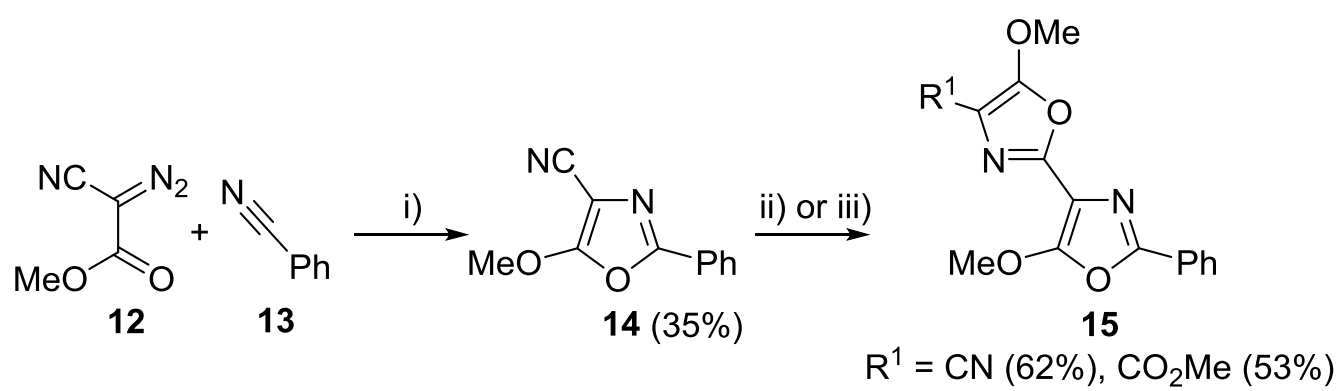

i) 12 (1.0 eq), 13 (2.0 eq), $\mathrm{Rh}_{2}(\mathrm{OAc})_{4}(1 \mathrm{~mol} \%), \mathrm{CHCl}_{3}, \mathrm{rt}, 20 \mathrm{~h}$, then reflux, $2 \mathrm{~h}$;

ii) $\left(\mathrm{MeO}_{2} \mathrm{C}\right)_{2} \mathrm{C}=\mathrm{N}_{2}(1.2 \mathrm{eq}), \mathrm{Rh}_{2}\left(\mathrm{NHCOCF}_{3}\right)_{4}(2 \mathrm{~mol} \%), \mathrm{CHCl}_{3}$, rt, $10 \mathrm{~h}$, then reflux, $2 \mathrm{~h}$;

iii) 12 (2.0 eq), $\mathrm{Rh}_{2}(\mathrm{OAc})_{4}(5 \mathrm{~mol} \%), \mathrm{CHCl}_{3}$, rt, $10 \mathrm{~h}$, then reflux, $4 \mathrm{~h}$.

Scheme 4. Rh(II)-catalysed synthesis of bisoxazoles 15

Yuan further extended the scope of the 4-substituent by the preparation of oxazole-4-phosphonates 17 through the $\mathrm{Rh}(\mathrm{II})$-catalysed reaction of diazophosphonates $\mathbf{1 6}$ and a nitrile $\mathbf{2}$ (Scheme 5). ${ }^{8}$ The substrate scope reported was limited to aromatic nitriles.

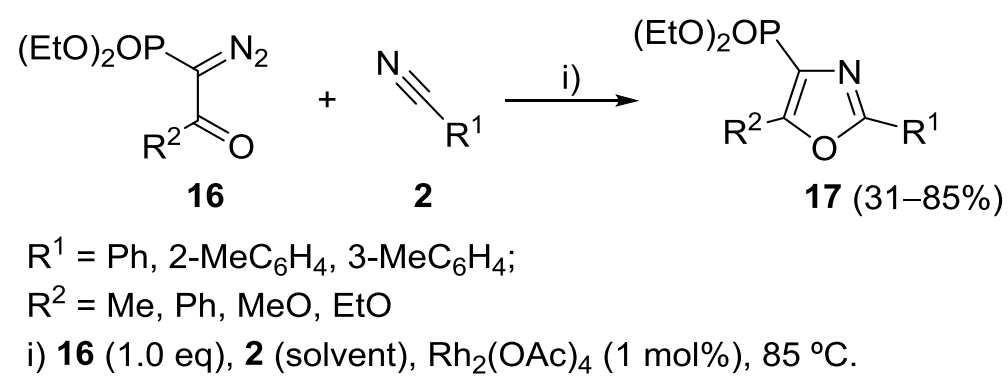

Scheme 5. Rh(II)-catalysed synthesis of oxazoles 17

Exploitation of this strategy in the preparation of poly-oxazole systems was reported by Yoo, who demonstrated the synthesis of tris-oxazole 22 through sequential $\mathrm{Rh}(\mathrm{II})$-catalysed reactions of dimethyl diazomalonate 1 with nitrile 18 (Scheme 6). ${ }^{9}$ The presence of poly-oxazole motifs in marine metabolites makes this an attractive protocol in natural product synthesis. 


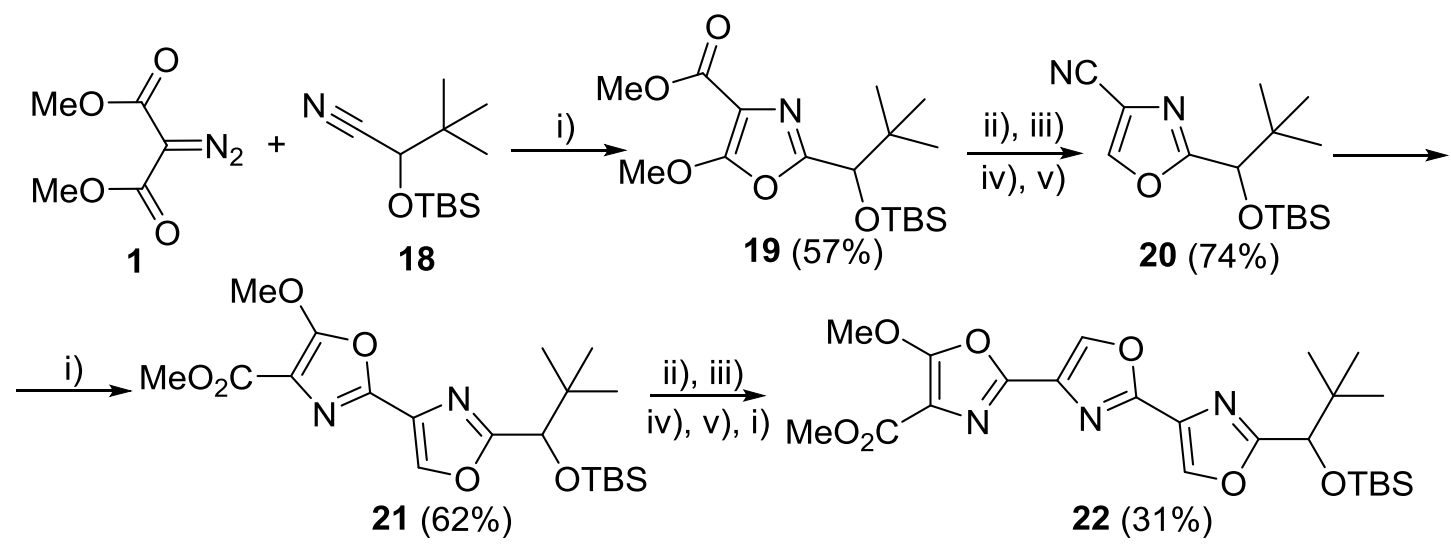

i) 1 (1.5 eq), 18 (1.0 eq), $\mathrm{Rh}_{2}(\mathrm{OAc})_{4}(2.0 \mathrm{~mol} \%), \mathrm{CHCl}_{3}$, reflux; ii) $\mathrm{LiAlH}_{4}(0.8 \mathrm{eq}), \mathrm{THF},-78^{\circ} \mathrm{C}$ for $3 \mathrm{~h}$ then rt; iii) oxalyl chloride, DMSO, $\mathrm{NEt}_{3}, \mathrm{CH}_{2} \mathrm{Cl}_{2}$; iv) $\mathrm{NH}_{2} \mathrm{OH} \cdot \mathrm{HCl}, \mathrm{K}_{2} \mathrm{CO}_{3}, \mathrm{EtOH}$; v) triflic anhydride, $\mathrm{Et}_{3} \mathrm{~N}, \mathrm{CH}_{2} \mathrm{Cl}_{2},-78^{\circ} \mathrm{C}$ to $0^{\circ} \mathrm{C}$.

Scheme 6. $\mathrm{Rh}(\mathrm{II})$-catalysed synthesis of tris-oxazole $\mathbf{2 2}$

An interesting mechanistic investigation on the $\mathrm{Rh}(\mathrm{II})$-catalysed decomposition of $\alpha$-diazocarbonyl compounds in the presence of nitriles was presented by Ibata, who described a Rh(II)-catalysed reaction of diazoacetophenones $\mathbf{2 3}$ with benzonitrile $\mathbf{1 3}$ in the presence of dimethyl acetylenedicarboxylate 27 (Scheme 7). ${ }^{10}$ The reaction course can be explained through the formation of a nitrile ylide $\mathbf{2 4}$, which undergoes intramolecular 1,5-cyclisation to yield oxazole 25 or intermolecular 1,3-dipolar cycloaddition with $\mathbf{2 7}$ to give pyrrole $\mathbf{2 6}$. Each of these products provides strong support for the intermediate $\mathbf{2 4}$.

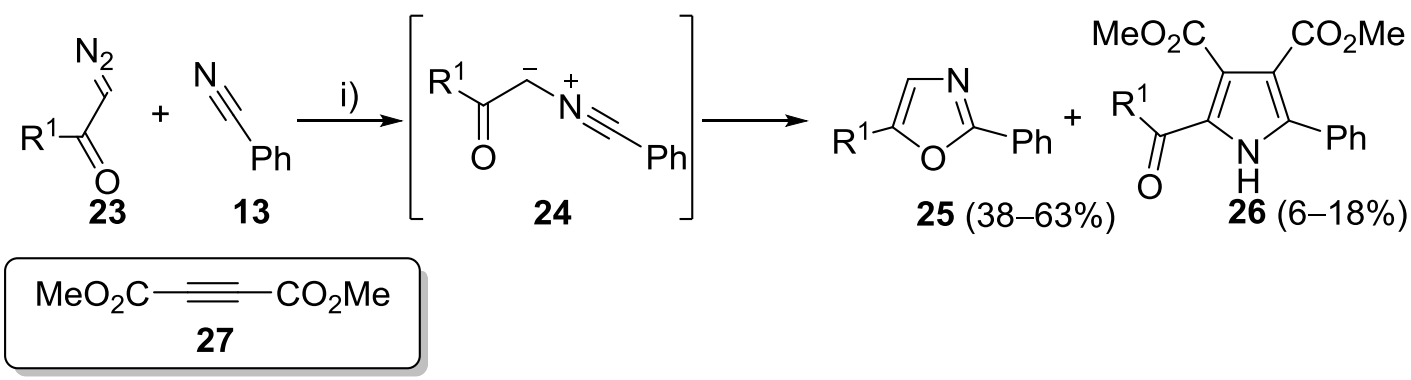

$\mathrm{R}^{1}=4-\mathrm{MeOC}_{6} \mathrm{H}_{4}, \mathrm{Ph}, 4-\mathrm{ClC}_{6} \mathrm{H}_{4}, 3-\mathrm{ClC}_{6} \mathrm{H}_{4}, 4-\mathrm{CNC}_{6} \mathrm{H}_{4}, 4-\mathrm{NO}_{2} \mathrm{C}_{6} \mathrm{H}_{4}, 3-\mathrm{NO}_{2} \mathrm{C}_{6} \mathrm{H}_{4}$

i) 25 (1.0 eq), 27 (20.0 eq), 13 (solvent), $\mathrm{Rh}_{2}(\mathrm{OAc})_{4}(5 \mathrm{~mol} \%), 60^{\circ} \mathrm{C}$.

Scheme 7. Rh(II)-catalysed reaction of $\mathbf{2 3}$ and $\mathbf{1 3}$ in the presence of $\mathbf{2 7}$

The synthesis of 2,5-disubstituted oxazoles 29 through the Rh(II)-catalysed decomposition of diazoacetyl indole 28 in the presence of nitriles 2 (Scheme 8) provides an important extension to this methodology. ${ }^{11,12}$ The knowledge that indole containing diazo compounds were suitable substrates for this rhodium catalysed method to access 2,5-disubstituted oxazoles was applied to the synthesis of more complex targets such as the core of diazonamide A. ${ }^{12}$ 


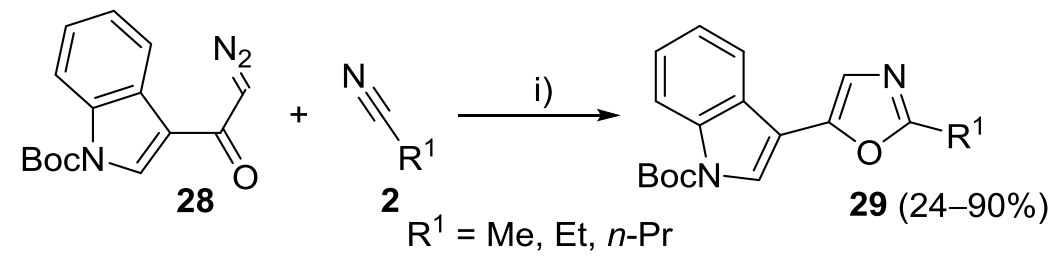

i) 28 (1.0 eq), 2 (solvent), $\mathrm{Rh}_{2}\left(\mathrm{NHCOCF}_{3}\right)_{4}(1 \mathrm{~mol} \%), \mathrm{CHCl}_{3}, \mathrm{rt}, 3-14 \mathrm{~h}$.

Scheme 8. Rh(II)-catalysed synthesis of oxazolylindolyl alkaloids 29

As suggested through the work of Moody, the $\mathrm{Rh}(\mathrm{II})$-catalysed reaction of diazo compounds with nitriles has found a number of applications in complex natural product synthesis highlighting the importance of this reaction in synthesis. Targets include phorboxazoles $\mathrm{A}$ and $\mathrm{B},{ }^{13}$ siphonazole, ${ }^{14}$ leucascandrolide $\mathrm{A},{ }^{15}$ telomestatin, ${ }^{16}$ nocardimicin $\mathrm{B}^{17}$ and discokiolide $\mathrm{B} .{ }^{18}$

$\mathrm{Xu}$ described the preparation of fluorinated oxazoles 31 using the reaction of ethyl 3-trifluoro-2-diazo-propionate $\mathbf{3 0}$ and nitriles 2 (Scheme 9). ${ }^{19}$ Interestingly, there was no formation of oxazole observed from picolinonitrile $\left(\mathrm{R}^{1}=\right.$ pyridin-2-yl) under the reaction conditions.

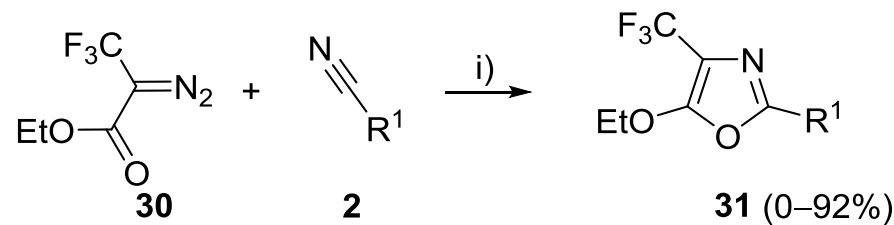

$\mathrm{R}^{1}=\mathrm{Ph}, 4-\mathrm{ClC}_{6} \mathrm{H}_{4}, \mathrm{Bn}$, pyridin-2-yl, $\mathrm{MeCH}=\mathrm{CH}, \mathrm{Me}, \mathrm{EtO}_{2} \mathrm{CCH}_{2}$

i) 30 (1.3 or $2.0 \mathrm{eq}), 2$ (1.0 eq), $\mathrm{Rh}_{2}(\mathrm{OAc})_{4}(1 \mathrm{~mol} \%), \mathrm{CHCl}_{3}$, reflux, 5 or $6 \mathrm{~h}$.

Scheme 9. Rh(II)-catalysed synthesis of oxazoles $\mathbf{3 1}$

Ibata further extended this work using cyanamides 33 as substrates to furnish 2-aminooxazoles 34 (Scheme 10). ${ }^{20}$ The substrate scope of this reaction was quite broad, however unsubstituted and monoalkyl cyanamides $\mathbf{3 3}$ generated the corresponding oxazole in low yield.

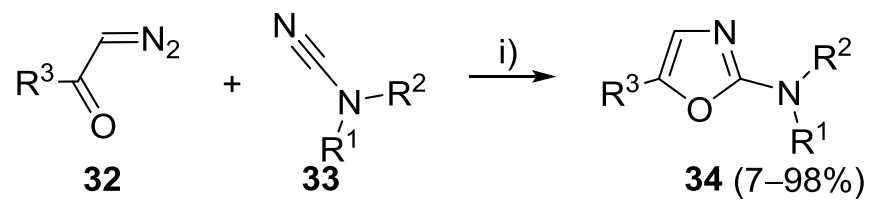

$\mathrm{R}^{1}, \mathrm{R}^{2}=i-\mathrm{Pr}, \mathrm{H}, \mathrm{Me}, t-\mathrm{Bu}, \mathrm{Et},-\left(\mathrm{CH}_{2}\right)_{5^{-}}, \mathrm{Ph}$;

$\mathrm{R}^{3}=4-\mathrm{NO}_{2} \mathrm{C}_{6} \mathrm{H}_{4}, 4-\mathrm{CNC}_{6} \mathrm{H}_{4}, 4-\mathrm{ClC}_{6} \mathrm{H}_{4}, \mathrm{Ph}, 4-\mathrm{MeC}_{6} \mathrm{H}_{4}, 4-\mathrm{MeOC}_{6} \mathrm{H}_{4}, \mathrm{H}, \mathrm{Me}$

i) 32 (1.0 eq), 33 (10 eq or solvent), $\mathrm{Rh}_{2}(\mathrm{OAc})_{4}(5 \mathrm{~mol} \%), \mathrm{CH}_{2} \mathrm{Cl}_{2}, 40^{\circ} \mathrm{C}$ or $60^{\circ} \mathrm{C}, 3 \mathrm{~h}$.

Scheme 10. Rh(II)-catalysed reaction of diazoacetophenones $\mathbf{3 2}$ and cyanamides $\mathbf{3 3}$ 
More recently Zhu showed fluorination of the 5-substituent was also possible using this diazonium technology (Scheme 11). ${ }^{21}$ The reaction proceeds regioselectively, providing trisubstituted oxazoles 36 in modest to excellent yields. Nitriles $\mathbf{2}$ bearing conjugated alkenyl or aryl groups led to high yields of $\mathbf{3 6}$ while substrates $\mathbf{3 5}$ containing perfluoroalkylated motifs were less effective.

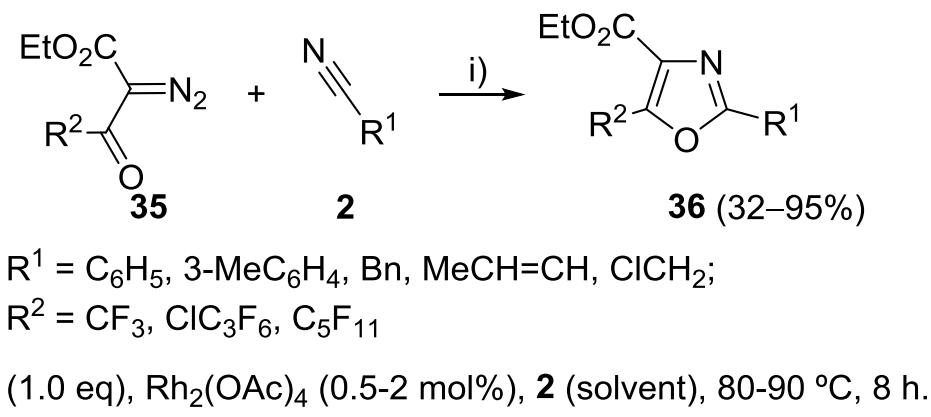

Scheme 11. Rh(II)-catalysed synthesis of oxazoles 36

Marsden prepared 4-silylated oxazoles $\mathbf{3 8}$ by performing a $\mathrm{Rh}(\mathrm{II})$-catalysed reaction of (triethylsilyl)diazoacetates 37 and nitriles 2 (Scheme 12). ${ }^{22}$ A range of nitriles 2 successfully underwent cycloaddition with 37. Nitriles bearing pyridyl or hydroxyl groups failed to give any oxazole product, due to catalyst deactivation or $\mathrm{OH}$ insertion reactions, respectively. Treatment of the product $\mathbf{3 8}$ with fluoride led to the corresponding 3,5-disubstituted oxazole, whereas treatment with $N$-halosuccinimides allowed introduction of halogens at the 4-position providing the opportunity for further elaboration.<smiles>[R]C(=O)C(=[NH2+])[SiH2]C</smiles>

37

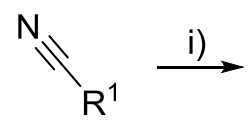

2<smiles>[R]c1nc([SiH2]C)c([R])o1</smiles>

$38(0-81 \%)$

$\mathrm{R}^{1}=\mathrm{Ph}, \mathrm{Me}$, Et, thiophen-2-yl, furan-2-yl, pyridin-2-yl, $\mathrm{MeCO}, \mathrm{MeO}_{2} \mathrm{C}$,

$\mathrm{MeO}_{2} \mathrm{CCH}_{2}, \mathrm{CH}_{2}=\mathrm{CH}, \mathrm{MeCH}(\mathrm{OH}), \mathrm{MeCH}(\mathrm{OTBS}), \mathrm{Me}_{2} \mathrm{~N}$;

$\mathrm{R}^{2}=\mathrm{EtO}, t-\mathrm{BuO}$

i) 37 (1.0 eq), 2 (4.0 eq), $\mathrm{Rh}_{2}$ (oct) $)_{4}(1-5 \mathrm{~mol} \%), \mathrm{PhH}, 0.5-24 \mathrm{~h}$, reflux.

Scheme 12. Rh(II)-catalysed synthesis of oxazoles 38

As an alternative to diazocarbonyl compounds, the $\mathrm{Rh}(\mathrm{II})$-catalysed reaction of iodonium ylide 39 and nitriles 2 to give oxazoles 40 was disclosed by Hadjìarapoglou (Scheme 13). ${ }^{23}$ Notably, the rhodium catalysed transformation proceeded with higher yields than the analogous $\mathrm{Cu}(\mathrm{II})$-catalysed process. 


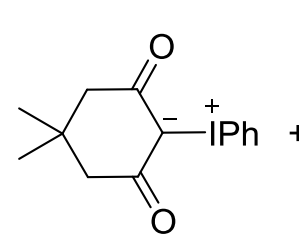

39<smiles>[R]C#N</smiles>

2

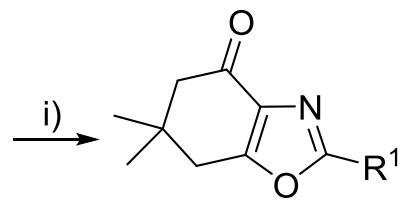

$40(23-68 \%)$

$\mathrm{R}^{1}=\mathrm{Me}, \mathrm{ClCH}_{2}, \mathrm{PhCH}_{2}, \mathrm{Ph}, 4-\mathrm{MeC}_{6} \mathrm{H}_{4}$

i) 39 (1.0 eq), 2 (solvent) $\mathrm{Rh}_{2}(\mathrm{OAc})_{4}$ (cat.), reflux or $80-100^{\circ} \mathrm{C}, 30 \mathrm{~min}-1 \mathrm{~h}$.

Scheme 13. Rh(II)-catalysed reaction of iodonium ylides 39 and nitriles 2

Lee extended the scope of this transformation to the reaction of iodonium ylides 41 and nitriles 2 to generate oxazoles 42 (Scheme 14). ${ }^{24}$ The reaction proceeded via formation of the carbene $\mathbf{4 3}$, which reacts with 2 to generate a nitrile ylide 44 followed by cyclisation to give $\mathbf{4 2}$. Along with formation of oxazoles, an undesired transformation leading to a dihydrofuran nucleus also takes place.

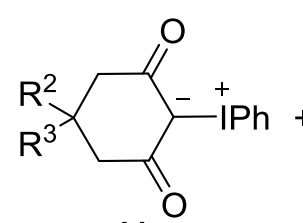

41<smiles>[R]C#N</smiles>

2<smiles>[R]c1nc2c(o1)CC([R])([R])CC2=O</smiles>

$42(20-59 \%)$

$\mathrm{R}^{1}=\mathrm{CH}_{2}=\mathrm{CH}, \mathrm{CH}_{2}=\mathrm{CMe}, \mathrm{MeCH}=\mathrm{CH}, \mathrm{MeCH}_{2} \mathrm{CH}=\mathrm{CH}$; $\mathrm{R}^{2}, \mathrm{R}^{3}=\mathrm{H}, \mathrm{Me}, \mathrm{Ph}$

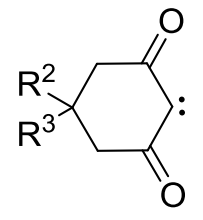

43

Proposed reaction mechanism

i) 41 (1.0 eq), $\mathrm{Rh}_{2}(\mathrm{OPiv})_{4}(0.5 \mathrm{~mol} \%), 2$ (solvent), rt, $12 \mathrm{~h}$.

Scheme 14. Rh(II)-catalysed synthesis of oxazoles $\mathbf{4 2}$

The scope of this approach was extended by Hadjìarapoglou to the synthesis of trisubstituted oxazoles $\mathbf{4 6}$ through the reaction of carbomethoxy iodonium ylides $\mathbf{4 5}$ and nitriles 2 (Scheme 15). ${ }^{25}$ This transformation proceeds efficiently with a number of substrates and provides the oxazole products in moderate to good yields. In the case of chloroacetonitrile and iodonium ylide $45\left(\mathrm{R}^{2}=\mathrm{Me}\right)$, a mixture of oxazoles with a low level of regio control was observed. 


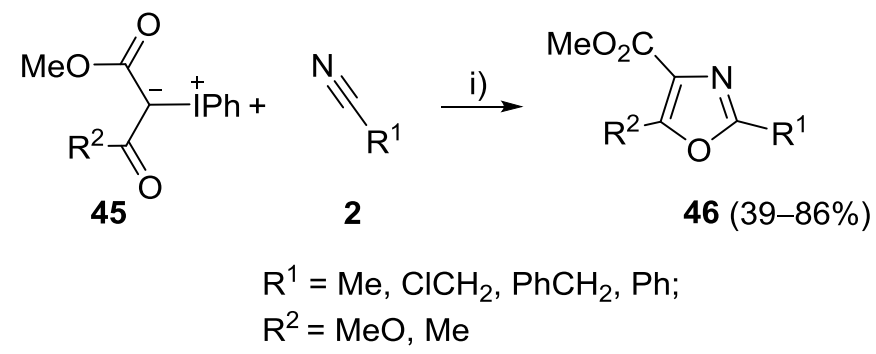

i) $\mathrm{Rh}_{2}(\mathrm{OAc})_{4}$ (cat), reflux or $105-125^{\circ} \mathrm{C}, 1-5 \mathrm{~min}$.

Scheme 15. Rh(II)-catalysed reaction of carbomethoxy iodonium ylides $\mathbf{4 5}$ and nitriles $\mathbf{2}$

In 2007, Ganem reported that using acyl cyanide $\mathbf{4 7}$ as a substrate led to the formation of an inseparable mixture of the oxazole 48 and the diazoester derived dimer 49 (Scheme 16). ${ }^{26}$

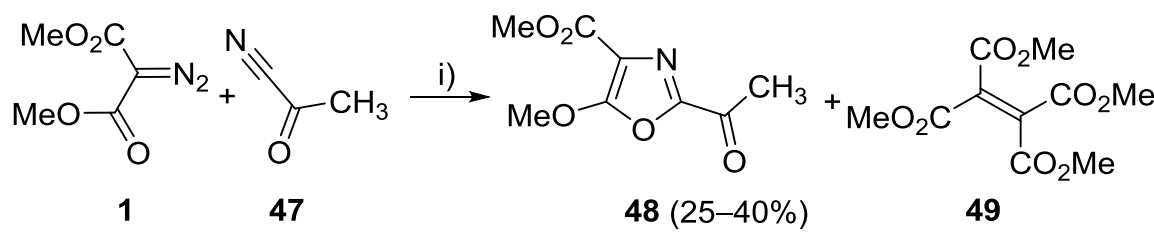

i) 1 (1.0-3.0 eq), $47(1.0 \mathrm{eq}), \mathrm{Rh}_{2}(\mathrm{OAc})_{4}(1-5 \mathrm{~mol} \%), \mathrm{CHCl}_{3}$, reflux, $8 \mathrm{~h}$.

Scheme 16. Rh(II)-catalysed synthesis of oxazole $\mathbf{4 8}$

More recently, Doyle disclosed an efficient synthesis of trisubstituted oxazoles $\mathbf{5 2}$ through the Rh(II)-catalysed reaction of styryl diazoacetate $\mathbf{5 0}$ with aryl oxime 51 (Scheme 17). ${ }^{27}$ The reaction proceeds via the formation of a metal carbene 53, which reacts with the oxime $\mathbf{5 1}$ to give a rhodium enolate 55. Cyclisation of $\mathbf{5 5}$ generates 56, which upon dehydration furnishes the observed oxazole 52. Notably, aryl oximes proved more effective than the corresponding nitrile analogues as substrates. Furthermore, the nature of the $\mathrm{R}^{1}$ substituent appears to have little effect on the reaction outcome.

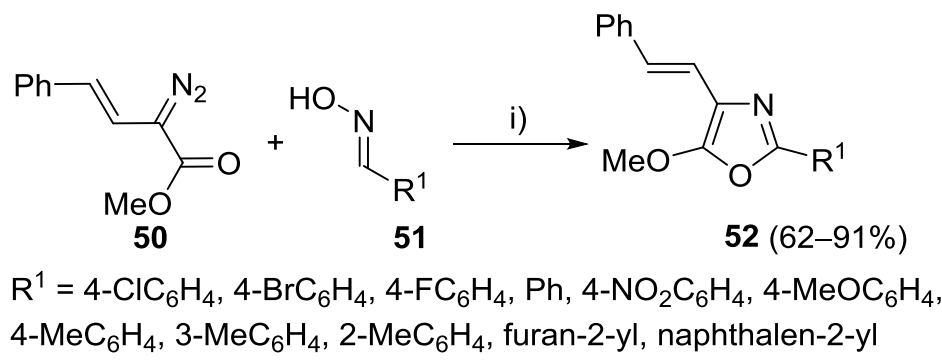

Proposed reaction mechanism

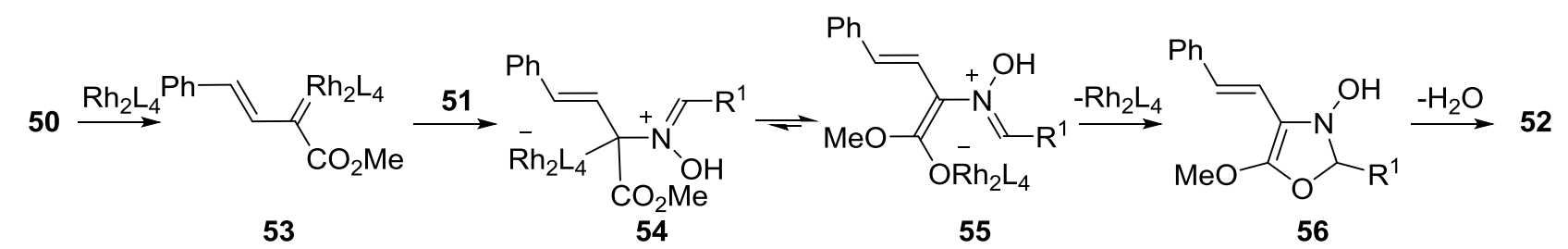

i) 51 (1.0 eq), 50 (1.2 or $1.5 \mathrm{eq}), \mathrm{Rh}_{2}(\mathrm{OAc})_{4}(2 \mathrm{~mol} \%), \mathrm{CH}_{2} \mathrm{Cl}_{2}, \mathrm{rt}, 1$ or $2 \mathrm{~h}$.

Scheme 17. Rh(II)-catalysed synthesis of oxazoles $\mathbf{5 2}$ 
Overall the $\mathrm{Rh}$ (II) catalysed reaction has proven to be a versatile method for the preparation of functionalised oxazoles, with a high functional group tolerance and broad substrate applicability. The scope and limitations of this method has been thoroughly explored such that the likely success of a proposed transformation can be readily evaluated based upon the significant literature precedent.

\section{COPPER(I) AND COPPER(II)}

Despite the success achieved with rhodium in preparing the oxazole framework, a considerable amount of research effort has been dedicated to establishing alternative transition metals to bring about the same overall reaction. The preparation of oxazoles through the reaction of diazocarbonyl compounds with nitriles was first introduced by Huisgen in $1961 .{ }^{28}$ Only trace amounts of oxazole were detected when this reaction was carried out thermally. Notably, the yields of the desired oxazole product were significantly increased by addition of a $\mathrm{Cu}(\mathrm{I})$ or $\mathrm{Cu}(\mathrm{II})$ catalyst. This transformation was further investigated by Alonso, who described the synthesis of oxazoles $\mathbf{5 8}$ through the $\mathrm{Cu}(\mathrm{II})$-catalysed reaction of ethyl diazopyruvate $\mathbf{5 7}$ and nitriles 2 (Scheme 18). This protocol provided moderate yields of the oxazole product $\mathbf{5 8} .^{29}$

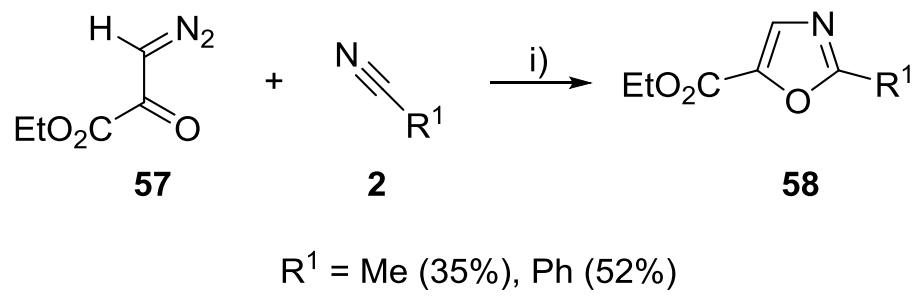

i) 59 (1.0 eq), 2 (1.8 eq), $\mathrm{Cu}(\mathrm{acac})_{2}(0.2 \mathrm{~mol} \%), \mathrm{PhH}$, reflux, $4 \mathrm{~h}$.

Scheme 18. Cu(II)-catalysed synthesis of oxazole $\mathbf{5 8}$

Iodonium ylides 39 were also shown to be feasible substrates within a $\mathrm{Cu}(\mathrm{II})$-catalysed reaction of acetonitrile 59 via a diketocarbene intermediate (Scheme 19). ${ }^{30}$ Although the substrate scope was not explored, this protocol shows the potential of $\mathrm{Cu}(\mathrm{II})$ as an alternative catalyst in the preparation of oxazoles.
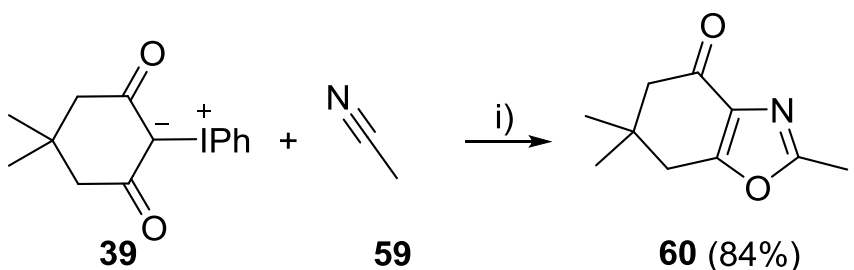

59

$60(84 \%)$

i) $\mathrm{Cu}(\mathrm{acac})_{2}(8 \mathrm{~mol} \%), \mathrm{MeCN}$ (solvent), reflux.

Scheme 19. $\mathrm{Cu}(\mathrm{II})$-catalysed synthesis of oxazoles $\mathbf{6 0}$ 
Sato described an interesting one-pot regioselective synthesis of trisubstituted oxazoles $\mathbf{6 2}$ through the $\mathrm{Cu}(\mathrm{II})$-mediated oxidation of ketones 61 in the presence of acetonitrile 59 (Scheme 20). ${ }^{31}$ The reaction was proposed to proceed via two consecutive single-electron oxidations of $\mathbf{6 1}$ by $\mathrm{Cu}(\mathrm{OTf})_{2}$. Although the functional group tolerance was not explored, this early work provides an outstanding foundation with which to develop this transformation.
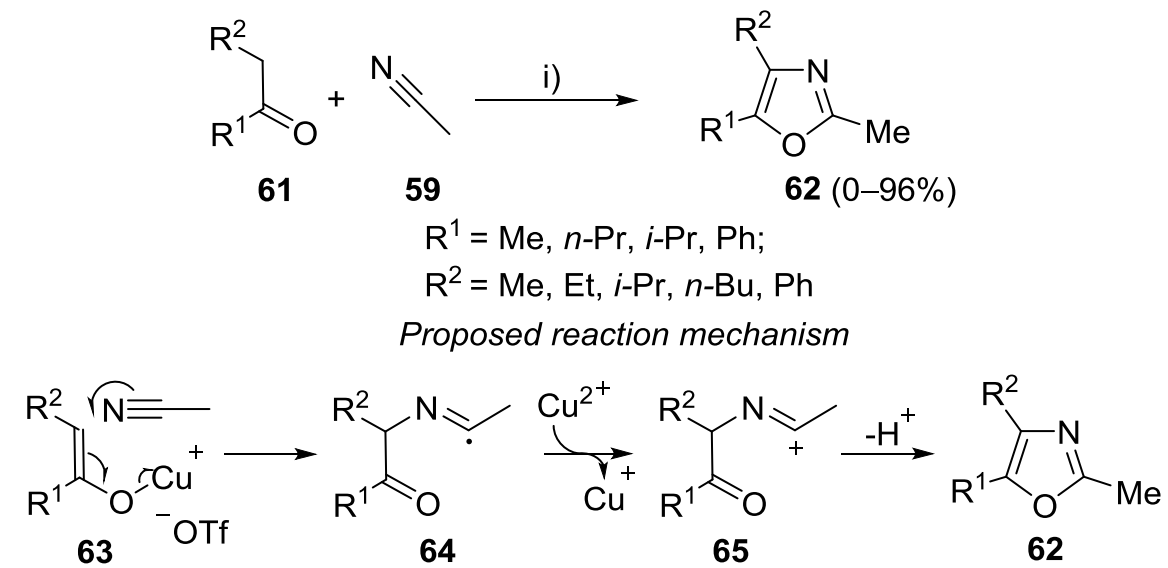

i) $\mathrm{Cu}(\mathrm{OTf})_{2}(2.0 \mathrm{eq}), \mathrm{p}-\mathrm{TsOH}$ (cat), MeCN, reflux, $2 \mathrm{~h}$.

Scheme 20. $\mathrm{Cu}(\mathrm{II})$-mediated synthesis of oxazoles $\mathbf{6 2}$

More recently, Wang described the synthesis of trisubstituted oxazoles $\mathbf{6 8}$ through the $\mathrm{Cu}(\mathrm{II})$-catalysed tandem oxidative cyclisation of 1,3-dicarbonyl compounds 66 and benzylamines 67 (Scheme 21). ${ }^{32}$ The reaction proceeds via formation of $\mathbf{6 9}$, which undergoes oxidation to give $\mathbf{7 0}$. $\mathrm{Cu}(\mathrm{II})$-catalysed cyclisation

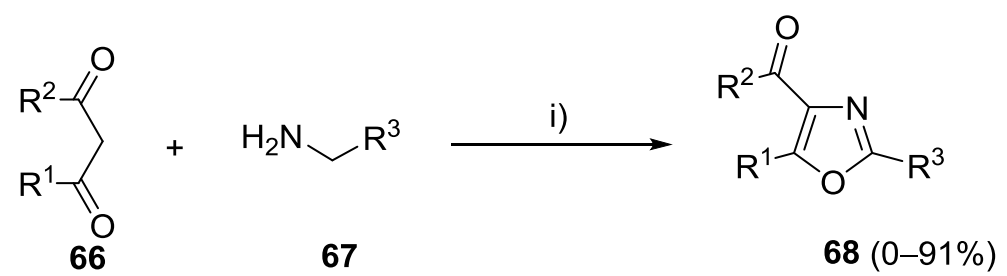

$\mathrm{R}^{1}=\mathrm{Me}, n-\mathrm{Pr}, i-\mathrm{Pr}, t-\mathrm{Bu}, \mathrm{PhCH}=\mathrm{CH}$;

$\mathrm{R}^{2}=\mathrm{OEt}$, OMe, $t$-BuO, Me, $\mathrm{Ph}, \mathrm{PhNH}$;

$\mathrm{R}^{3}=\mathrm{Ph}, 4-\mathrm{MeOC}_{6} \mathrm{H}_{4}, 4-\mathrm{MeC}_{6} \mathrm{H}_{4}, 4-\mathrm{FC}_{6} \mathrm{H}_{4}, 4-\mathrm{ClC}_{6} \mathrm{H}_{4}, 3-\mathrm{NO}_{2} \mathrm{C}_{6} \mathrm{H}_{4}, 2-\mathrm{ClC}_{6} \mathrm{H}_{4}$, pyridin-2-yl, furan-2-yl, $n-\mathrm{Pr}$ Proposed reaction mechanism

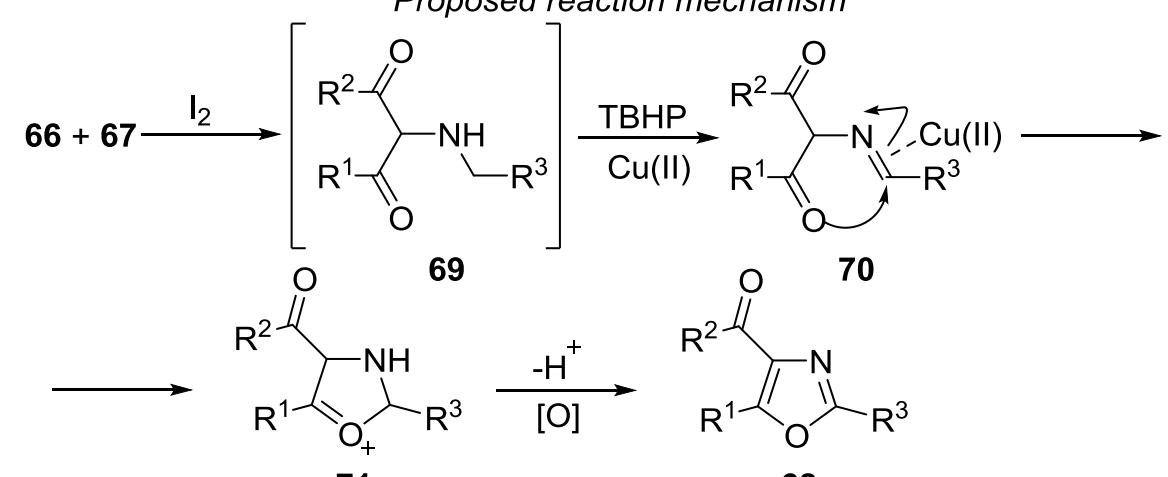

i) 66 (1.0 eq), 67 (2.0 eq), $\mathrm{Cu}(\mathrm{OAc})_{2} \mathrm{H}_{2} \mathrm{O}$ (10 mol\%), TBHP (2.0 eq), $\mathrm{I}_{2}$ (1.2 eq), DMF, rt. 
Scheme 21. Cu(II)-catalysed tandem oxidative cyclisation of 1,3-dicarbonyl compounds $\mathbf{6 6}$ and benzylamines 67

of 70 generates an oxazoline 71, which upon oxidation furnishes the observed oxazole $\mathbf{6 8}$. This reaction displays a good scope. Cyclisation of substrates 67 possessing electron-withdrawing groups gave higher yields of 68 than those bearing electron-donating groups.

Overall it has been shown that copper can be used to mirror the reactivity of rhodium, although the reactions tend to be less efficient. One distinct advantage offered through the use of copper is the potential to use ketones as substrates rather than the reaction with potentially hazardous diazo compounds.

\section{PALLADIUM(II)}

In an early example Teyssié reported the synthesis of 2,5-disubstituted oxazoles 73 through the $\mathrm{Pd}(\mathrm{II})$-catalysed reaction of ethyl diazoacetate $\mathbf{7 2}$ with nitriles 2 (Scheme 22). ${ }^{33}$ The reaction proceeds via the $\mathrm{Pd}(\mathrm{II})$-catalysed decomposition of $\mathbf{7 2}$ generating a metal carbene species which undergoes 1,3-dipolar cycloaddition with 2 to furnish oxazole 73. Subsequently, Teyssié found that higher yields of $\mathbf{7 3}$ were achieved using $\mathrm{Cu}(\mathrm{OTf})_{2}$ as the catalyst $(15-80 \%)$ and a butyldiazoacetate substrate. ${ }^{34}$

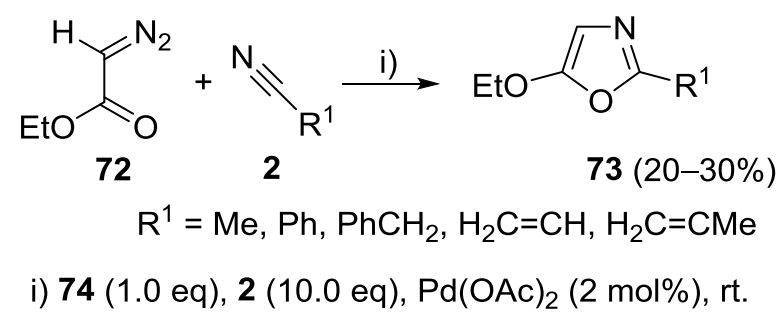

Scheme 22. Pd(II)-catalysed synthesis of oxazoles $\mathbf{7 3}$

\section{TUNGSTEN(VI)}

Use of tungsten in the decomposition of diazo compounds was shown to be possible by Kitatani who 


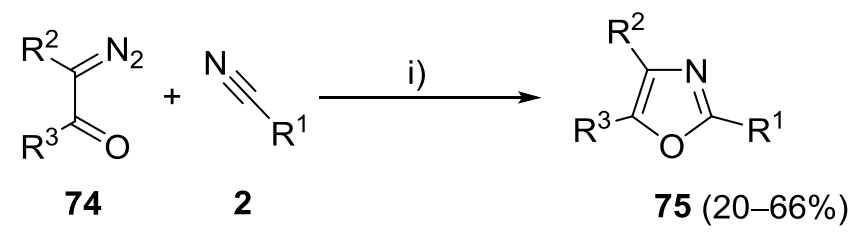

$\mathrm{R}^{1}=\mathrm{Ph}, \mathrm{Me}, \mathrm{Et}, \mathrm{CH}_{2}=\mathrm{CH}$;

$\mathrm{R}^{2}=\mathrm{Ph}, \mathrm{H}$;

$\mathrm{R}^{3}=\mathrm{Ph}, \mathrm{MeO}$

Proposed reaction mechanism

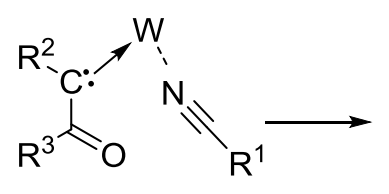

76

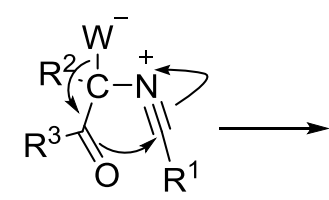

77<smiles>[R]c1nc([R])c([R])o1</smiles>

75

i) 76 (1.0 eq), 2 (solvent), $\mathrm{WCl}_{6}(1.0 \mathrm{eq}), \mathrm{rt}, 0.25-44 \mathrm{~h}$.

Scheme 23. W(VI)-mediated synthesis of oxazoles $\mathbf{7 5}$

described a synthesis of trisubstituted oxazoles 75 (Scheme 23). ${ }^{35,36}$ Notably, due to a highly Lewis acidic character and a good affinity for carbenes, $\mathrm{WCl}_{6}$ proved more effective than copper(II) salts. ${ }^{37}$

\section{RUTHENIUM(II)}

Lacour described the synthesis of trisubstituted oxazoles 79 through the Ru(II)-catalysed cyclisation of diazoacetoacetate $\mathbf{7 8}$ and nitriles $\mathbf{2}$ in the presence of 1,10-phenanthroline $\mathbf{8 1}$ as a ligand (Scheme 24). ${ }^{38}$ The reactions proceed regioselectively, delivering trisubstituted oxazoles in up to $75 \%$ yield. Further development could make ruthenium complexes an attractive alternative to the more commonly employed rhodium and copper salts in this class of transformation.

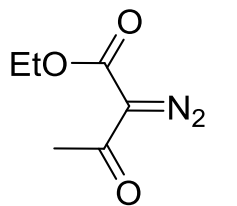

78

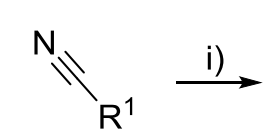

2

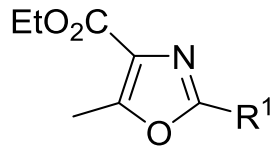

$79(54-75 \%)$

$\mathrm{R}^{1}=\mathrm{Me}, \mathrm{Et}, i-\mathrm{Pr}, \mathrm{Ph}$

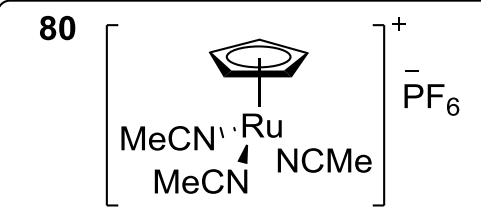

81<smiles>c1cnc2c(c1)ccc1cccnc12</smiles>

i) 78 (1.0 eq), 81 (2.5 mol\%), 80 (2.5 mol\%), 2 (solvent), $60{ }^{\circ} \mathrm{C}, 1 \mathrm{~h}$.

Scheme 24. Ru(II)-catalysed synthesis of oxazoles 79 


\section{TIN(II)}

An interesting alternative approach to the preparation of oxazoles was reported by Russowsky who described the $\mathrm{Sn}(\mathrm{II})$ catalysed reaction of benzils 82 in the presence of $\mathrm{NH}_{4} \mathrm{OAc}$ (Scheme 25). ${ }^{39}$ The use of $\mathrm{SnCl}_{2}$ as a mild and inexpensive Lewis acid catalyst makes this a simple protocol for the preparation of triaryloxazoles, with the specific limitation that each aryl group is identical.

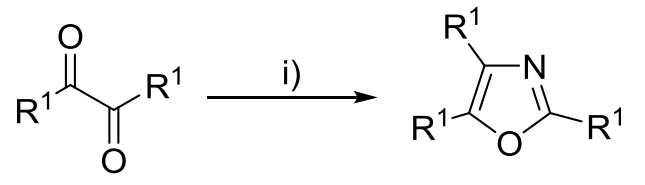

82 $83(44-94 \%)$

$$
\mathrm{Ar}=\mathrm{C}_{6} \mathrm{H}_{5}, 4-\mathrm{FC}_{6} \mathrm{H}_{4}
$$

i) $82(1.0 \mathrm{eq}), \mathrm{NH}_{4} \mathrm{OAc}(5.0 \mathrm{eq}), \mathrm{SnCl}_{2} \cdot \mathrm{H}_{2} \mathrm{O}(5 \mathrm{~mol} \%)$, EtOH, reflux, $4 \mathrm{~h}$.

Scheme 25. Sn(II)-catalysed synthesis of oxazoles $\mathbf{8 3}$

\section{IRON(III), ZIRCONIUM(IV), MOLYBDENUM(V), TIN(IV), TITANIUM(IV), TANTALUM(V) AND TUNGSTEN(VI)}

In 1980, Doyle described a synthesis of disubstituted oxazoles 84 through the Lewis acid (LA) promoted cycloaddition reaction of diazocarbonyl compounds 23 in the presence of acetonitrile 59 as the solvent (Scheme 26). ${ }^{40}$ The reaction proceeded via the cycloaddition of a Lewis acid activated diazocarbonyl compound 85 with 59 leading to 86 (Scheme 26, Pathway A), or more plausibly via 87 which upon reaction with 23 generates 88 (Scheme 26, Pathway B). A range of Lewis acids such as $\mathrm{FeCl}_{3}, \mathrm{ZrCl}_{4}, \mathrm{MoCl}_{5}, \mathrm{SnCl}_{4}$, $\mathrm{TiF}_{4}, \mathrm{TaCl}_{5}$ and $\mathrm{WCl}_{6}$ were also successfully employed for this transformation providing oxazoles 84 in moderate to excellent yields. Interestingly, $\mathrm{CuF}_{2}, \mathrm{NiBr}_{2}$ and $\mathrm{ZnCl}_{2}$ failed to produce the corresponding oxazole product. A limitation of this protocol is the $\alpha$-chlorination of $\mathbf{2 3}$, which was observed predominantly when using $\mathrm{ZrCl}_{4}, \mathrm{MoCl}_{5}, \mathrm{SnCl}_{4}$ or $\mathrm{TiF}_{4}$ as the Lewis acid. Notably, no products generated by Wolff rearrangement were observed under the reaction conditions. 


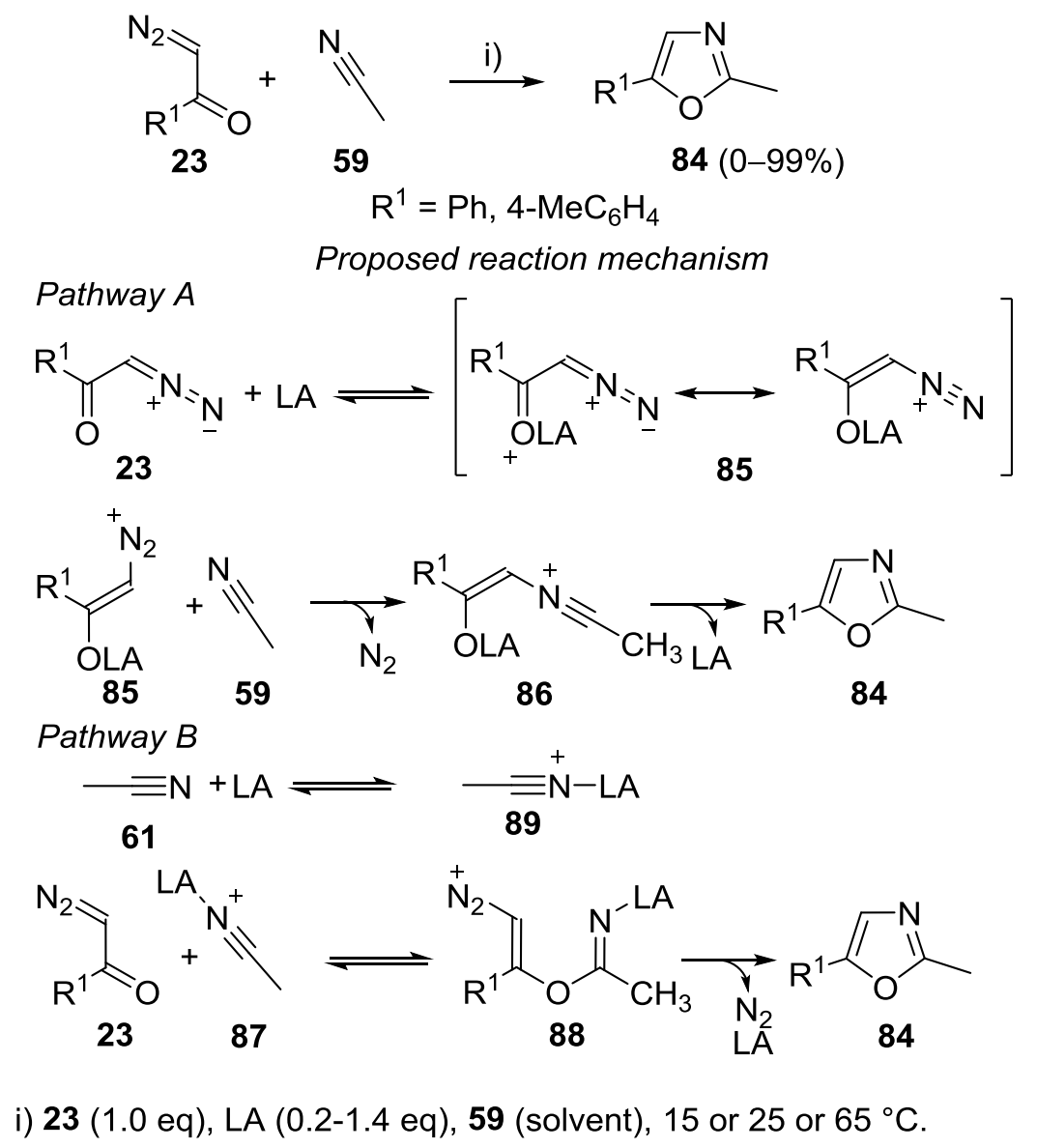

Scheme 26. Lewis acid promoted synthesis of oxazoles 84

Preparation of oxazoles through an $\mathrm{O} 1-\mathrm{C} 2$ and $\mathrm{N} 3-\mathrm{C} 4$ bond disconnection has been thoroughly investigated and represents a versatile method for the preparation of di- and trisubstituted variants. The assortment of catalysts which are effective for this transformation provide significant alternatives for those adopting this disconnective strategy. The major challenge within this work is preparation of the diazonium (or equivalent) substrate. Recent advances using oxidative cyclisations with ketone substrates provide a useful alternative and further development of this reaction class would be particularly helpful.

\section{O1-C5 AND N3-C4 BOND DISCONNECTION}

\section{RHODIUM(II)}

In 1996, Moody demonstrated an alternative approach to access oxazoles based on the Rh(II)-catalysed reaction of diazocarbonyl compounds $\mathbf{7 4}$ and amides 89 (Scheme 27). ${ }^{41,42}$ The reaction proceeds through the regioselective insertion of a Rh-carbenoid into the $\mathrm{NH}$ bond of $\mathbf{8 9}$ to give $\mathbf{9 0}$, which can subsequently undergo cyclodehydration as described by Wipf. ${ }^{43}$ A range of diazomalonates $\mathbf{7 4}$ and amides $\mathbf{8 9}$ were 
successfully used for this transformation, providing $\mathbf{7 5}$ in moderate to good yield. Notably, in the case of $\alpha$-chiral amides, the reaction generated products without erosion of optical purity, greatly adding to the applicability of this work. The method was applied to the synthesis of trisubstituted oxazoles 93 which proceeds in high yields when compared to the analogous rhodium carbene transformation employing nitriles as substrates (Scheme 28). ${ }^{42}$<smiles>[R]C(=[W])C([R])=[W]</smiles>

74<smiles>[R]C(N)=O</smiles>

89<smiles>[R]c1nc([R])c([R])o1</smiles>

$75(0-88 \%)$

$\mathrm{R}^{1}=(\mathrm{EtO})_{2} \mathrm{CH}\left(\mathrm{CH}_{2}\right)_{2}, \mathrm{CBzNHCH}{ }_{2},(S)-\mathrm{CBzNHCHMe},(\mathrm{S})-\mathrm{CBzNHCH} i-\mathrm{Pr}$,

(S)-N-CBz-pyrrolidin-2-yl, (S)-N-BocNHCHi-Pr;

$\mathrm{R}^{2}=\mathrm{MeO}_{2} \mathrm{C}, t-\mathrm{BuO}_{2} \mathrm{C}, \mathrm{EtO}_{2} \mathrm{C}$;

$\mathrm{R}^{3}=\mathrm{MeO}, t-\mathrm{BuO}, \mathrm{Me}, \mathrm{Et}, \mathrm{Ph}, \mathrm{ClCH}_{2}$

Proposed reaction mechanism

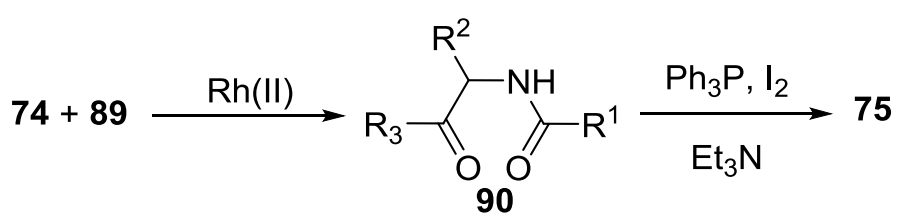

i) 74 (1.4 eq), 89 (1.0 eq), $\mathrm{Rh}_{2}(\mathrm{OAc})_{4}(2 \mathrm{~mol} \%), \mathrm{CHCl}_{3}$, reflux, $6.5 \mathrm{~h}$;

ii) 90 (1.0 eq), $\mathrm{Et}_{3} \mathrm{~N}(4.1 \mathrm{eq}), \mathrm{PPh}_{3}(2.0 \mathrm{eq}), \mathrm{I}_{2}(2.0 \mathrm{eq}), \mathrm{CH}_{2} \mathrm{Cl}_{2}$, rt, on.

Scheme 27. Rh(II)-catalysed reaction of diazocarbonyl compounds $\mathbf{7 4}$ and amides 89 followed by cyclodehydration<smiles>[R20]C(=O)C([R9])=[W]</smiles><smiles>[NH+]=CN</smiles><smiles>CCOC(CC)CCC(N)=O</smiles><smiles>[C]1[C+]=CC=C1</smiles><smiles>[R]OC#[R]</smiles><smiles>[R10]Oc1oc(CCC(OCC)OCC)nc1CC</smiles>
$93 \mathrm{R}^{1}=\mathrm{Me}(84 \%), t-\mathrm{Bu}(79 \%)$

$$
\mathrm{R}^{1}=\mathrm{Me}, t-\mathrm{Bu}
$$

i) 91 (1.0 eq), 92 (2.0 eq), $\mathrm{Rh}_{2}(\mathrm{OAc})_{4}(2 \mathrm{~mol} \%), \mathrm{PhMe}$, reflux, on;

ii) $\mathrm{Et}_{3} \mathrm{~N}$ (4.1 eq), $\mathrm{PPh}_{3}(2.0 \mathrm{eq}), \mathrm{I}_{2}(2.0 \mathrm{eq}), \mathrm{CH}_{2} \mathrm{Cl}_{2}$, rt, on.

Scheme 28. Rh(II)-catalysed reaction of diazocarbonyl compounds 91 and amides 92 followed by cyclodehydration

Giacomelli demonstrated this methodology could be applied to the preparation of a range of novel optically active oxazole-containing amino acids. ${ }^{44}$ Thus, the Rh(II)-catalysed reaction of 94 and 95 followed by cyclodehydration afforded oxazoles 96 in modest to good yields (Scheme 29). 


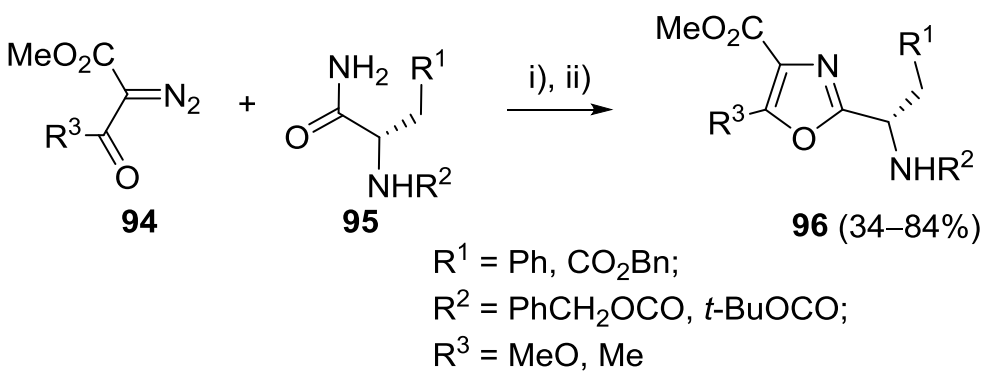

i) 94 (1.4 eq), 95 (1.0 eq), $\mathrm{Rh}_{2}(\mathrm{OAc})_{4}(2 \mathrm{~mol} \%), \mathrm{CHCl}_{3}$, reflux, $27 \mathrm{~h}$;

ii) $\mathrm{PPh}_{3}(2.0 \mathrm{eq}), \mathrm{I}_{2}(2.0 \mathrm{eq}), \mathrm{Et}_{3} \mathrm{~N}(4.0 \mathrm{eq}), \mathrm{CH}_{2} \mathrm{Cl}_{2}$, rt, on.

Scheme 29. Rh(II)-catalysed reaction of diazocarbonyl compounds 94 and amides 95 followed by cyclodehydration

Expansion of the substrate scope to encompass aliphatic and aromatic amides $\mathbf{8 9}$ as well as diazocarbonyl substrates 74 also met with success (Scheme 30). ${ }^{45}$ Janda adapted this chemistry for solid-phase synthesis using a polymer-bound $\alpha$-diazo- $\beta$-ketoester. ${ }^{46}$

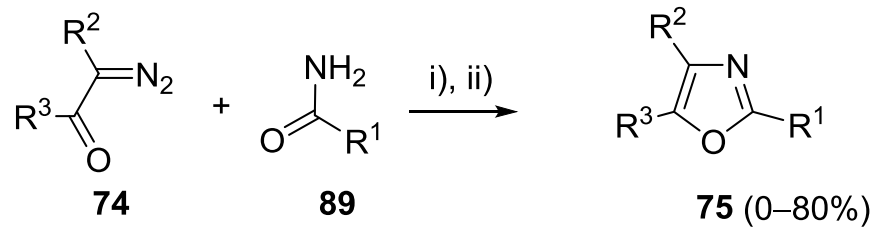

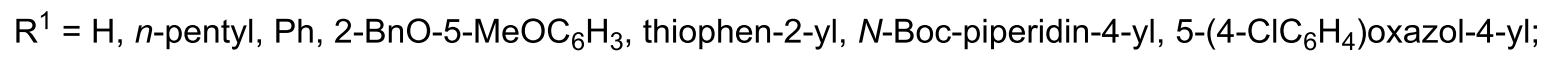

$\mathrm{R}^{2}=\mathrm{MeO}_{2} \mathrm{C}, \mathrm{Ph}, \mathrm{EtO}_{2} \mathrm{C}$;

$\mathrm{R}^{3}=\mathrm{Me}, \mathrm{Ph}, 4-\mathrm{ClC}_{6} \mathrm{H}_{4}, 4-\mathrm{MeO}_{2} \mathrm{CC}_{6} \mathrm{H}_{4}$

i) 74 (1.4 eq), 89 (1.0 eq), $\mathrm{Rh}_{2}(\mathrm{OAc})_{4}\left(2.5 \mathrm{~mol} \%\right.$ ) or $\mathrm{Rh}_{2}(\mathrm{OOct})_{4}(2.5 \mathrm{~mol} \%), \mathrm{C}_{2} \mathrm{H}_{4} \mathrm{Cl}_{2}$ or $\mathrm{CH}_{2} \mathrm{Cl}_{2}$, reflux, 18-20 h; ii) $\mathrm{PPh}_{3}\left(2.0\right.$ eq), $\mathrm{I}_{2}$ (2.0 eq), $\mathrm{Et}_{3} \mathrm{~N}$ (4.1 eq), $\mathrm{CH}_{2} \mathrm{Cl}_{2}$, rt, $16 \mathrm{~h}$.

Scheme 30. Rh(II)-catalysed reaction of $\alpha$-diazo- $\beta$-keto-carboxylate $\mathbf{7 4}$ with amides 89 followed by cyclodehydration

With 3-indolyl $\alpha$-diazo- $\beta$-ketoester 97 substrates a competing $\mathrm{N}-\mathrm{H}$ insertion and Wolff rearrangement during the $\mathrm{Rh}(\mathrm{II})$-catalysed reaction has been reported (Scheme 31 ). ${ }^{47}$ Ketoamides 99 were subsequently transformed into the corresponding oxazoles 101 upon cyclodehydration (Scheme 32). ${ }^{47}$ Notably, the presence of strong electron-withdrawing groups on the indole moiety favoured the $\mathrm{N}-\mathrm{H}$ insertion process over Wolff rearrangement which was exploited to prepare a potential precursor to the natural product martefragin $\mathrm{A}^{47}$ 


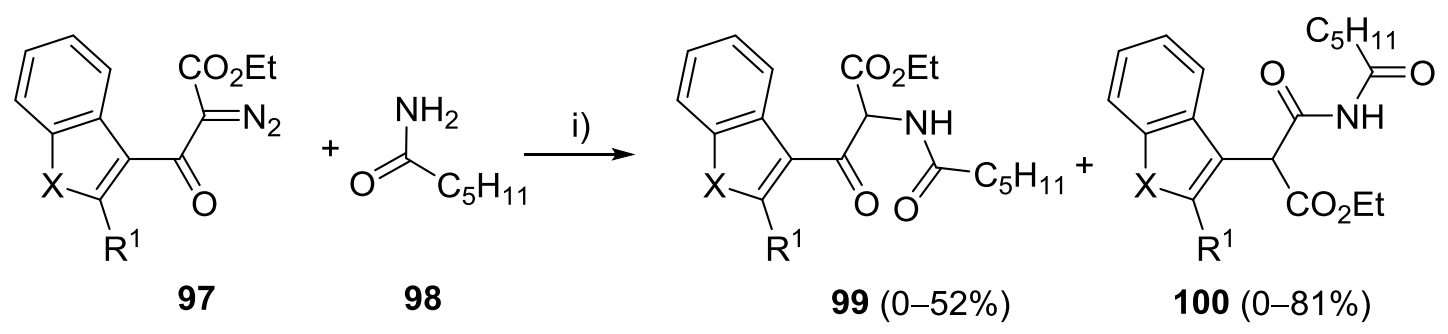

$\mathrm{X}=t-\mathrm{BuO}_{2} \mathrm{CN}, \mathrm{C}_{6} \mathrm{H}_{5} \mathrm{SO}_{2} \mathrm{~N}, 2-\mathrm{NO}_{2} \mathrm{C}_{6} \mathrm{H}_{4} \mathrm{SO}_{2} \mathrm{~N}, \mathrm{MeN}$;

$\mathrm{R}^{1}=\mathrm{H}, \mathrm{Cl}$

i) 97 (1.2-24.0 eq), 98 (1.0 eq), $\mathrm{Rh}_{2}(\mathrm{Oct})_{4}(2-6 \mathrm{~mol} \%), \mathrm{CH}_{2} \mathrm{Cl}_{2}$, reflux, $16.5 \mathrm{~h}$.

Scheme 31. Rh(II)-catalysed reaction of 3-indolyl $\alpha$-diazo- $\beta$-ketoester 97 with hexanamide 98

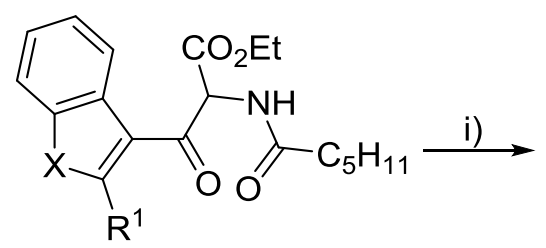

99<smiles>[R]c1[X]c2ccccc2c1-c1oc([AsH2])nc1C(=O)OCC</smiles>

$101(65-85 \%)$

$\mathrm{X}=t-\mathrm{BuO}_{2} \mathrm{CN}, \mathrm{C}_{6} \mathrm{H}_{5} \mathrm{SO}_{2} \mathrm{~N}, 2-\mathrm{NO}_{2} \mathrm{C}_{6} \mathrm{H}_{4} \mathrm{SO}_{2} \mathrm{~N}, \mathrm{MeN}$

$\mathrm{R}^{1}=\mathrm{H}, \mathrm{Cl}$

i) 99 (1.0 eq), $\mathrm{PPh}_{3}(2.0 \mathrm{eq}), \mathrm{I}_{2}(2.0 \mathrm{eq}), \mathrm{Et}_{3} \mathrm{~N}(2.1 \mathrm{eq}), \mathrm{CH}_{2} \mathrm{Cl}_{2}, \mathrm{rt}, 16 \mathrm{~h}$

Scheme 32. Cyclodehydration of ketoamides 99

In 2009, Moody described a robust regioselective synthesis of oxazole-4-carboxylates and oxazole-4-phosphonates. For example, $\mathrm{Rh}(\mathrm{II})$-catalysed reaction of $\alpha$-diazo- $\beta$-keto-carboxylate 102 with carboxamide 89 afforded oxazole-4-carboxylate 103 (Scheme 33) whilst the same transformation applied to $\alpha$-diazo- $\beta$-keto-phosphonate 104 and benzamide 105 provides oxazole-4-phosphonate 106 (Scheme $34){ }^{48,49}$ Surprisingly, $\alpha$-diazo- $\beta$-keto-sulfones failed to deliver the 4-sulfonyloxazoles analogue under similar reaction conditions and presents opportunities for further research.<smiles>COC(=O)C(C)=O</smiles>

102<smiles>[R]C(N)=O</smiles>

89<smiles>[R]Cc1nc(C(=O)OC)c(C)o1</smiles>

$103(70-83 \%)$

$\mathrm{R}^{1}=\mathrm{Ph}, 4-\mathrm{MeOC}_{6} \mathrm{H}_{4}, 4-\mathrm{BrC}_{6} \mathrm{H}_{4}$

i) 102 (1.1 eq), 89 (1.0 eq), $\mathrm{Rh}_{2}(\mathrm{OAc})_{4}(2 \mathrm{~mol} \%), \mathrm{C}_{2} \mathrm{H}_{4} \mathrm{Cl}_{2}$, reflux, on;

ii) $\mathrm{PPh}_{3}(2.0 \mathrm{eq}), \mathrm{I}_{2}(2.0 \mathrm{eq}), \mathrm{Et}_{3} \mathrm{~N}(4.1 \mathrm{eq}), \mathrm{CH}_{2} \mathrm{Cl}_{2}$, rt, on.

Scheme 33. $\mathrm{Rh}(\mathrm{II})$-catalysed reaction of $\alpha$-diazo- $\beta$-keto-carboxylate $\mathbf{1 0 2}$ with amides $\mathbf{8 9}$ followed by cyclodehydration 


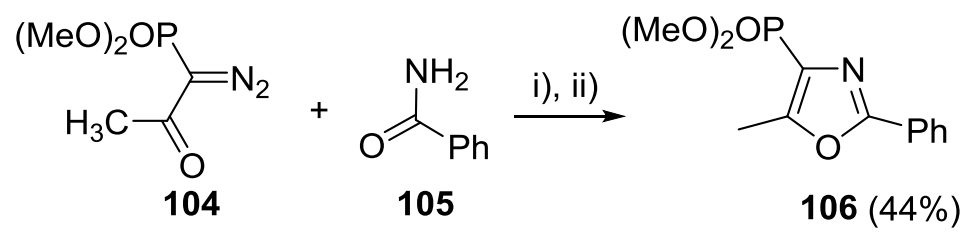

i) 104 (1.1 eq), 105 (1.0 eq), $\mathrm{Rh}_{2}(\mathrm{OAc})_{4}$ (2 mol\%), $\mathrm{CH}_{2} \mathrm{Cl}_{2}$, reflux, on;

ii) solid-phase $\mathrm{PPh}_{3}(2.0 \mathrm{eq}), \mathrm{I}_{2}(2.0 \mathrm{eq}), \mathrm{Et}_{3} \mathrm{~N}$ (4.1 eq), $\mathrm{CH}_{2} \mathrm{Cl}_{2}$, rt, on.

Scheme 34. $\mathrm{Rh}(\mathrm{II})$-catalysed reaction of $\alpha$-diazo- $\beta$-keto-carboxylate $\mathbf{1 0 4}$ with amides $\mathbf{1 0 5}$ followed by cyclodehydration

Remarkably, when the above transformation was performed using dirhodium tetrakis(heptafluorobutyramide) as a catalyst, regioisomeric oxazole-5-carboxylates $\mathbf{1 0 7}$ were obtained as the only products (Scheme 35). In the same fashion, oxazole-5-phosphonates 109 (Scheme 36) and oxazole-5-sulfones 111 (Scheme 37) were also prepared. ${ }^{48,49}$ Of particular note is the ready availability of carboxamides 89 which renders this protocol a convenient, selective and attractive method to access both 4and 5-functionalised oxazoles based upon judicious choice of catalyst.

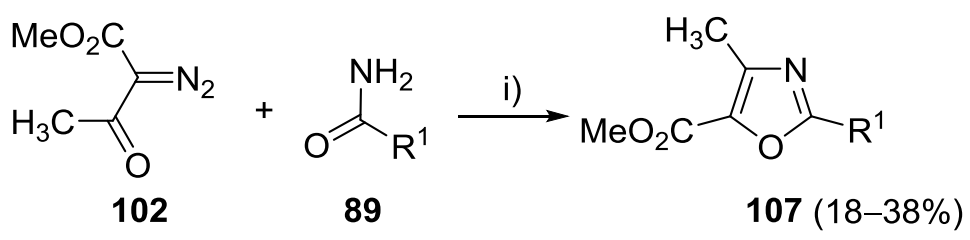

$\mathrm{R}^{1}=\mathrm{Ph}, 4-\mathrm{MeOC}_{6} \mathrm{H}_{4}, 4-\mathrm{BrC}_{6} \mathrm{H}_{4}$

i) 102 (1.1 eq), 89 (1.0 eq), $\mathrm{Rh}_{2}\left(\mathrm{NHCOC}_{3} \mathrm{~F}_{7}\right)_{4}(2 \mathrm{~mol} \%), \mathrm{MW}$ irrad, $\mathrm{C}_{2} \mathrm{H}_{4} \mathrm{Cl}_{2}, 105^{\circ} \mathrm{C}, 30 \mathrm{~min}$.

Scheme 35. Rh(II)-catalysed synthesis of oxazole-5-carboxylates 107<smiles>[R6]O[PH2]C(=[NH2+])C([R])=O</smiles>

$\mathrm{R}^{1}=\mathrm{Ph}, 2-\mathrm{BrC}_{6} \mathrm{H}_{4}, 2-\mathrm{BnOC}_{6} \mathrm{H}_{4}, 4-\mathrm{BrC}_{6} \mathrm{H}_{4}, 4-\mathrm{MeOC}_{6} \mathrm{H}_{4}, 4-\mathrm{NO}_{2} \mathrm{C}_{6} \mathrm{H}_{4}, 4-\mathrm{CbzNHC}_{6} \mathrm{H}_{4}$, 4- $\mathrm{PhC}_{6} \mathrm{H}_{4}, 3,5-\mathrm{F}_{2} \mathrm{C}_{6} \mathrm{H}_{3}$, thiophen-2-yl, benzothiophen-2-yl, $\mathrm{PhCH}=\mathrm{CH}$;

$\mathrm{R}^{2}=\mathrm{Me}, \mathrm{Ph}$;

$\mathrm{R}^{3}=\mathrm{Me}, \mathrm{Et}$

i) 108 (1.1 eq), 89 (1.0 eq), $\mathrm{Rh}_{2}\left(\mathrm{NHCOC}_{3} \mathrm{~F}_{7}\right)_{4}(2 \mathrm{~mol} \%)$, PhMe, reflux, $16 \mathrm{~h}$ or

108 (1.1 eq), 89 (1.0 eq), $\mathrm{Rh}_{2}\left(\mathrm{NHCOC}_{3} \mathrm{~F}_{7}\right)_{4}(2 \mathrm{~mol} \%), \mathrm{MW}$ irrad, $\mathrm{PhMe}, 135^{\circ} \mathrm{C}, 30 \mathrm{~min}$.

Scheme 36. Rh(II)-catalysed synthesis of oxazole-5-phosphonates 109 


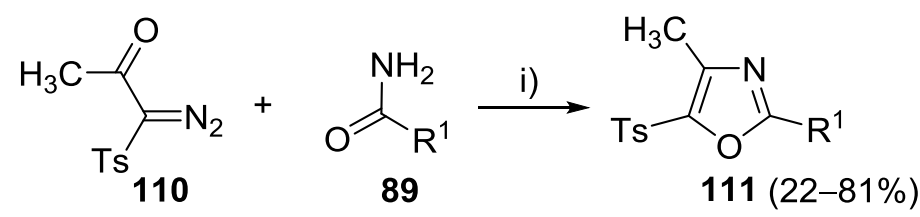

$\mathrm{R}^{1}=\mathrm{Ph}, 2-\mathrm{BrC}_{6} \mathrm{H}_{4}, 2-\mathrm{BnOC}_{6} \mathrm{H}_{4}, 4-\mathrm{BrC}_{6} \mathrm{H}_{4}, 4-\mathrm{NO}_{2} \mathrm{C}_{6} \mathrm{H}_{4}, 4-\mathrm{CbzNHC}_{6} \mathrm{H}_{4}, 4-\mathrm{PhC}_{6} \mathrm{H}_{4}$, thiophen-2-yl, $\mathrm{PhCH}=\mathrm{CH}$

i) 110 (1.1 eq), 89 (1.0 eq), $\mathrm{Rh}_{2}\left(\mathrm{NHCOC}_{3} \mathrm{~F}_{7}\right)_{4}(2 \mathrm{~mol} \%), \mathrm{C}_{2} \mathrm{H}_{4} \mathrm{Cl}_{2}$, reflux, $16 \mathrm{~h}$ or

110 (1.1 eq), 89 (1.0 eq), $\mathrm{Rh}_{2}\left(\mathrm{NHCOC}_{3} \mathrm{~F}_{7}\right)_{4}(2 \mathrm{~mol} \%), \mathrm{MW}$ irrad, $\mathrm{C}_{2} \mathrm{H}_{4} \mathrm{Cl}_{2}, 105^{\circ} \mathrm{C}, 30 \mathrm{~min}$.

Scheme 37. Rh(II)-catalysed synthesis of oxazole-5-sulfones 111

This overall method can also be applied to the synthesis of trifluoromethyloxazoles e.g. 113 and 114. $\mathrm{Rh}(\mathrm{II})$-catalysed reaction of trifluoroacetyl diazoketoester 112 with amide $\mathbf{8 9}$ generated a mixture of regioisomeric 5-trifluoromethyloxazoles 113 and 4-trifluoromethyloxazoles 114 (Scheme 38 ). ${ }^{50}$ The lack of regioselectivity in formation of 5-trifluoromethyloxazoles $\mathbf{1 1 3}$ is due to a competing $\mathrm{O}-\mathrm{H}$ insertion process of the carbenoid species generated from 112, suggesting the trifluoromethyl group influences the electrophilicity of the carbenoid.

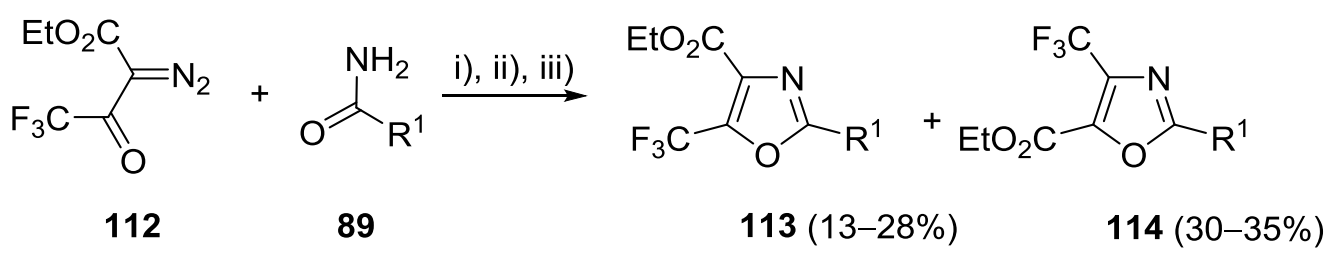

$\mathrm{R}^{1}=\mathrm{Ph}, 2-\mathrm{BrC}_{6} \mathrm{H}_{4}, 4-\mathrm{MeOC}_{6} \mathrm{H}_{4}, 4-\mathrm{BrC}_{6} \mathrm{H}_{4}$

i) 112 (1.1 eq), 89 (1.0 eq), $\mathrm{Rh}_{2}(\mathrm{OAc})_{4}(2 \mathrm{~mol} \%), \mathrm{CH}_{2} \mathrm{Cl}_{2}, \mathrm{MW}$ irrad, $80^{\circ} \mathrm{C}, 15 \mathrm{~min}$;

ii) $\mathrm{POCl}_{3}(2.0 \mathrm{eq})$, MW irrad, $105^{\circ} \mathrm{C}, 20 \mathrm{~min}$; iii) Amberlyst 15 , MW irrad, $105^{\circ} \mathrm{C}, 15 \mathrm{~min}$.

Scheme 38. Rh(II)-catalysed synthesis of 5-trifluoromethyloxazoles $\mathbf{1 1 3}$ and 4-trifluoromethyloxazoles 114

The power of this $\mathrm{Rh}(\mathrm{II})$-catalysed synthesis of oxazoles can be seen in its applications in natural product synthesis with the preparation of diazonamide $A,,^{51-54}(+)$-nostocyclamide, ${ }^{55}$ promothiocin $\mathrm{A}$, 56 telomestatin, ${ }^{16}$ siphonazole ${ }^{14}$ and martefragin $\mathrm{A} .{ }^{47}$

\section{COPPER(I), COPPER(II)}

Along with rhodium, copper has also been shown to be an efficient catalyst for this strategy of preparing oxazoles. Glorious described an interesting single-step synthesis of $\mathbf{1 1 6}$ through the $\mathrm{Cu}(\mathrm{I})$-catalysed domino reaction of 1,2-dihaloalkenes 115 and primary amides 89 (Scheme 39). ${ }^{57}$ This transformation proceeds via a sequential $\mathrm{Cu}(\mathrm{I})$-catalysed $\mathrm{C}-\mathrm{N}$ and $\mathrm{C}-\mathrm{O}$ bond forming process. Initial non-regioselective 
formation of an enamide intermediate followed by cyclisation gives a mixture of 2,4- and 2,5-disubstituted oxazoles 116. The use of 1,2-dibromo olefins favours the formation of 2,5-disubstituted oxazoles over the 2,4-disubstituted isomers. Use of the more reactive 1,2-diiodo olefins tended to generate 1:1 mixtures or to favour the formation of 2,4-disubstituted oxazoles suggesting complementary strategies for oxazole synthesis may be possible.
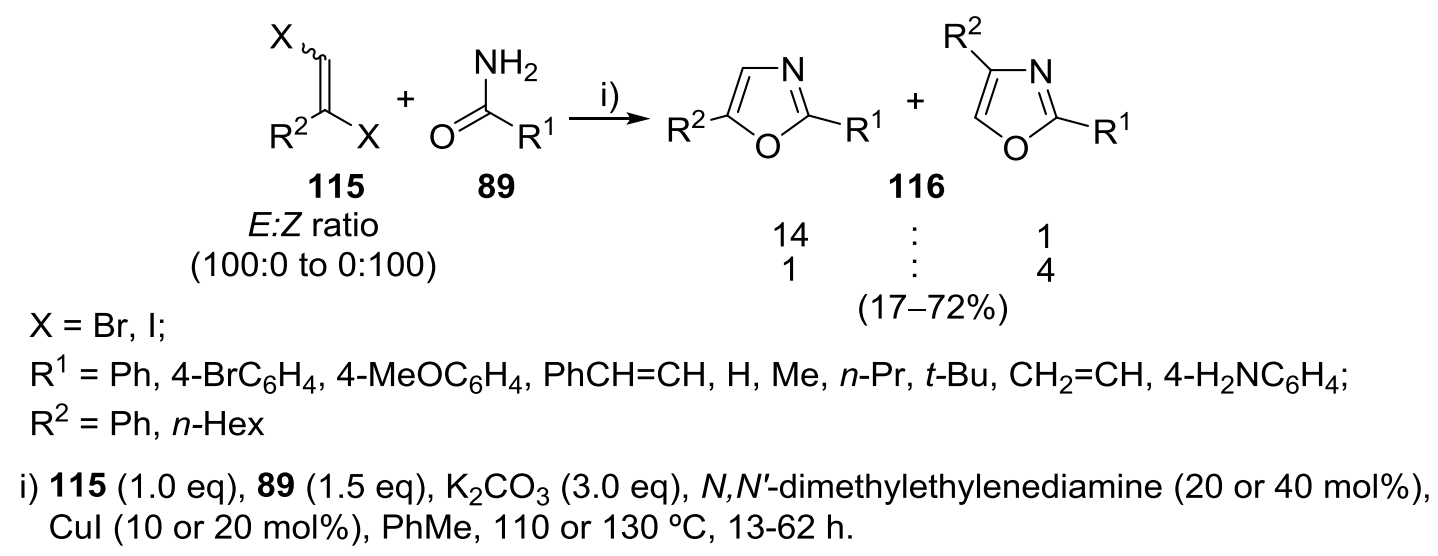

Scheme 39. $\mathrm{Cu}(\mathrm{I})$-catalysed synthesis of oxazoles 116

Buchwald reported an alternative $\mathrm{C}-\mathrm{N}$ and $\mathrm{C}-\mathrm{O}$ bond forming process to access the oxazole core. ${ }^{58}$ $\mathrm{Cu}(\mathrm{I})$-catalysed reaction of aliphatic or aromatic amides 89 with vinyl bromides 118 generates enamides 119. Iodine-promoted cyclisation of $\mathbf{1 1 9}$ furnishes oxazolines 120, which lead to the oxazole product 75 upon reaction with base (Scheme 40). This method allowed for an efficient synthesis of a range of trisubstituted oxazoles from readily available starting materials in good yield. To overcome the issue of regioselectivity described by Glorious, ${ }^{57}$ Buchwald applied this strategy ${ }^{58}$ to a one-pot regioselective synthesis of disubstituted oxazoles 122 through the $\mathrm{Cu}(\mathrm{I})$-catalysed reaction of 1,2-iodobromoalkene 121 and amide 89 (Scheme 41). ${ }^{58}$ Notably, the initial $\mathrm{C}-\mathrm{N}$ bond formation occurred solely at the vinyl iodide moiety. The need of a general method for the synthesis of $\mathbf{1 2 1}$ represents a drawback of this protocol. 


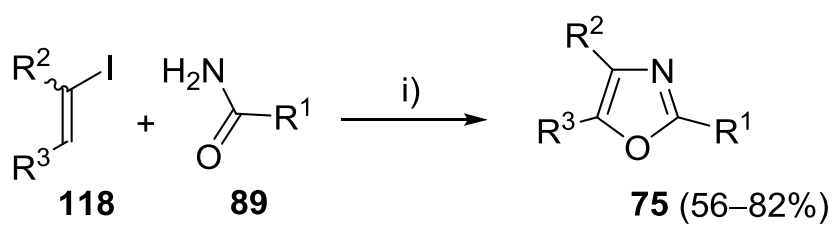

$\mathrm{R}^{1}=\mathrm{Ph}$, cyclohexyl, $\mathrm{Ph}_{2} \mathrm{CH}$, pyridin-3-yl, furan-2-yl, 2- $\mathrm{ClC}_{6} \mathrm{H}_{4}$;

$\mathrm{R}^{2}=-\mathrm{CH}_{2}\left(\mathrm{CH}_{2}\right)_{4} \mathrm{CH}_{2^{-}}, n$ - $\mathrm{Pr}$, TIPSO $\left(\mathrm{CH}_{2}\right)_{2}, \mathrm{Ph}, \mathrm{NC}\left(\mathrm{CH}_{2}\right)_{3}$, thiophen-2-yl, EtO ${ }_{2} \mathrm{C}, n$-Bu;

$\mathrm{R}^{3}=-\mathrm{CH}_{2}\left(\mathrm{CH}_{2}\right)_{4} \mathrm{CH}_{2}$, n-Pr, thiophen-2-yl, $\mathrm{Ph}, \mathrm{NC}\left(\mathrm{CH}_{2}\right)_{3}, \mathrm{EtO}_{2} \mathrm{CCH}=\mathrm{CH}, \mathrm{Me}, 5-\mathrm{F}_{3} \mathrm{C}$-pyridin-2-yl

Proposed reaction mechanism

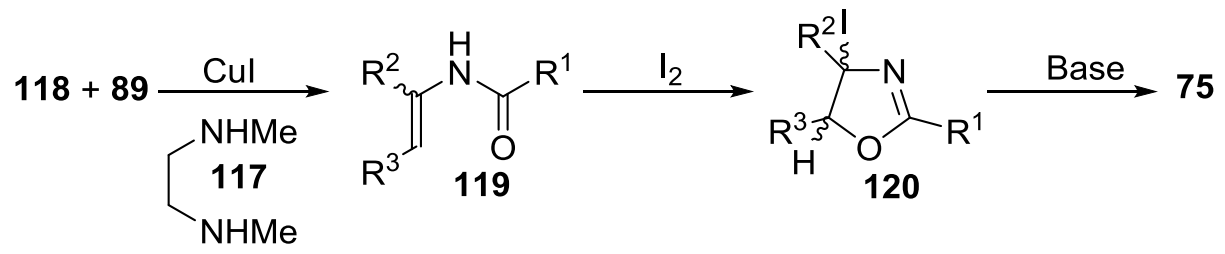

i) 118 (1.0 eq), 89 (1.2 eq), Cul (5 mol\%), N,N'-dimethylethylenediamine 117 (20 mol\%), $\mathrm{Cs}_{2} \mathrm{CO}_{3}(1.5 \mathrm{eq}), \mathrm{THF}$, $80^{\circ} \mathrm{C}, 3-8 \mathrm{~h}$; ii) $\mathrm{I}_{2}(1.1 \mathrm{eq}), \mathrm{K}_{2} \mathrm{CO}_{3}(2.0 \mathrm{eq}), \mathrm{DBU}(2.0 \mathrm{eq})$, rt to $80^{\circ} \mathrm{C}, 5-10 \mathrm{~h}$.

Scheme 40. Sequential one-pot $\mathrm{Cu}(\mathrm{I})$-catalysed amidation-iodination protocol for the synthesis of oxazoles 75

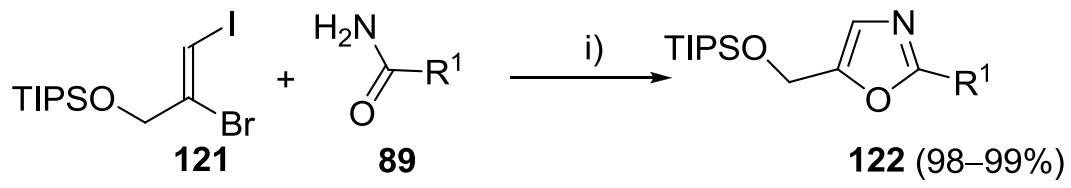

$$
\mathrm{R}^{1}=\mathrm{Ph}, 4-\mathrm{ClC}_{6} \mathrm{H}_{4}, 4-\mathrm{CF}_{3} \mathrm{C}_{6} \mathrm{H}_{4}
$$

i) 121 (1.0 eq), 89 (1.2 eq), Cul (5 mol\%), N,N'-dimethylethylenediamine (20 mol\%), $\mathrm{Cs}_{2} \mathrm{CO}_{3}(3.0 \mathrm{eq}), \mathrm{THF}, 80^{\circ} \mathrm{C}, 8 \mathrm{~h}$.

Scheme 41. $\mathrm{Cu}(\mathrm{II})$-catalysed synthesis of oxazoles $\mathbf{1 2 2}$

No space for consistency in [3+2]

More recently, Pérez described a catalytic and regioselective synthesis of 2,5-disubstituted oxazoles 125 through the cycloaddition of terminal alkynes 123 and acyl azides 124 using a copper(I) catalyst precursor (Scheme 42). ${ }^{59}$ The reaction proceeds via the [3+2] cycloaddition of the copper acetylide of $\mathbf{1 2 3}$ with $\mathbf{1 2 4}$ generating a copper triazolyl intermediate $\mathbf{1 2 7}$. Conversion of $\mathbf{1 2 7}$ to a copper ketenimide $\mathbf{1 3 0}$ proceeds via the formation of 128 or 129. Protonation of 130 promotes cyclisation to $132 / 132$ ', followed by a 1,2-hydrogen shift to give $\mathbf{1 2 5}$ and release of the catalyst. Trisubstituted oxazoles $\mathbf{1 2 6}$ can also be generated through the aromatisation of $\mathbf{1 3 3}$ and coupling with a copper acetylide 135. Although substrate scope was limited with alkyl acetylenes and internal alkynes being ineffective substrates, development of more reactive catalysts will make this an attractive and readily accessible methodology for oxazole construction. 


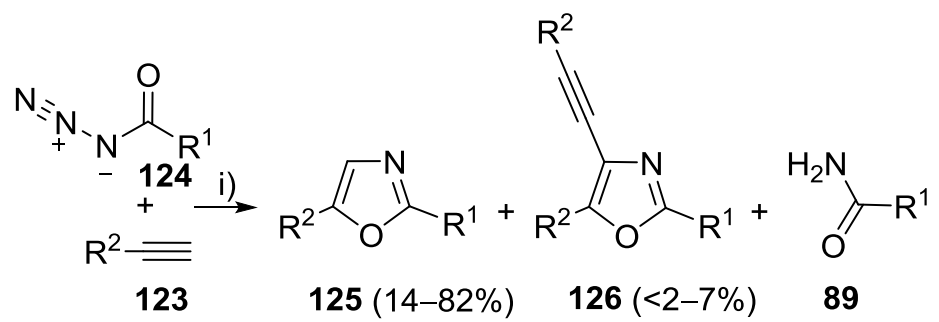

$\mathrm{R}^{1}=\mathrm{Ph}, 4-\mathrm{MeC}_{6} \mathrm{H}_{4}, 4-\mathrm{MeOC}_{6} \mathrm{H}_{4}, 4-\mathrm{NO}_{2} \mathrm{C}_{6} \mathrm{H}_{4}$, thiophene-2-yl;

$\mathrm{R}^{2}=\mathrm{Ph}, 4-\mathrm{MeC}_{6} \mathrm{H}_{4}, 4-\mathrm{MeOC}_{6} \mathrm{H}_{4}, 4-\mathrm{BrC}_{6} \mathrm{H}_{4}$, thiophene-3-yl, $n$ - $\mathrm{Pr}, n$-Bu, cyclopropyl

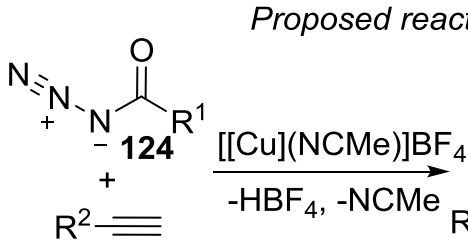

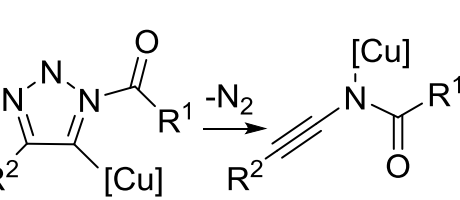

123

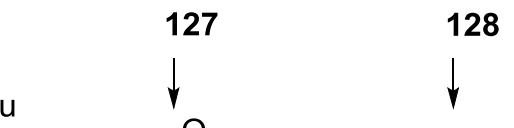

$[\mathrm{Cu}]=\mathrm{Tpm}^{*} \mathrm{BrCu}$<smiles>[R]C(=O)N=C([GeH3])C([R])=O</smiles>

129<smiles>[R]C(=O)N=C([R])[GeH2]C#N</smiles>

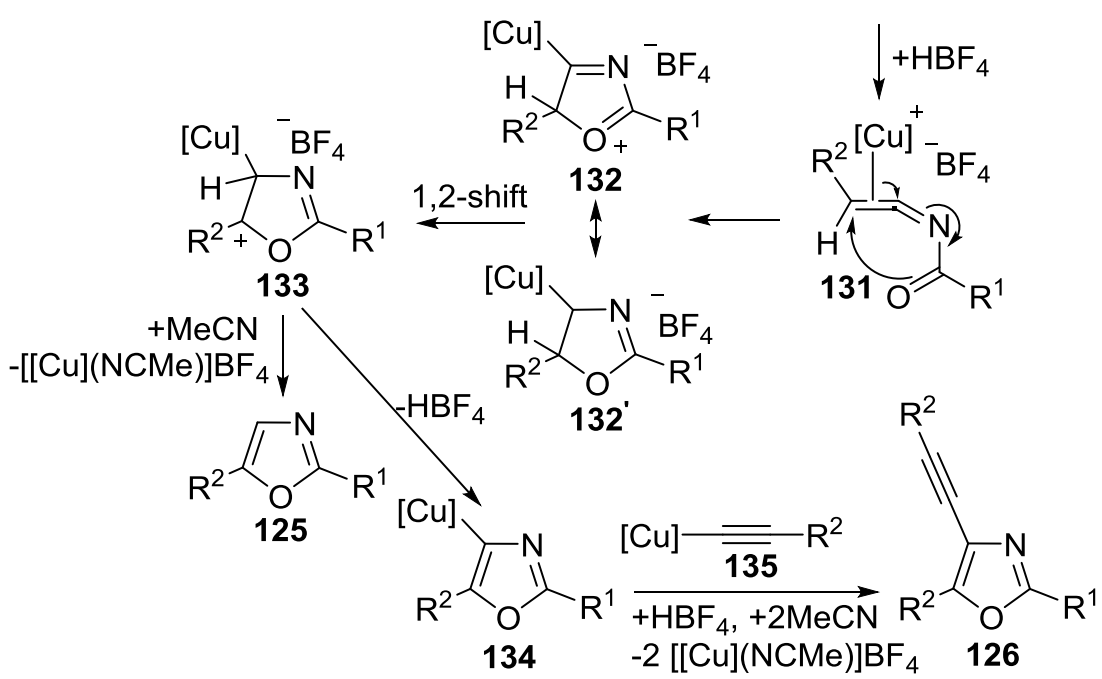

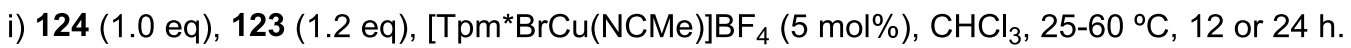

Scheme 42. Cu(I)-catalysed cycloaddition of alkynes $\mathbf{1 2 3}$ and acyl azides $\mathbf{1 2 4}$

\section{GOLD(I), GOLD(III)}

Davies described an interesting synthesis of fully substituted oxazoles 138 through the $\mathrm{Au}(\mathrm{III})$-catalysed [3+2] cycloaddition of ynamides 136 and aminides 137 (Scheme 43), ${ }^{60}$ providing the first example of a gold-catalysed intermolecular cycloaddition across a $\mathrm{C}-\mathrm{C} \pi$-system. The reactions proceeded regioselectively and chemoselectively, delivering highly substituted and functionalised oxazole products in good yield. The reaction proceeds by nucleophilic attack of an aminide $\mathbf{1 3 7}$ to a gold activated ynamide 140/140' giving 141. Adduct 141 cyclises to $143 / 143$ ' after extrusion of pyridine either through a $4 \pi$ 
electrocyclisation via 144/144', or more plausibly via 142. Elimination of the gold-catalyst from 143 then yields oxazole 138. Of particular note with this work is the high functional group tolerance which makes this methodology particularly attractive.<smiles>[R]C#CN([R])[CH]N(C(=O)Br)[n+]1ccccc1</smiles>

$\mathrm{R}^{1}=\mathrm{Ph}, 2-\mathrm{BrC}_{6} \mathrm{H}_{4}$, furan-2-yl, $\mathrm{PhCH}=\mathrm{CH}, \mathrm{MeCH}=\mathrm{CH}, \mathrm{Et}, \mathrm{MeO}$

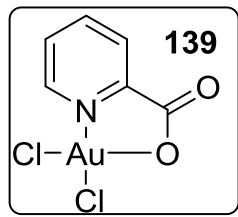

$\mathrm{R}^{2}, \mathrm{R}^{3}=\mathrm{Ms}, \mathrm{Ph}, \mathrm{Bn}, 4-\mathrm{NO}_{2} \mathrm{C}_{6} \mathrm{H}_{4} \mathrm{SO}_{2}, \mathrm{Ts}, \mathrm{Bn}, \mathrm{TMSC} \equiv \mathrm{CCH}_{2}, \mathrm{TBSO}\left(\mathrm{CH}_{2}\right)_{2}, \mathrm{CH}_{2}=\mathrm{CHCH}_{2}$, oxazolidin-3-yl; $\mathrm{R}^{4}=\mathrm{Ph}, \mathrm{TBDPSO}\left(\mathrm{CH}_{2}\right)_{3}, \mathrm{Br}\left(\mathrm{CH}_{2}\right)_{2}, \mathrm{THPO}\left(\mathrm{CH}_{2}\right)_{3}, n-\mathrm{Bu}$, cyclopropyl

Proposed reaction mechanism

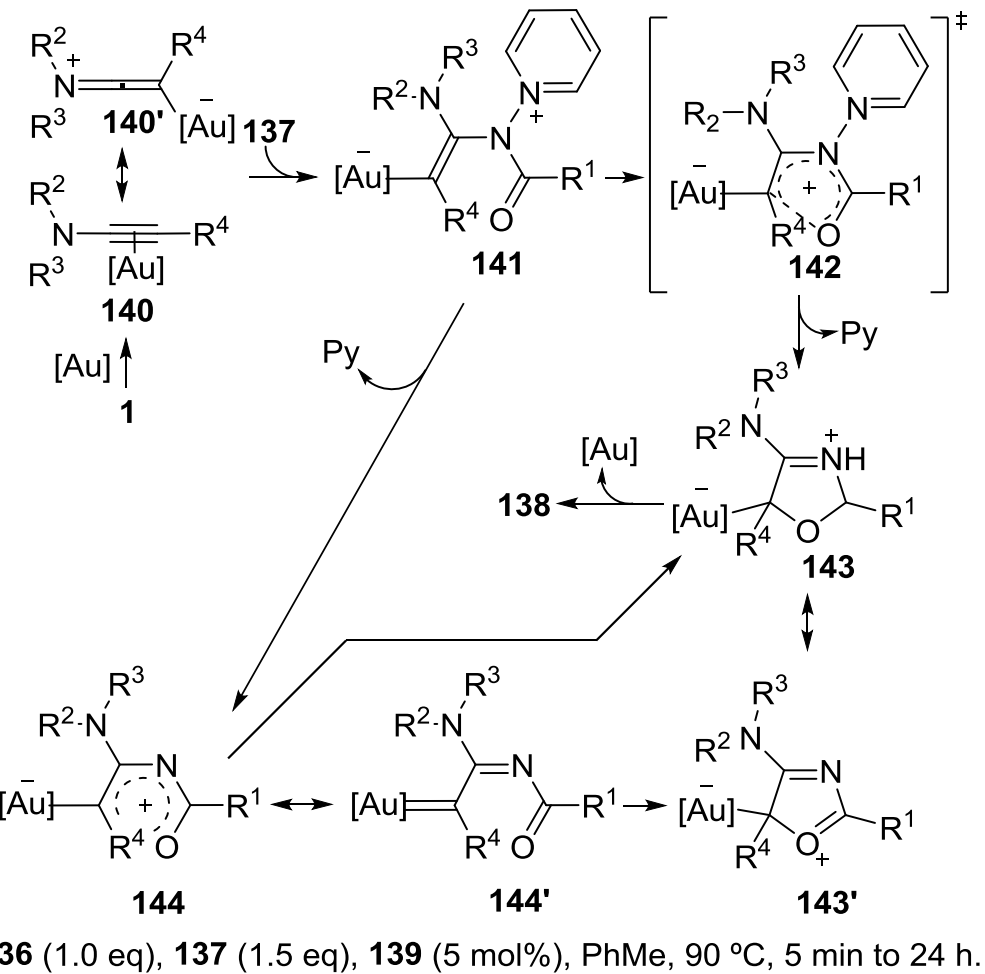

Scheme 43. Au(III)-catalysed [3+2] intermolecular cycloaddition of ynamides $\mathbf{1 3 6}$ and aminides $\mathbf{1 3 7}$

The scope for this class of transformation was expanded by Davies, who described the preparation of trisubstituted oxazoles 75 through the $\mathrm{Au}(\mathrm{I})$-catalysed [3+2] cycloaddition of unsymmetrical alkynes 145 and aminides 137 (Scheme 44). ${ }^{61}$ Remarkably, the reactions proceeded with excellent regioselectivity, due to the $\pi$-electron-donating ability of the remote nitrogen in $\mathrm{R}^{2}$. A broad range of 3-indolyl and benzenoid alkynes 145, including substrates bearing sterically hindered groups, successfully delivered oxazoles $\mathbf{7 5}$ in good yield. Importantly, 3-indolyl alkynes 145 bearing alkyl substituents, unlike the ynamide counterparts previously employed, ${ }^{60}$ were generally less effective substrates. 


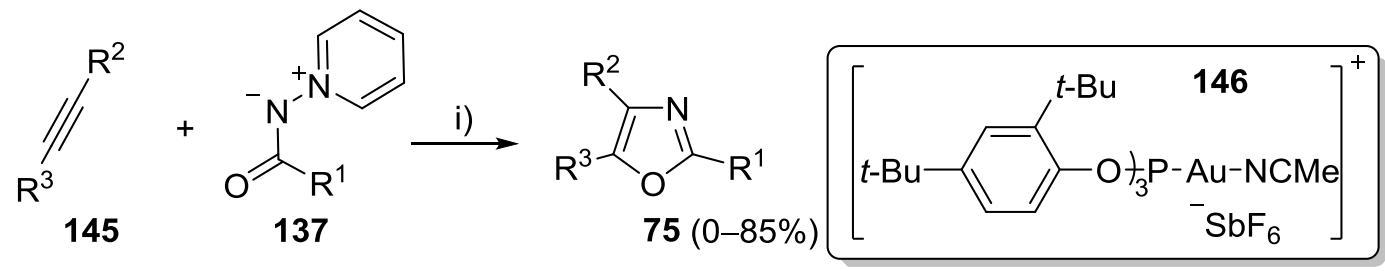

$\mathrm{R}^{1}=\mathrm{Ph}, 2-\mathrm{BrC}_{6} \mathrm{H}_{4}, 4-\mathrm{MeOC}_{6} \mathrm{H}_{4}, 4-\mathrm{FC}_{6} \mathrm{H}_{4}$, furan-2-yl, thiophen-2-yl;

$\mathrm{R}^{2}=$ indol-3-yl, 1-Me-indol-3-yl, 1-Bn-indol-3-yl, 1-allyl-indol-3-yl, 5-Br-1-Me-indol-3-yl, 6-MeO ${ }_{2} \mathrm{C}-\mathrm{indol}_{-3}-\mathrm{yl}$,

4- $\mathrm{Me}_{2} \mathrm{NC}_{6} \mathrm{H}_{4}, 4$ (morpholin-4-yl) $\mathrm{C}_{6} \mathrm{H}_{4}$, 4(pyrrolidin-1-yl) $\mathrm{C}_{6} \mathrm{H}_{4}$, 3(pyrrolidin-1-yl) $\mathrm{C}_{6} \mathrm{H}_{4}, 4-\mathrm{MeOC}_{6} \mathrm{H}_{4}$;

$\mathrm{R}^{3}=\mathrm{Ph}$, thiophen-2-yl, furan-2-yl, 4- $\mathrm{MeOC}_{6} \mathrm{H}_{4}, 4-\mathrm{FC}_{6} \mathrm{H}_{4}$, cyclopropyl, 2- $\mathrm{BrC}_{6} \mathrm{H}_{4}$

i) 137 (1.5 eq), 145 (1.0 eq), 146 (5 mol\%), m-xylene, $120^{\circ} \mathrm{C}, 24$ or $48 \mathrm{~h}$.

Scheme 44. Au(I)-catalysed synthesis of oxazoles 75

An efficient modular synthesis of 2,4-disubstituted oxazoles 125 through a [3+2] annulation strategy between a terminal alkyne $\mathbf{1 2 3}$ and a carboxamide 89 using a gold catalysed oxidation strategy has also been described (Scheme 45). ${ }^{62}$ Careful choice of supporting ligand for gold provided the key to success in this work. It is established that terminal $\alpha$-oxo gold carbenes are highly electrophilic species and thus can only be trapped efficiently intramolecularly or using solvent as the nucleophile. ${ }^{63}$ Within this work it was shown that terminal $\alpha$-oxo gold carbenes (e.g. 147) could be stabilised with the bidentate ligand Mor-DalPhos $^{64}$ through a tricoordinated $\mathrm{Au}(\mathrm{I})$ complex. This stabilisation allows trapping of the $\mathrm{Au}(\mathrm{I})$ intermediate by stoichiometric external nucleophiles greatly increasing the efficiency of the procedure. It is possible this observation will open up further exciting opportunities in homogeneous gold catalysis.

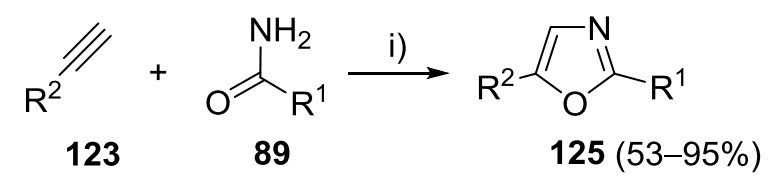

$\mathrm{R}^{1}=4-\mathrm{MeC}_{6} \mathrm{H}_{4}, \mathrm{Ph}, 4-\mathrm{ClC}_{6} \mathrm{H}_{4}, 4-\mathrm{BrC}_{6} \mathrm{H}_{4}, 4-\mathrm{FC}_{6} \mathrm{H}_{4}$, furan-2-yl, thiophen-2-yl, $\mathrm{PhCH}=\mathrm{CH}$,

$\mathrm{MeCH}=\mathrm{CH},(\mathrm{Me})_{2} \mathrm{C}=\mathrm{CH}, 4-\mathrm{MeOC}_{6} \mathrm{H}_{4}$;

$\mathrm{R}^{2}=n$-decyl, cyclohexyl, cyclopropyl, $\mathrm{PhthN}\left(\mathrm{CH}_{2}\right)_{4}, \operatorname{TIPSO}\left(\mathrm{CH}_{2}\right)_{4}, \mathrm{Cl}\left(\mathrm{CH}_{2}\right)_{4}, \mathrm{AcO}\left(\mathrm{CH}_{2}\right)_{4}$,

$\mathrm{Ph}\left(\mathrm{CH}_{2}\right)_{2}, \mathrm{Ph}, 4-\mathrm{MeC}_{6} \mathrm{H}_{4}, 4-\mathrm{MeOC}_{6} \mathrm{H}_{4}$

Proposed reaction mechanism

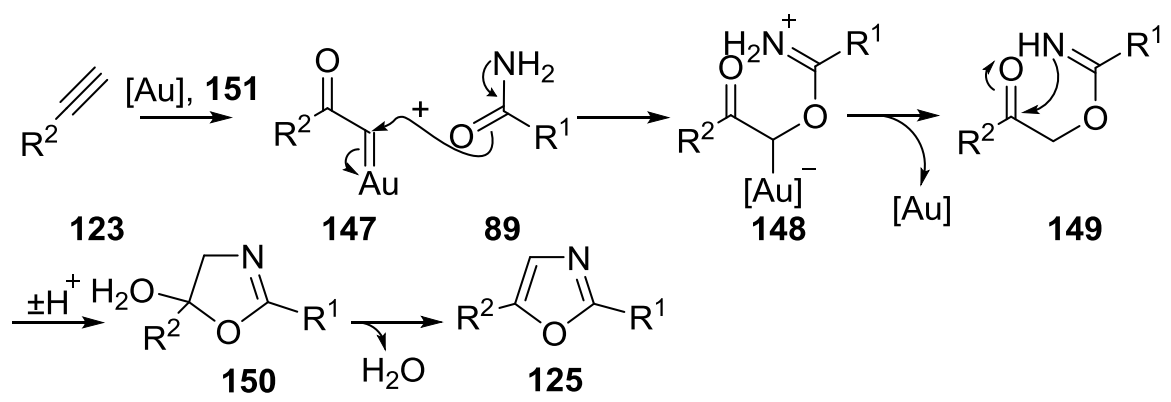

i) 123 (1.5 or 2.0 eq), 89 (1.0 eq), Mor-DalPhosAuCl (5 mol\%), NaBArF 4 (10 mol\%), 8-methylquinoline- $N$-oxide 151 (2.2 or $3.0 \mathrm{eq})$, chlorobenzene, 60 or $100^{\circ} \mathrm{C}, 16 \mathrm{~h}$.

Scheme 45. Au(I)-catalysed [3+2] annulation of terminal alkynes $\mathbf{1 2 3}$ and carboxamides $\mathbf{8 9}$ 
Mechanistically, it was proposed the reaction proceeded via nucleophilic attack of 89 on 147 to give imidate 148. Protodeauration, cyclisation and dehydration then leads to the 2,4-substituted oxazole 125. The efficient trapping of $\mathbf{1 4 7}$ by $\mathbf{8 9}$ is ascribed to the formation of a tricoordinated gold carbene species through coordination of the nitrogen atom of Mor-DalPhos to the gold atom of 147 which reduces the electrophilicity of the carbenoid carbon. Functional group tolerance was not extensively explored within this work, however, some useful functionality was introduced.

\section{SILVER(I)}

Moses developed a $\operatorname{Ag}(\mathrm{I})$-mediated synthesis of 2,4-disubstituted- and 2,4,5-trisubstituted oxazoles 75 through the microwave promoted reaction of $\alpha$-bromo-ketones $\mathbf{1 5 2}$ and primary amides $\mathbf{8 9}$ in the presence of a stoichiometric silver salt (Scheme 46). ${ }^{65}$ The reaction proceeds via the nucleophilic attack of an amide 89 on 152 followed by intramolecular cyclisation to give the oxazoline 155. Dehydration of 155 leads to the corresponding oxazole 75. Although this method represents an improvement of the Blümlein-Lewy oxazole synthesis, ${ }^{66}$ the scope in amides $\mathbf{8 9}$ is primarily limited to aromatic substrates. In an extension of the work a symmetrical bis-oxazole was also prepared using this method.
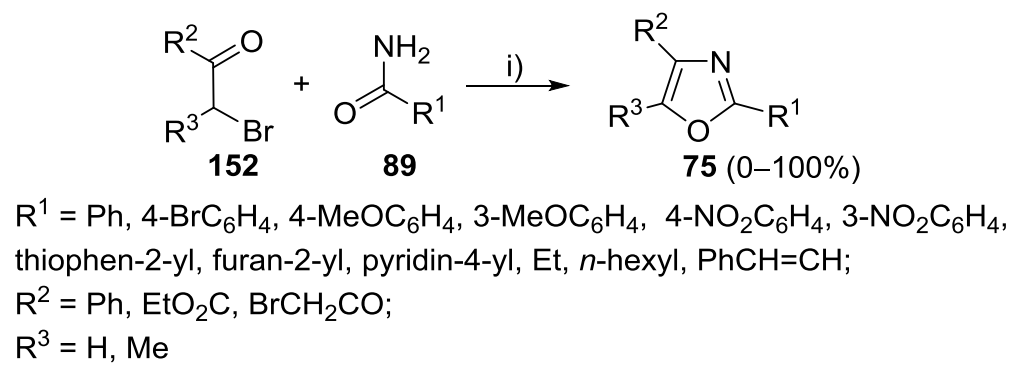

Proposed reaction mechanism

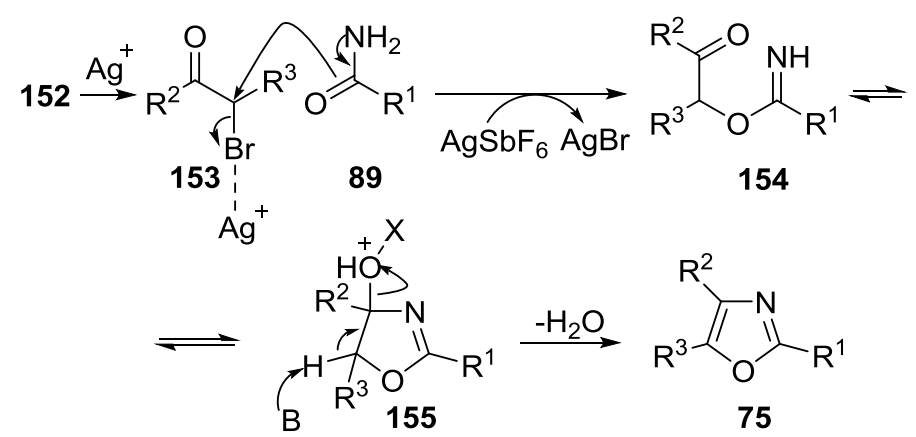

i) 152 (1.0 or $1.8 \mathrm{eq}), 89$ (1.0 or $2.0 \mathrm{eq}), \mathrm{AgSbF}_{6}(1.0$ or $2.0 \mathrm{eq}), \mathrm{C}_{2} \mathrm{H}_{4} \mathrm{Cl}_{2}, 90^{\circ} \mathrm{C}$, $1 \mathrm{~min}$ then $\mathrm{MW}$ irrad, $90^{\circ} \mathrm{C}, 2$ or $3 \mathrm{~h}$.

Scheme 46. $\operatorname{Ag}(\mathrm{I})$-mediated synthesis of oxazoles $\mathbf{7 5}$

In a useful study, Moses explored alternative $\alpha$-haloketone substrates 156 (Scheme 47). ${ }^{67} \alpha$-Bromo and $\alpha$-iodoketones were better substrates in comparison with their $\alpha$-chloroketone analogues. No formation of oxazole was observed using a methanesulfonyloxy substrate under the reaction conditions. This suggests the reaction occurs via pathway A (Scheme 47), supported by the known halophilicity of silver(I) salts. 


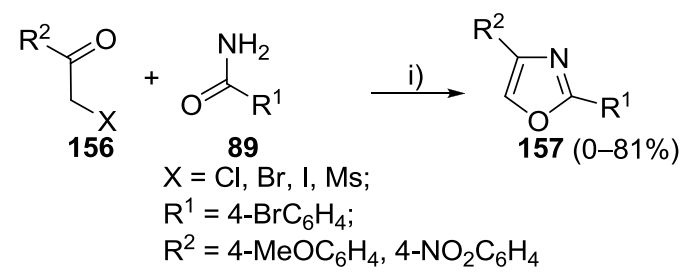

Proposed reaction mechanism

$$
\mathrm{Ag}^{+}
$$

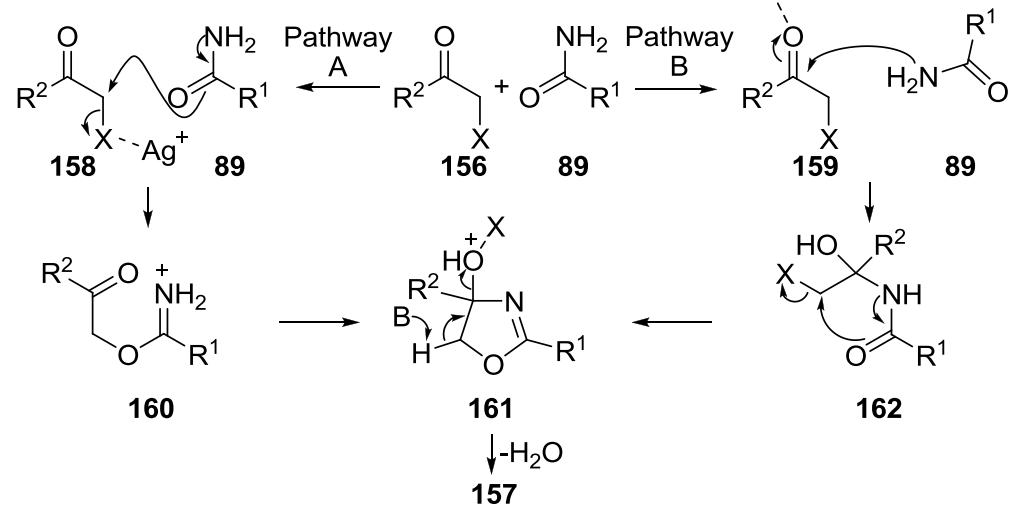

i) $\mathrm{AgSbF}_{6}(1.0 \mathrm{eq}), \mathrm{MW}$ irrad, $\mathrm{C}_{2} \mathrm{H}_{4} \mathrm{Cl}_{2}, 90^{\circ} \mathrm{C}, 2 \mathrm{~h}$.

Scheme 47. Ag(I)-mediated synthesis of oxazoles 157<smiles>[R]C(=O)OCc1oc([R10])nc1C([R])[R]</smiles>

$\mathrm{R}^{1}=\mathrm{Ph}, 3-\mathrm{MeOC}_{6} \mathrm{H}_{4}, 3-\mathrm{BrC}_{6} \mathrm{H}_{4}, 4-\mathrm{FC}_{6} \mathrm{H}_{4}, 4-\mathrm{MeC}_{6} \mathrm{H}_{4}, 4-\mathrm{ClC}_{6} \mathrm{H}_{4}, 4-\mathrm{FC}_{6} \mathrm{H}_{4}, 4-\mathrm{F}_{3} \mathrm{CC}_{6} \mathrm{H}_{4}$, EtO, cyclopentyl; $\mathrm{R}^{2}=\mathrm{Ph}, 2-\mathrm{FC}_{6} \mathrm{H}_{4}, 3-\mathrm{FC}_{6} \mathrm{H}_{4}, 3-\mathrm{MeOC}_{6} \mathrm{H}_{4}, 4-\mathrm{BrC}_{6} \mathrm{H}_{4}$, naphthalen-1-yl, naphthalen-2-yl, furan-2-yl; $\mathrm{R}^{3}=4-\mathrm{MeC}_{6} \mathrm{H}_{4} \mathrm{SO}_{2}, \mathrm{MeSO}_{2}$ Proposed reaction mechanism

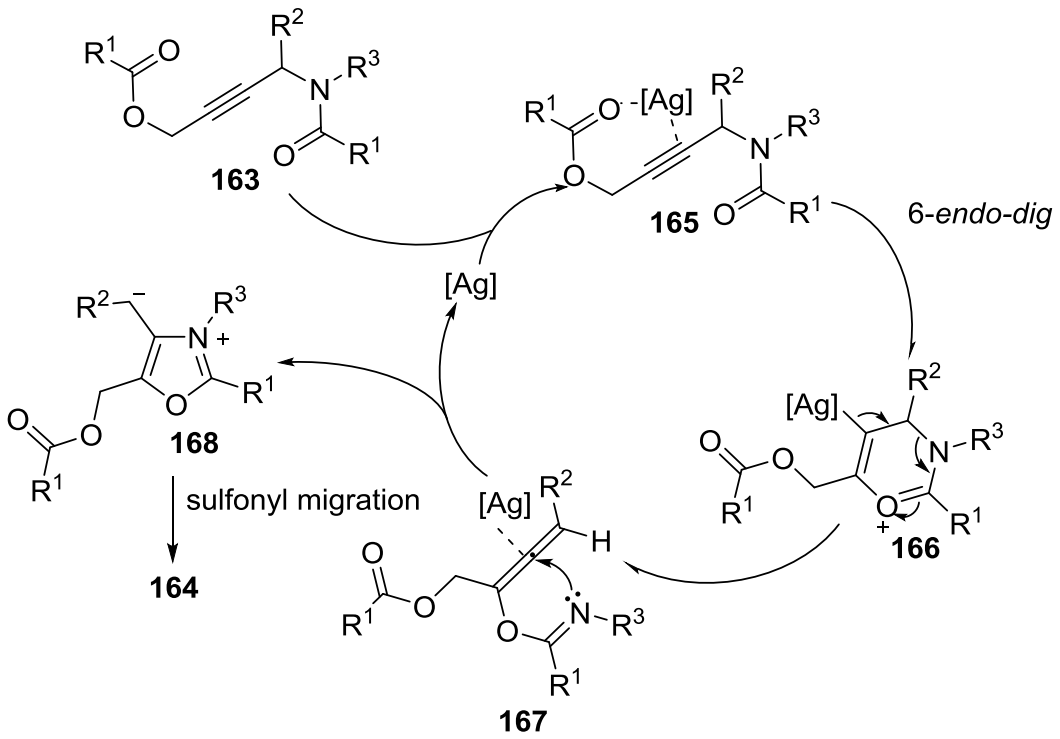

i) $\mathrm{AgBF}_{4}(10 \mathrm{~mol} \%)$, toluene, $80^{\circ} \mathrm{C}, 10 \mathrm{~h}$.

Scheme 48. Ag(II)-catalysed cyclisation of $N$-sulfonylpropargylamides 163 
The synthesis of trisubstituted oxazoles 164 through the $\operatorname{Ag}(\mathrm{I})$-catalysed cyclisation of $N$-sulfonylpropargylamides 163 (Scheme 48) was reported by Wan. ${ }^{68}$ It was proposed that $\mathrm{Ag}(\mathrm{I})$ complexes both the alkyne and the acyloxy groups of 163 to generate 165, which upon 6-endo-dig cyclisation produces 166. Intermediate 166 collapses to the allene species 167. Cyclisation of 167 furnishes 168, which undergoes a sulfonyl shift resulting in the observed oxazole 164. The reaction scope was limited to aryl-substituted $N$-sulfonylpropargylamides 163.

\section{IRON(III)}

Iron represents a cheap and abundant transition metal and therefore has received significant interest from the synthetic community as an alternative to precious metal catalysts. In 2009, Lin described a one-pot method for the preparation of trisubstituted oxazoles $\mathbf{1 7 0}$ through the Fe(III)-catalysed tandem propargylation/cycloisomerisation reaction of propargyl acetates 169 and amides 89 under microwave irradiation (Scheme 49). ${ }^{69}$ Reactions employing electron rich amides provided better yields of the oxazole products 170 .
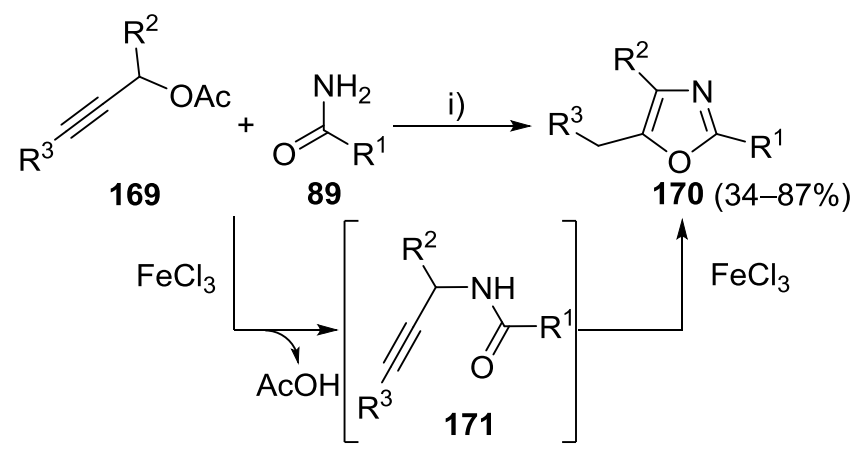

$\mathrm{R}^{1}=\mathrm{Ph}, 4-\mathrm{MeC}_{6} \mathrm{H}_{4}, 4-\mathrm{MeOC}_{6} \mathrm{H}_{4}, 4-\mathrm{NO}_{2} \mathrm{C}_{6} \mathrm{H}_{4}, 4-\mathrm{ClC}_{6} \mathrm{H}_{4}, \mathrm{Me}$;

$\mathrm{R}^{2}=\mathrm{Ph}$, naphthalen-1-yl, 4- $-\mathrm{MeOC}_{6} \mathrm{H}_{4}, 4-\mathrm{BrC}_{6} \mathrm{H}_{4}, 4-\mathrm{MeO}_{2} \mathrm{CC}_{6} \mathrm{H}_{4}$;

$\mathrm{R}^{3}=\mathrm{TMS}, \mathrm{H}, n-\mathrm{Bu}$

i) 169 (1.0 eq), 89 (3.0 eq), $\mathrm{FeCl}_{3}$ (15 mol\%), silica gel, $\mathrm{MW}$ irrad, $\mathrm{MeCN}, 4-17 \mathrm{~min}$.

Scheme 49. Fe(III)-catalysed synthesis of oxazoles $\mathbf{1 7 0}$

More recently, a complimentary one-pot regioselective Fe(III)-mediated synthesis of 2,5-di- and 2,4,5-trisubstituted oxazoles 174 through the reaction of propargylamines 172 and acid chlorides 173 was reported (Scheme 50). ${ }^{70}$ The reaction proceeds via the formation of the propargylamide $\mathbf{1 7 5}$ followed by 5-exo-dig cyclisation leading to 174. A range of propargylamines 172 bearing a variety of functional groups was prepared and reacted to afford $\mathbf{1 7 4}$ in good to excellent yields. The operational simplicity as well as the efficiency of this inexpensive protocol is particularly noteworthy. 


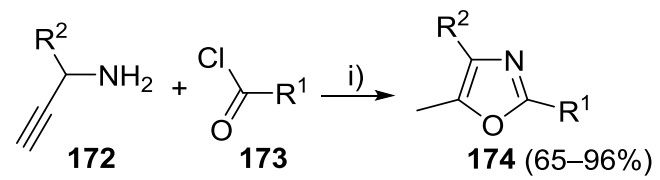

$\mathrm{R}^{1}=n$-nonyl, 3,4,5-(MeO) ${ }_{3} \mathrm{C}_{6} \mathrm{H}_{2} \mathrm{CH}=\mathrm{CH}, \mathrm{PhCH}=\mathrm{CH}, n-\mathrm{Bu}, 2-\mathrm{Cl}-4-\mathrm{NO}_{2} \mathrm{C}_{6} \mathrm{H}_{3}, 3-\mathrm{MeO}-4-\mathrm{HOC}_{6} \mathrm{H}_{3}, 2-\mathrm{MeNHC}_{6} \mathrm{H}_{4}$, furan-2-yl, benzofuran-2-yl, benzothiophen-2yl, indol-2-yl, 5-nitrofuran-2-yl, $t$-Bu, $\mathrm{Me}, 3,4-(\mathrm{MeO})_{2} \mathrm{C}_{6} \mathrm{H}_{3}, \mathrm{Ph}$, $4-\mathrm{MeC}_{6} \mathrm{H}_{4}, 3-\mathrm{MeOC}_{6} \mathrm{H}_{4}, 3,4,5-(\mathrm{MeO})_{3} \mathrm{C}_{6} \mathrm{H}_{2}, 2-\mathrm{BrC}_{6} \mathrm{H}_{4}, 4-\mathrm{F}_{3} \mathrm{CC}_{6} \mathrm{H}_{4}, 3-\mathrm{NO}_{2} \mathrm{C}_{6} \mathrm{H}_{4}, 4-\mathrm{NO}_{2} \mathrm{C}_{6} \mathrm{H}_{4}$; $\mathrm{R}^{2}=\mathrm{H}, \mathrm{Ph}$

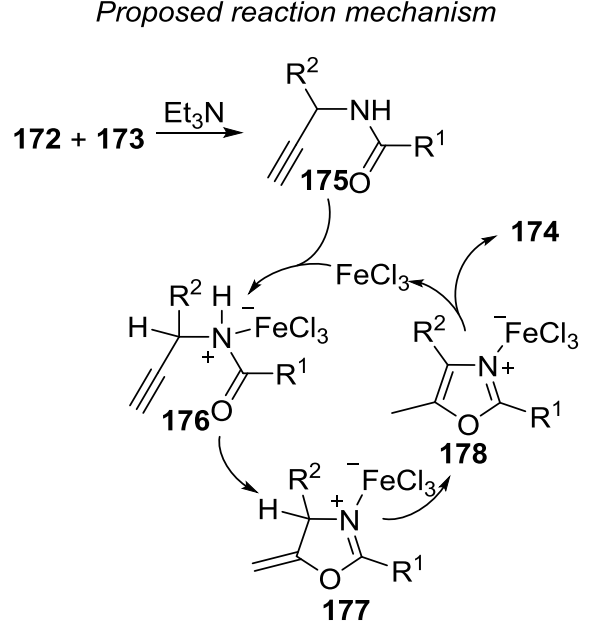

i) 172 (1.2 eq), 173 (1.0 eq), $\mathrm{Et}_{3} \mathrm{~N}(2.0 \mathrm{eq}), \mathrm{CH}_{2} \mathrm{Cl}_{2}$, rt, 2-12 $\mathrm{h}$ then $\mathrm{FeCl}_{3}(30$ or $50 \mathrm{~mol} \%), \mathrm{C}_{2} \mathrm{H}_{4} \mathrm{Cl}_{2}, 80^{\circ} \mathrm{C}, 1-12 \mathrm{~h}$.

Scheme 50. Fe(III)-mediated synthesis of oxazoles 174

\section{RUTHENIUM(III) AND GOLD(III)}

In 2004, Uemura described a one-pot synthesis of 2,4,5-trisubstituted oxazoles 174 through the sequential

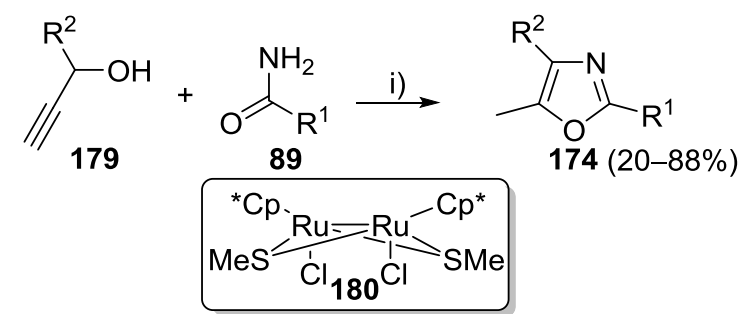

$\mathrm{R}^{1}=i-\mathrm{Pr}, \mathrm{Me}$, vinyl, $\mathrm{CH}_{2}=\mathrm{CMe}, 4-\mathrm{MeC}_{6} \mathrm{H}_{4}, 4-\mathrm{ClC}_{6} \mathrm{H}_{4}$;

$\mathrm{R}^{2}=\mathrm{Ph}, 4-\mathrm{MeC}_{6} \mathrm{H}_{4}, 4-\mathrm{ClC}_{6} \mathrm{H}_{4}$, naphthalen-2-yl, $\mathrm{Ph}_{2} \mathrm{C}=\mathrm{CH}$

Proposed reaction mechanism
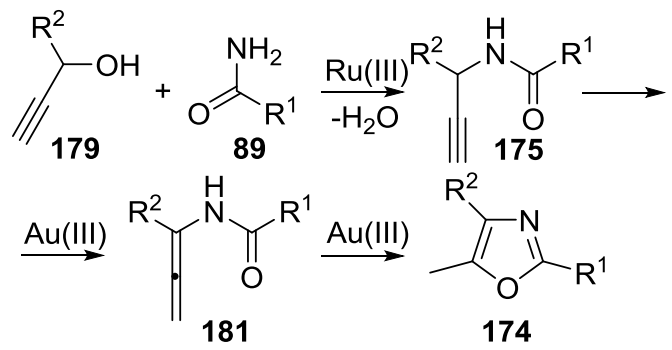

i) 179 (1.0 eq), 89 (5.0 eq), 180 (5 mol\%), $\mathrm{NH}_{4} \mathrm{BF}_{4}$ (10 mol\%), DCE,

$60{ }^{\circ} \mathrm{C}, 1 \mathrm{~h}$ then $\mathrm{AuCl}_{3}(10 \mathrm{~mol} \%), 80^{\circ} \mathrm{C}, 18 \mathrm{~h}$.

Scheme 51. One-pot Ru(III)- and Au(III)-catalysed cyclisation of terminal propargylic alcohols $\mathbf{1 7 9}$ with amides 89 
$\mathrm{Ru}(\mathrm{III})$ - and $\mathrm{Au}(\mathrm{III})$-catalysed cyclisation of terminal propargylic alcohols 179 and amides 89 (Scheme 51). ${ }^{71}$ This transformation occurs with complete regioselectivity and delivered oxazoles $\mathbf{1 7 4}$ in up to $88 \%$ yield. The reaction proceeds via the formation of propargylic amide 175, isomerisation to the allenamide 181 followed by intramolecular cyclisation to give the oxaxole 174 (Scheme 51). The reaction is effective for both alkyl- and aryl-substituted amides but no reaction is observed in the case of alkyl-substituted propargylic alcohols.

\section{ZINC(II) AND RUTHENIUM(II)}

Liu reported the $\mathrm{Zn}(\mathrm{II})$ - and $\mathrm{Ru}(\mathrm{II})$-catalysed synthesis of trisubstituted oxazoles $\mathbf{1 8 2}$ through the reaction of terminal propargylic alcohols 179 with amides 89 (Scheme 52). ${ }^{72}$ Mechanistic studies suggested that $\mathrm{Zn}(\mathrm{OTf})_{2}$ was involved in the $\mathrm{C}-(2)$-amination of $\mathbf{1 7 9}$, which generates an $\alpha$-carbonyl amide intermediate 183. Although the $\mathrm{Zn}(\mathrm{OTf})_{2}$ could also bring about subsequent cyclisation to give $\mathbf{1 8 2}$, the co-catalyst $\mathrm{TpRuPPh}_{3}(\mathrm{MeCN})_{2} \mathrm{PF}_{6}$ proved more effective for this process leading to the oxazole products in high yield.

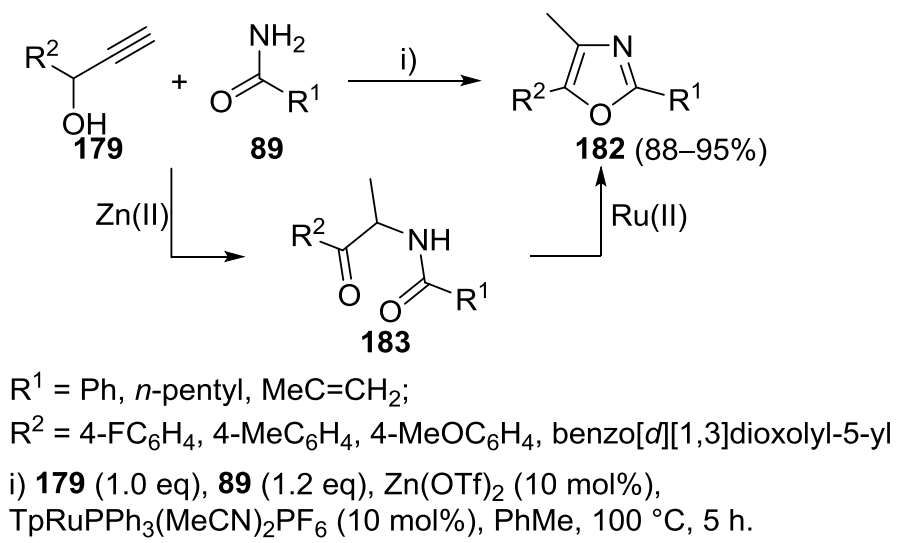

Scheme 52. Zn(II)- and Ru(II)-catalysed reaction of propargylic alcohols $\mathbf{1 7 9}$ with amides 89

\section{RUTHENIUM(II) AND COPPER(II)}

$\mathrm{He}$ and co-workers described an intriguing synthesis of disubstituted oxazoles $\mathbf{1 8 6}$ through the tandem $\mathrm{Ru}(\mathrm{II}) / \mathrm{Cu}(\mathrm{II})$-catalysed reaction of aryl acetylenes 184 and 3-aryl-1,4,2-dioxazol-5-ones 185 in the presence of iodine (Scheme 53). ${ }^{73}$ It was proposed the reaction proceeded via the thermal decomposition of 185 in the presence of iodine and $\mathrm{Ru}(\mathrm{TTP}) \mathrm{CO}$ generating a ruthenium imido complex $\mathbf{1 8 8}$, which reacts with 187 to give an acylaziridine 190. Isomerisation of 190 to 191 in the presence of $\mathrm{CuCl}_{2}$ and subsequent rearrangement gives 192. Cyclisation of 192 generates 186 and releases the $\mathrm{CuCl}_{2}$. Easy access to the starting materials 184 and 185 and the use of mild reaction conditions make this transformation a convenient method for delivering 2,5-diaryloxazoles. 


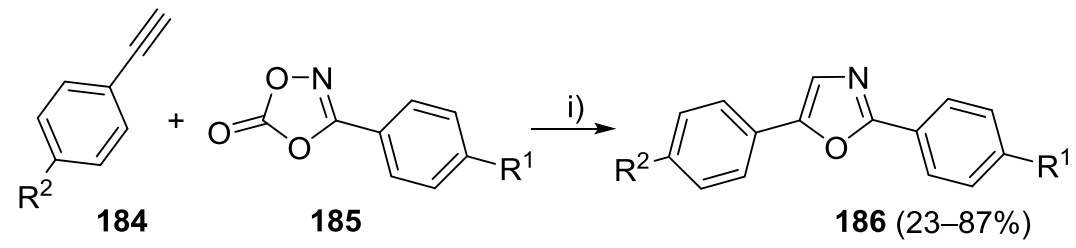

$\mathrm{R}^{1}=\mathrm{H}, \mathrm{Me}$, thiophen-2-yl, 4-EtOC $\mathrm{H}_{4}, 4-\mathrm{BuC}_{6} \mathrm{H}_{4}, 4-\mathrm{ClC}_{6} \mathrm{H}_{4}$, furan-2-yl, 4-MeOC $6 \mathrm{H}_{4}, 3,4-\mathrm{Me}_{2} \mathrm{OC}_{6} \mathrm{H}_{3}$;

$\mathrm{R}^{2}=\mathrm{MeO}, \mathrm{EtO}, \mathrm{H}$

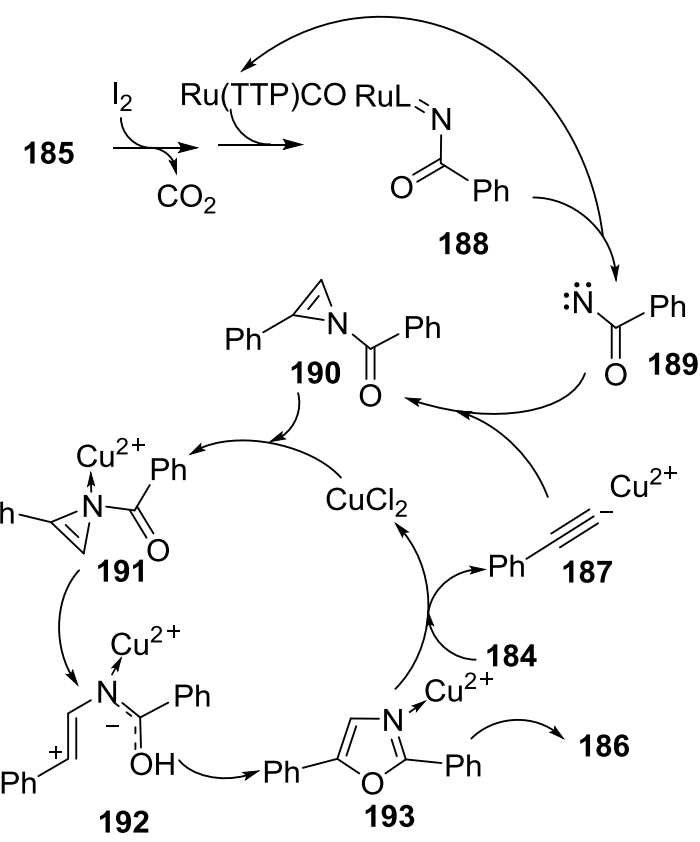

i) 184 (1.0 eq), 185 (4.0 eq), Ru(TTP)CO (10 mol\%), $\mathrm{CuCl}_{2}(15 \mathrm{~mol} \%), \mathrm{I}_{2}(30 \mathrm{~mol} \%), \mathrm{PhMe}, 50$ or $80^{\circ} \mathrm{C}, 3-4 \mathrm{~h}$.

Scheme 53. $\mathrm{Ru}(\mathrm{II})$ - and $\mathrm{Cu}(\mathrm{II})$-catalysed synthesis of oxazoles 186

\section{O1-C5 BOND DISCONNECTION}

\section{GOLD(I), GOLD(III)}

Hashmi reported the synthesis of 2,5-disubstituted oxazoles 195 through a Au(III)-catalysed 5-exo-dig cyclisation of terminal $N$-propargylamides 194 (Scheme 54). ${ }^{74}$ The reaction proceeds via a stereospecific anti-addition across the gold-activated triple bond, which generates 198. Proto-demetallation of 198 furnishes an alkylidene oxazoline 199, which isomerises to give the oxazole 195. Functional group diversity at the 2-position was good but substituted $N$-propargylamides and some electron-deficient substrates gave no product. 


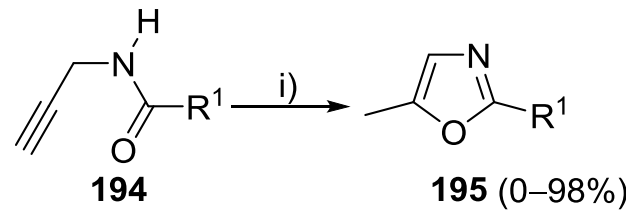

$\mathrm{R}^{1}=\mathrm{Me}, \mathrm{Ph}$, furan-2-yl, adamantan-1-yl, 2,5-dimethylfuran-3-yl, 5-nitrofuran-2-yl, $\mathrm{PhCH}=\mathrm{CH}, \mathrm{EtO}_{2} \mathrm{C}, \mathrm{EtO}_{2} \mathrm{CCH}_{2}, \mathrm{MeO}_{2} \mathrm{CCH}_{2}, \mathrm{MeO}_{2} \mathrm{C}\left(\mathrm{CH}_{2}\right)_{2}, \mathrm{BnTsNCH}$

Proposed reaction mechanism
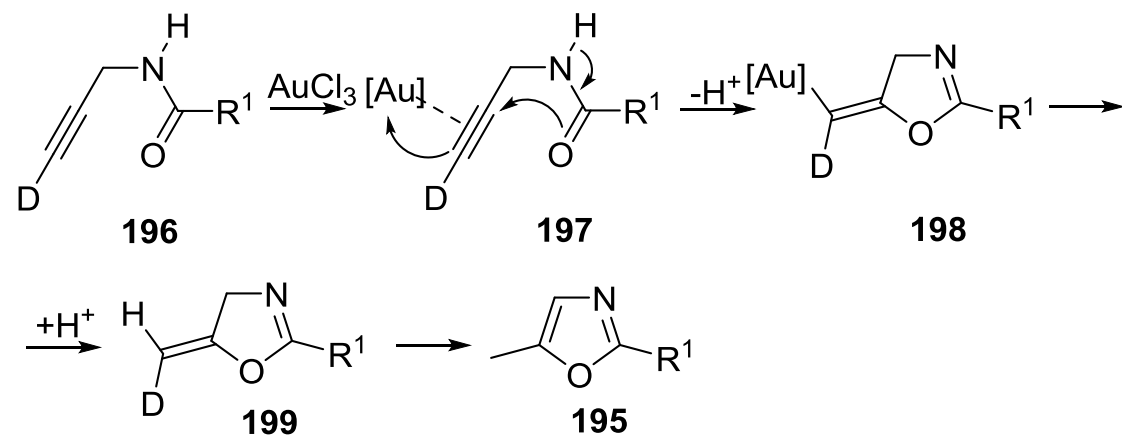

i) $\mathrm{AuCl}_{3}\left(5 \mathrm{~mol} \%, 10 \mathrm{w} / \mathrm{w} \%\right.$ in $\left.\mathrm{CD}_{3} \mathrm{CN}\right), \mathrm{CH}_{2} \mathrm{Cl}_{2}$ or $\mathrm{CD}_{3} \mathrm{CN}$, r.t or $45^{\circ} \mathrm{C}$ or $50^{\circ} \mathrm{C}, 2-96 \mathrm{~h}$.

Scheme 54. $\mathrm{Au}(\mathrm{III})$-catalysed cycloisomerisation of $N$-propargylamides 194

The substrate scope of this approach was subsequently expanded to include aliphatic and aromatic terminal $N$-propargylamides 195 (Scheme 55). ${ }^{75}$

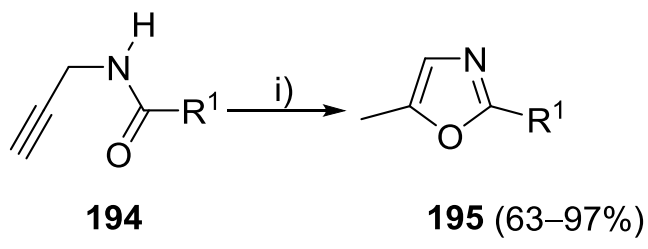

$\mathrm{R}^{1}=t-\mathrm{Bu}, \mathrm{Bn}$, thiophen-2-yl, anthracen-9-yl, 1,1'-biphenyl-4-yl

i) $\mathrm{AuCl}_{3}(2.5-5 \mathrm{~mol} \%), \mathrm{CH}_{2} \mathrm{Cl}_{2}$ or $\mathrm{MeCN}$, rt, $5 \mathrm{~min}-21 \mathrm{~h}$.

Scheme 55. $\mathrm{Au}(\mathrm{III})$-catalysed cycloisomerisation of $N$-propargylamides 194

Interestingly, substrates containing multiple propargylic moieties (e.g. 200 and 202) also underwent cyclisation to furnish the corresponding di- and tri-oxazoles 201 and 203 . ${ }^{75}$ Some representative results are summarized in Scheme 56. In general, $N$-propargylamides bearing electron-withdrawing substituents were less effective substrates, presumably due to a decreased nucleophilicity of the oxygen atom. 

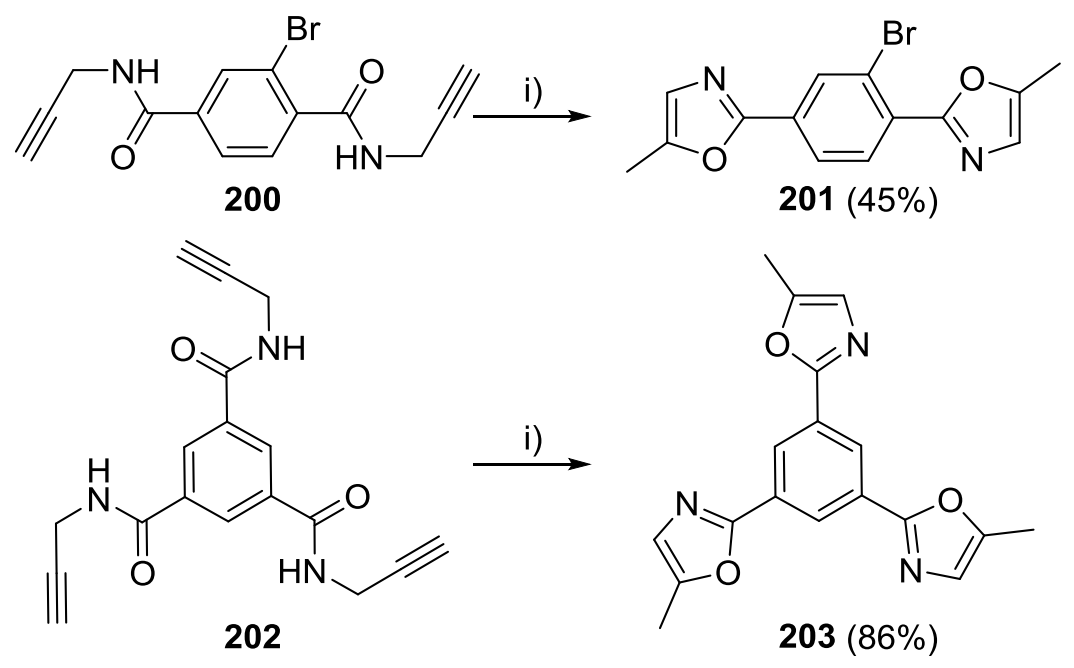

i) $\mathrm{AuCl}_{3}(2.5-5 \mathrm{~mol} \%), \mathrm{CH}_{2} \mathrm{Cl}_{2}$ or $\mathrm{MeCN}$, rt or $50^{\circ} \mathrm{C}, 5$ or $12 \mathrm{~h}$.

Scheme 56. $\mathrm{Au}(\mathrm{III})$-catalysed synthesis of oxazoles 201 and 203

Remarkably, 204, which failed to provide the corresponding oxazole under Au(III) catalysis, ${ }^{74}$ successfully delivered oxazole 205 in good yield using a $\mathrm{Au}(\mathrm{I})$ precatalyst (Scheme 57). ${ }^{75}$ In the majority of cases under these reaction conditions the proposed intermediate methyleneoxazolines were obtained selectively using $\mathrm{Au}(\mathrm{III})$ catalysis, without further prototopic isomerisation to the corresponding oxazole. Methyleneoxazolines can also serve as reactive partners for electrophilic reagents such as NBS or NCS, which generate halomethyloxazoles $\mathbf{2 0 5}$, albeit in poor yield (Scheme 58). ${ }^{75}$

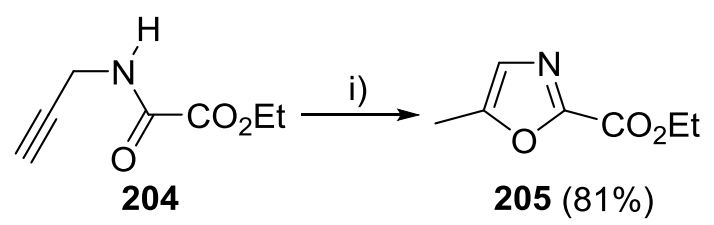

i) $\left[\mathrm{PPh}_{3} \mathrm{Au}\right] \mathrm{OTs}(5 \mathrm{~mol} \%), \mathrm{CH}_{2} \mathrm{Cl}_{2}$, rt, $48 \mathrm{~h}$.

Scheme 57. Au(I)-catalysed synthesis of oxazole 205

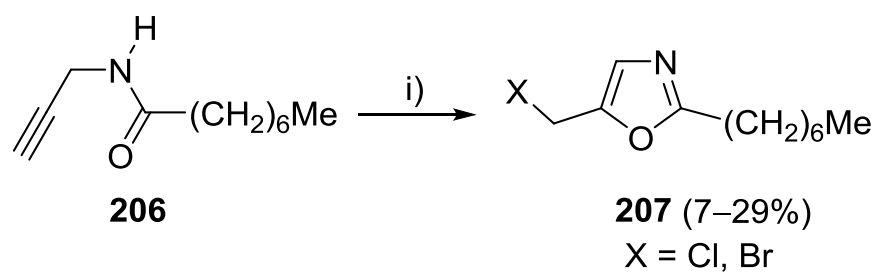

i) NCS or NBS (1.2-5.0 eq), $\left[\mathrm{Ph}_{3} \mathrm{Au}\right] \mathrm{NTf} 2(3.0 \mathrm{~mol} \%)$ or $\mathrm{AuCl}_{3}(3.0 \mathrm{~mol} \%), \mathrm{CH}_{2} \mathrm{Cl}_{2}, 20$ or $40{ }^{\circ} \mathrm{C}, 48 \mathrm{~h}$.

Scheme 58. $\mathrm{Au}(\mathrm{I})$ - and $\mathrm{Au}(\mathrm{III})$-catalysed syntheses of halomethyloxazoles $\mathbf{2 0 7}$ 
The scope of this chemistry was expanded by De Brabander, who reported the preparation of 5-bromomethyloxazoles $\mathbf{2 0 8}$ through a one-pot $\mathrm{Au}(\mathrm{III})$-catalysed cyclisation-bromination of $N$-propargylamides 194 (Scheme 59). ${ }^{76}$ Under the optimised conditions, various 2,5-disubstituted oxazoles including amino acid-derived oxazoles were prepared in good yield. No epimerization of an $\alpha$-stereogenic centre was observed under these reaction conditions increasing the power of this transformation. The substrate scope for the $\mathrm{Au}(\mathrm{III})$-catalysed cyclisation of terminal $N$-propargylamides was further investigated by Padwa who showed that the transformation was tolerant of the indole nucleus within the substrate. $^{77,78}$

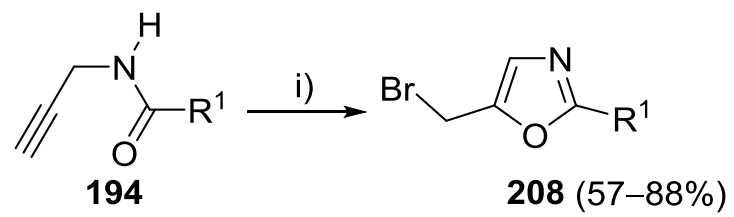

$\mathrm{R}^{1}=\mathrm{Ph}, \mathrm{MeCH}_{2} \mathrm{CHNHBoc}, \mathrm{BnCHNHBoc}, t$-BuCHNHBoc, N-Boc-pyrrolidin-2-yl, $\mathrm{NHBoc}\left(\mathrm{CH}_{2}\right)_{3} \mathrm{CHNHBoc}, t-\mathrm{Bu}, \mathrm{Ph}, \mathrm{CH}_{2}=\mathrm{CHCH}_{2} \mathrm{CHMe}$

i) $\mathrm{AuCl}_{3}(5 \mathrm{~mol} \%), \mathrm{CHCl}_{3}$, rt then 2,6-lutidine (1.1 eq), $\mathrm{Br}_{2}(1.0 \mathrm{eq}), \mathrm{CHCl}_{3}, 0^{\circ} \mathrm{C}$ to rt.

Scheme 59. One-pot $\mathrm{Au}(\mathrm{III})$-catalysed synthesis of 5-bromomethyloxazoles $\mathbf{2 0 8}$

It has also been shown that the $\mathrm{Au}(\mathrm{I})$-catalysed cyclisation of the internal $N$-propargylamide 209 delivered six-membered oxazines 210 via a 6-endo-dig cyclisation pathway (Scheme 60). ${ }^{79}$ Under the same reaction conditions, no product was formed using a $\mathrm{Au}(\mathrm{III})$ catalyst. The scope of the $\mathrm{Au}(\mathrm{I})$-catalysed cyclisation of 209 was subsequently expanded to give functionalised alkyl- and aryl- $N$-propargylamides 211, which result in the formation of 2,5-disubstituted oxazoles 212, oxazolines 213 and oxazines 214 (Scheme 61). ${ }^{80} \mathrm{~A}$ combination of two catalysts (IPr)AuCl and AgOTs was required for this transformation. Although the method is not general for the synthesis of oxazoles, it shows product distribution from this reaction can be significantly influenced through both substrate and catalyst architecture.

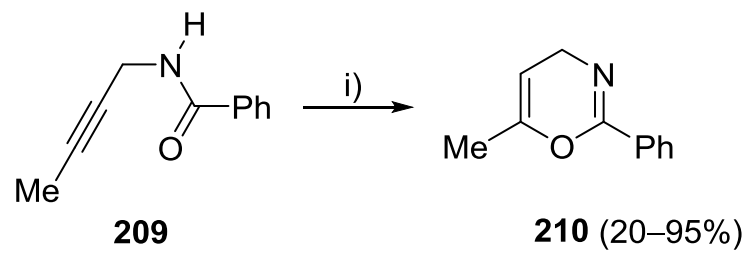

i) $\left[\mathrm{PPh}_{3} \mathrm{Au}\right]\left[\mathrm{NTf}_{2}\right](5 \mathrm{~mol} \%$ or $1.0 \mathrm{eq}), \mathrm{CH}_{2} \mathrm{Cl}_{2}$ or [IPrAu][OTs] (1.0 eq) or $\mathrm{Et}_{3} \mathrm{~N} / \mathrm{PhH}$ or $\mathrm{Et}_{3} \mathrm{~N} / \mathrm{PhMe}$ or $\mathrm{Et}_{3} \mathrm{~N} / \mathrm{THF}$, rt, up to $6 \mathrm{~d}$.

Scheme 60. $\mathrm{Au}(\mathrm{I})$-catalysed cyclisation of internal $N$-propargylamides 209 


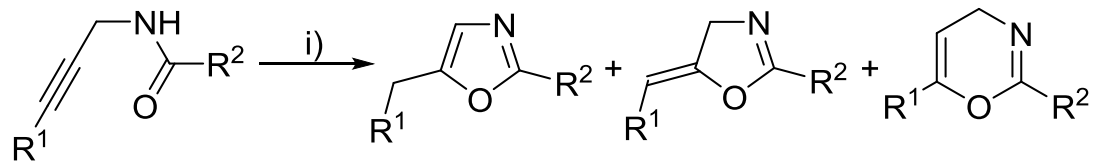

211

212 (up to $92 \%$ ) 213 (up to $95 \%$ ) 214 (up to $35 \%$ )

$\mathrm{R}^{1}=\mathrm{Me}, \mathrm{Et}, n-\mathrm{Pr}, n-\mathrm{Bu}, \mathrm{ClCH}_{2}, \mathrm{CH}_{3} \mathrm{OCH}, \mathrm{HC} \equiv \mathrm{C}\left(\mathrm{CH}_{2}\right)_{3}, \mathrm{HC} \equiv \mathrm{CCH}_{2} \mathrm{OCH}_{2}, \mathrm{HC} \equiv \mathrm{C}\left(\mathrm{CH}_{2}\right)_{4}$, $\mathrm{CH}_{2}=\mathrm{CH}\left(\mathrm{CH}_{2}\right)_{3}, 4-\mathrm{NO}_{2} \mathrm{C}_{6} \mathrm{H}_{4}$, pyridin-2-yl, naphthalen-1-yl, 4-MeOC $6 \mathrm{H}_{4}, 4-\mathrm{CNC}_{6} \mathrm{H}_{4}, 4-\mathrm{CHOC}_{6} \mathrm{H}_{4}$, thiophen-2-yl, 5-formyl-furan-2-yl, $\mathrm{Ph}$;

$\mathrm{R}^{2}=\mathrm{Ph}$, furan-2-yl, $\mathrm{Bn}, t-\mathrm{Bu}, 4-\mathrm{BrC}_{6} \mathrm{H}_{4}, \mathrm{PhCH}=\mathrm{CH}_{2}, 2,5$-dimethylfuran-3-yl, adamantan-1-yl

i) (IPr)AuCl (5 mol\%), AgOTs (5 mol\%), THF, rt or $40^{\circ} \mathrm{C}, 12 \mathrm{~h}-6 \mathrm{~d}$.

Scheme 61. $\mathrm{Au}(\mathrm{I})$-catalysed cyclisation of internal $\mathrm{N}$-propargylamides $\mathbf{2 1 1}$

The preparation of oxazoles 195 through the $\mathrm{Au}(\mathrm{III})$-catalysed cycloisomerisation of $N$-propargyl amides 194 using a range of gold catalysts was reported by Urriolabeitia and Contel (Scheme 62). ${ }^{81}$ Yields of oxazoles 195 obtained using the gold iminophosphorane complexes 215 and 216 were comparable to those using $\mathrm{AuCl}_{3}$, albeit with longer reaction times being required.

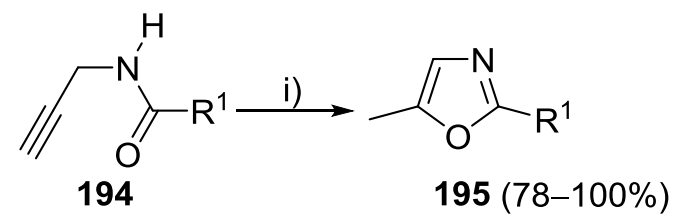

$\mathrm{R}^{1}=$ furan-2-yl, thiophen-2-yl, 2,6- $\mathrm{Cl}_{2} \mathrm{C}_{6} \mathrm{H}_{3}$
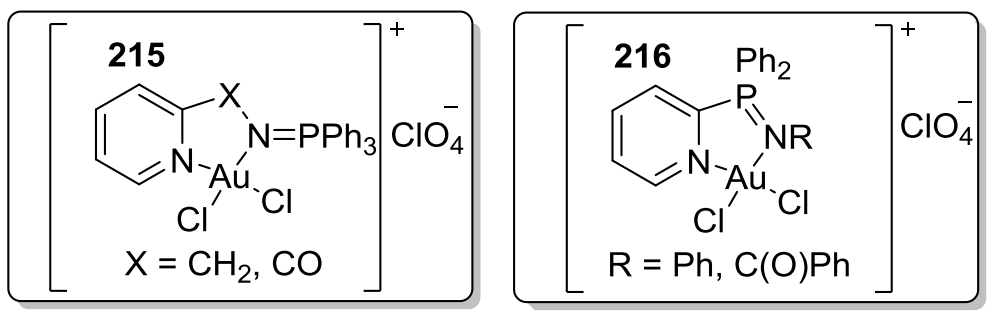

i) $\mathrm{AuCl}_{3}(5 \mathrm{~mol} \%)$ or 215 (5 mol\%) or $216(5 \mathrm{~mol} \%), \mathrm{CH}_{2} \mathrm{Cl}_{2}, \mathrm{rt}, 30-72 \mathrm{~h}$.

Scheme 62. Au(III)-catalysed cycloisomerisation of $N$-propargylamides 194

This technology was applied to the preparation of a fluorescent chemical sensor for the detection of $\mathrm{Au}$ (III) ions. The protocol is based on the cyclisation of the rhodamine-alkyne derivative $\mathbf{2 1 7}$, which generates the oxazole 218 in the presence of $\mathrm{Au}(\mathrm{III})$ ions (Scheme 63), ${ }^{82}$ providing a fluorescent and colourimetric chemical probe for the selective detection of gold(III) species.

Another interesting application of the gold catalysed cyclisation of propargylamides was reported by Ahn who described the development of a selective Au(I)/(III) sensor (Scheme 64). ${ }^{83}$ Treatment of the rhodamine derived alkyne 217 with either a $\mathrm{Au}(\mathrm{I})$ or $\mathrm{Au}(\mathrm{III})$ species led to 218 and $\mathbf{2 1 9}$ which provides a fluorescent and colourimetric method for the detection of these gold species. 


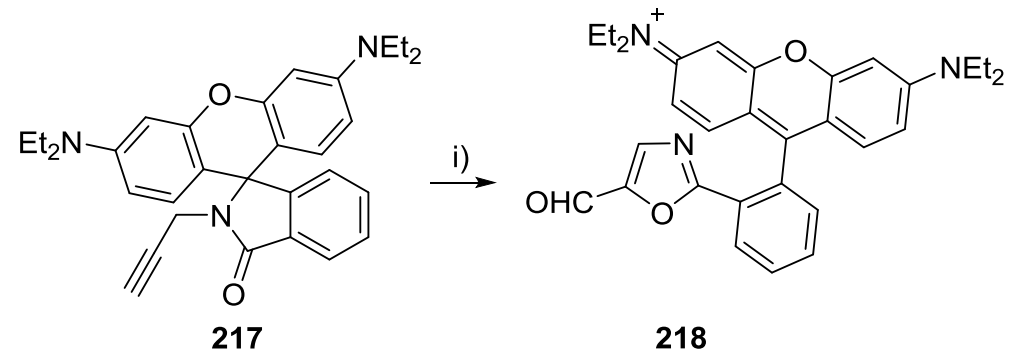

i) $\mathrm{AuCl}_{3}, 1: 1 \mathrm{EtOH} / \mathrm{PBS}$ buffer $(\mathrm{pH}=7.4), \lambda_{\text {ex }}=558 \mathrm{~nm}$.

Scheme 63. Au(III)-mediated synthesis of oxazole 218

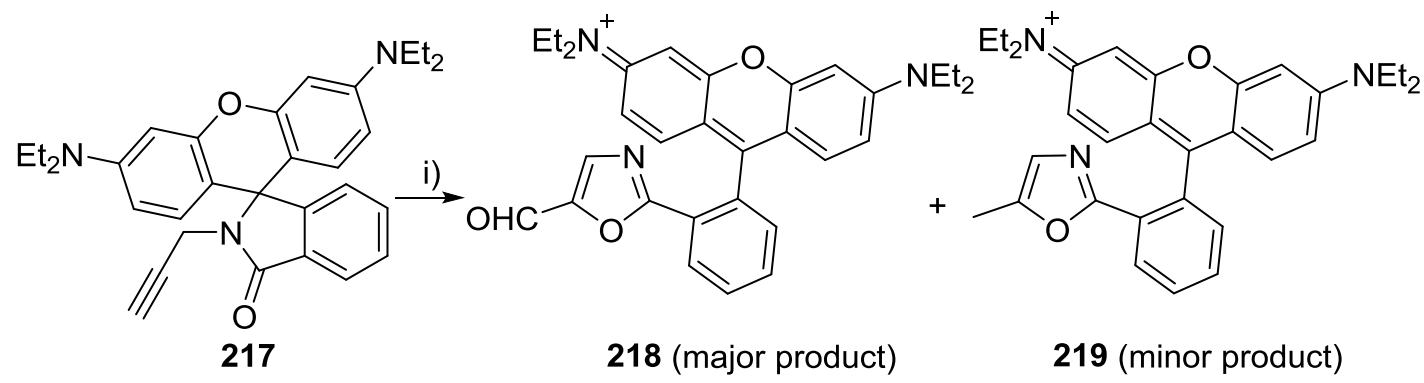

Proposed reaction mechanism

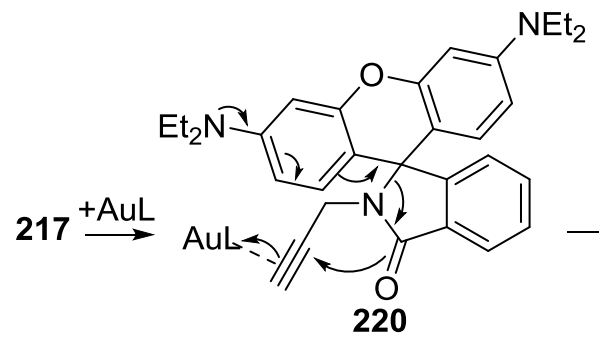

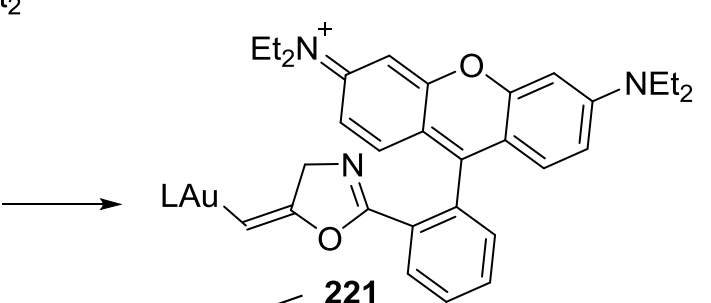

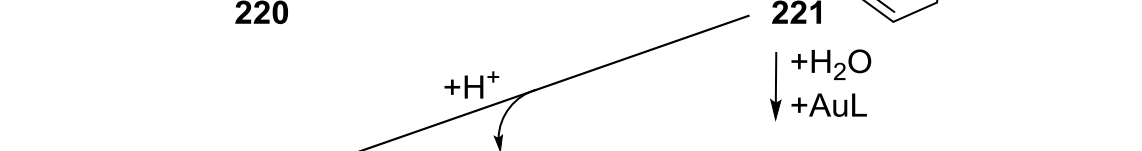<smiles>C=C1CN=C(c2ccccc2-c2c3ccc(=[NH+]CC)cc-3oc3cc(N(CC)CC)ccc23)O1</smiles>

$\mathrm{H}^{+}$<smiles>CC[N+]=Nc1ccc2c(c1)Oc1cc(N(CC)CC)ccc1C2c1ccccc1C1=NCC(C)(C(C)(C)O)O1</smiles><smiles>CC[NH+]=c1ccc2c(-c3ccccc3-c3ncc(C)o3)c3ccc(N(CC)CC)cc3oc-2c1</smiles>

$\checkmark 2 \mathrm{Au}(\mathrm{H}) \mathrm{L}$<smiles>[Z16]c1ccccc1-c1c2ccc(=[N+]CC)cc-2oc2cc(N(CC)CC)ccc12</smiles>

i) $\mathrm{AuCl}$ or $\mathrm{AuCl}_{3}, 1: 1 \mathrm{MeCN} / \mathrm{PBS}$ buffer $(\mathrm{pH}=7.2), \lambda_{\mathrm{ex}}=530 \mathrm{~nm}$.

Scheme 64. $\mathrm{Au}(\mathrm{I})$ and $\mathrm{Au}(\mathrm{III})$-mediated synthesis of oxazole2 218 and 219 
Ahn reported the preparation of 2-phenyloxazole-5-carboxaldehyde 225 through the $\mathrm{Au}(\mathrm{I}) /(\mathrm{III})$-mediated cyclisation of $N$-(propargyl)benzamide 224 in aqueous media (Scheme 65). ${ }^{84}$ The formyloxazole 225 was only formed as the major product either using a stoichiometric amount of a $\mathrm{Au}(\mathrm{III})$ or $\mathrm{Au}(\mathrm{I})$ species or an excess of a $\mathrm{Au}(\mathrm{I})$ species. The reaction proceeds via the gold-mediated 5-exo-dig cyclisation of 224 generating a vinylgold intermediate $\mathbf{2 2 6}$ followed by oxidation generating the carbenoid intermediate $\mathbf{2 2 7}$ which leads to $\mathbf{2 2 5}$ in the presence of water. This alternative fate for a vinyl gold species reveals interesting opportunities for alternative functionalisations in this class of transformation.

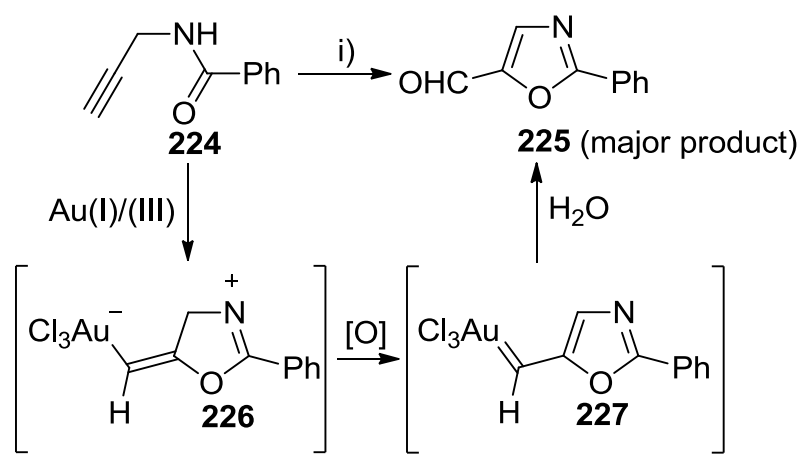

i) $\mathrm{AuCl}_{3}\left(1.0\right.$ eq) or $\mathrm{HAuCl}_{4}(1.0 \mathrm{eq})$ or $\mathrm{AuCl}(3.5 \mathrm{eq}), \mathrm{MeCN} / \mathrm{H}_{2} \mathrm{O}(1: 1 \mathrm{v} / \mathrm{v}), \mathrm{rt}, 1 \mathrm{~h}$.

Scheme 65. Au(I)- or Au(III)-mediated preparation of formyloxazole 225

In 2012, Hashmi described a one-pot synthesis of disubstituted oxazoles 229/231 through the $\mathrm{Au}(\mathrm{I})$-catalysed cycloisomerisation of $N$-propargylamides 194 in the presence of enophiles $\mathbf{2 2 8} / \mathbf{2 3 0}$

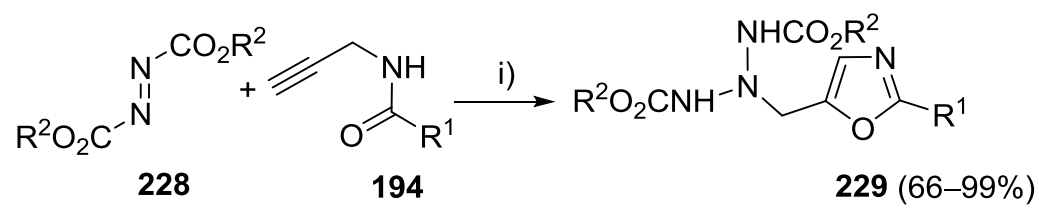

$\mathrm{R}^{1}=t-\mathrm{Bu}, \mathrm{Bn}$, thienyl, cyclopropyl, adamantyl;

$\mathrm{R}^{2}=\mathrm{Et}, i-\mathrm{Pr}, t-\mathrm{Bu}, \mathrm{Bn}$

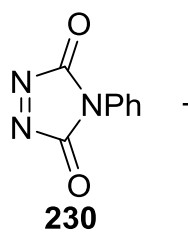<smiles>[R]C(=O)NCC#C</smiles>

194

$\mathrm{R}^{1}=t-\mathrm{Bu}, \mathrm{Bn}$, thienyl

Proposed reaction mechanism

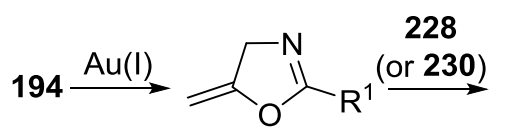

229 (or 231)

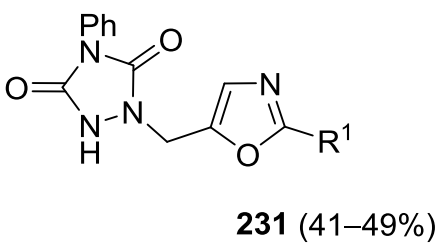

$231(41-49 \%)$

i) 228 or 230 (1.8-1.0 eq), 194 (1.0 eq), [ $\left.\mathrm{Ph}_{3} \mathrm{PAuNTf}_{2}\right]$ (3-7 mol\%), $\mathrm{CDCl}_{2}, \mathrm{rt}, 3 \mathrm{~h}$ to $11 \mathrm{~d}$.

Scheme 66. Au(I)-catalysed synthesis of oxazoles 229 and 231 
(Scheme 66). ${ }^{85}$ The reaction proceeds via the formation of an oxazoline 232, which undergoes Alder-Ene reaction with enophiles 228 or 230 to yield oxazoles 229 or 231, respectively. Reaction of 194 with enophile 228 provided good to high yields of the corresponding oxazole while $\mathbf{2 3 0}$ was less effective. Higher yields of the oxazole products could be obtained in some cases by employing $\mathrm{Au}(\mathrm{I})$ catalysts containing ligands from the KIT-PHOS family. ${ }^{85}$

In search for alternative $\mathrm{Au}(\mathrm{III})$ catalysts, Blanc and Frémont discovered that the cycloisomerisation of $\mathrm{N}$-propargylamide 224 catalysed by $\mathrm{N}$-heterocyclic carbene complexes $\mathbf{2 3 5}$ and $\mathbf{2 3 6}$ in the presence of $\mathrm{AgSbF}_{6}$ yielded a mixture of oxazole 233 and oxazoline 234 (Scheme 67). ${ }^{86}$
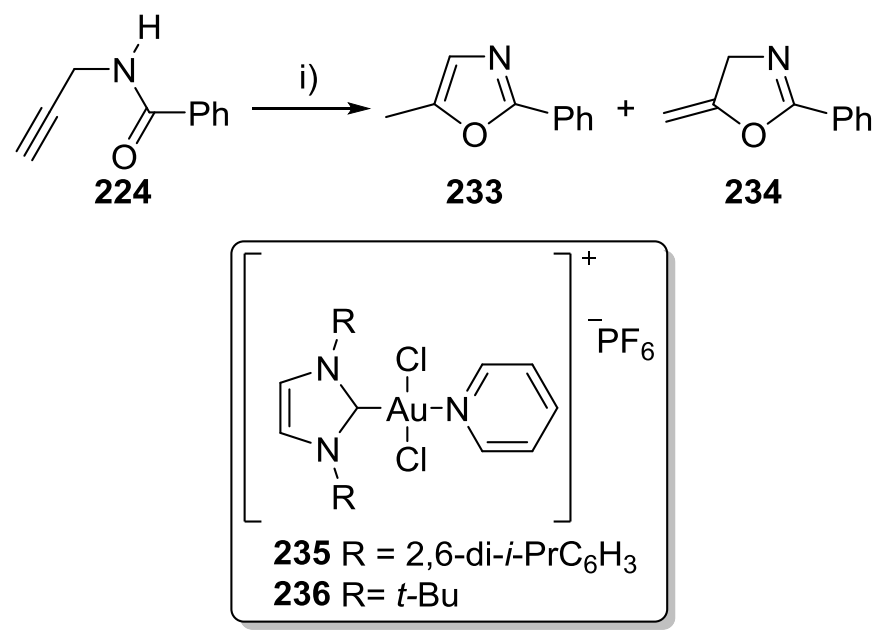

i) 235 or $236\left(5 \mathrm{~mol}^{\circ}\right), \mathrm{AgSbF}_{6}(1.0 \mathrm{eq}), \mathrm{CH}_{2} \mathrm{Cl}_{2}, 45^{\circ} \mathrm{C}, 1.5$ or $12 \mathrm{~h}$.

Scheme 67. Au(III)-catalysed cycloisomerisation of $N$-propargylamides 224

Tran-Dubé showed that formation of the amide substrate and subsequent cyclisation could be carried out in one-pot through the preparation of trisubstituted oxazoles 174 (Scheme 68). ${ }^{87}$ The transformation proceeds via the reaction of propargyl amines $\mathbf{1 7 2}$ and acid chlorides 173 to give a propargylamide $\mathbf{1 7 5}$, which

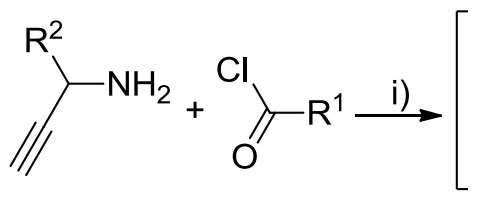

172

173<smiles>[R]c1nc([R])c(CCCCC)o1</smiles>

175

$174(26-95 \%)$

$\mathrm{R}^{1}=i-\mathrm{Pr}$, tetrahydro-2H-pyran-4-yl, $\mathrm{PhCH}=\mathrm{CH}_{2}, \mathrm{Ph}$, pyridin-2-yl, thiazol-4-yl,

1-MeCO-piperidin-4-yl, 2- $\mathrm{CF}_{3}$-pyridin-5-yl, adamantan-1-yl;

$\mathrm{R}^{2}=\mathrm{Me}, \mathrm{EtO}_{2} \mathrm{CCH}_{2}$

i) 172 (1.5 eq), 173 (1.0 eq), $\mathrm{Et}_{3} \mathrm{~N}$ (1.5 eq), $\mathrm{MeCN}, \mathrm{rt}, 30 \mathrm{~min}$ then $\mathrm{AuCl}_{3}(2-30 \mathrm{~mol} \%), 45^{\circ} \mathrm{C}, 2-6 \mathrm{~h}$.

Scheme 68. Au(III)-catalysed two-step sequential procedure for the synthesis of oxazoles $\mathbf{1 7 4}$ 
undergoes $\mathrm{Au}(\mathrm{III})$-catalysed cyclisation to yield oxazoles 174. Although the scope of the reaction is broad with tolerance for a wide array of functional groups, reactants $\mathbf{1 7 2}$ bearing heterocyclic substituents were less effective substrates and required a higher catalyst loading and longer reaction times to provide reasonable quantities of the product. Nevertheless, this protocol provides a quick access to trisubstituted oxazoles from readily available starting materials.

The scope and limitations of the gold catalysed preparation of oxazoles through the construction of the $\mathrm{O} 1-\mathrm{C} 5$ bond has been thoroughly investigated. Subtleties associated with the nature of the gold catalyst, supporting ligand and substitution pattern of the starting materials allows for appropriate reaction conditions to be selected after careful consideration of literature precedent. Of particular note are the mild reaction conditions, convenient access to starting materials and the high functional group tolerance which make this methodology particularly attractive.

\section{SILVER(I)}

During a study of the multicomponent reaction of $\alpha$-isocyano amide 237, acetone 238 and benzylamine 239 leading to 2H-2-imidazoline 241 (Scheme 69), Orru discovered conditions where the disubstituted oxazole 240 was obtained as the major product. ${ }^{88}$ Oxazole $\mathbf{2 4 0}$ is generated via the formation of the activated $\alpha$-isocyano amide 242 followed by a 5-endo cyclisation leading to $\mathbf{2 4 3}$, which upon proto-demetallation generates oxazole 240. Selective functionalisation at the $\mathrm{C} 4$ and $\mathrm{C} 5$ positions is uncommon, therefore this procedure provides access to alternative oxazole substitution patterns.

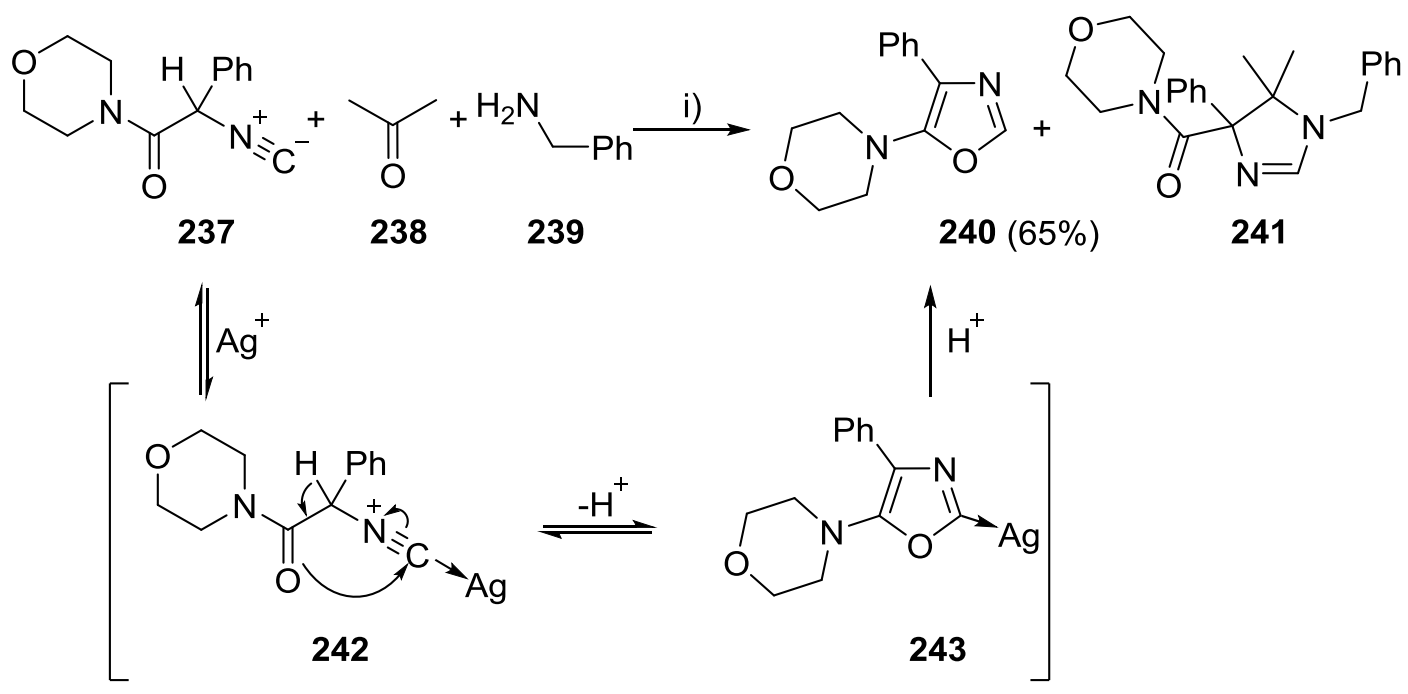

i) 237 (1.0 eq), 238 (2.0 eq), 239 (1.5 eq), $\mathrm{MgSO}_{4}$ (0.8 eq), AgOAc (2 mol\%), MeOH, rt, 21 h.

Scheme 69. $\operatorname{Ag}(\mathrm{I})$-catalysed synthesis of oxazoles $\mathbf{2 4 0}$ 
A versatile method for the preparation of fully substituted oxazoles 245 involves the $A g(I)-m e d i a t e d$ 5-endo cyclisation of $\beta$-bis(methylthio)enamides 244 (Scheme 70) ${ }^{89,90}$ Enamides 244 can be prepared in 2-steps from readily available starting materials and give the corresponding oxazoles $\mathbf{2 4 5}$ in excellent yield (74-98\%). Although the substitution pattern of the product is specific, the ability to readily manipulate functionality in the 5-position of the oxazole makes this a useful procedure. Reducing the amount of silver required for this transformation would significantly increase the applicability of this process.

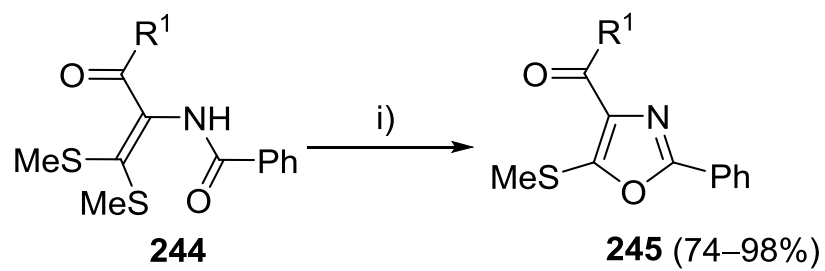

$\mathrm{R}^{1}=\mathrm{EtO}, \mathrm{MeO}, t$-BuO, PhO, Et, $n$-Bu, Ph, 4- $\mathrm{MeOC}_{6} \mathrm{H}_{4}, 2-\mathrm{NH}_{2} \mathrm{C}_{6} \mathrm{H}_{4} \mathrm{NH}$,

$\mathrm{PhNH}, 4-\mathrm{MeOC}_{6} \mathrm{H}_{4} \mathrm{NH}, 4-\mathrm{FC}_{6} \mathrm{H}_{4} \mathrm{NH}$, 4-Me-2- $\mathrm{BrC}_{6} \mathrm{H}_{3} \mathrm{NH}, \mathrm{EtNH}$ indol-3-yl- $\left(\mathrm{CH}_{2}\right)_{2} \mathrm{NH}$-, $\mathrm{PhCH}_{2} \mathrm{NMe}$, piperidin-1-yl, 4-benzylpiperazin-1-yl, 4-EtO ${ }_{2} \mathrm{C}$-piperazin-1-yl, $\mathrm{MeSCH}_{2} \mathrm{CH}_{2}(\mathrm{CH}) \mathrm{CO}_{2} \mathrm{EtNH}, i-\mathrm{Pr}-(\mathrm{CH}) \mathrm{CO}_{2} \mathrm{EtNH}$, $\mathrm{PhCH}_{2}(\mathrm{CH}) \mathrm{CO}_{2} \mathrm{EtNH}$

i) 306 (1.0 eq), $\mathrm{Ag}_{2} \mathrm{CO}_{3}(4.0 \mathrm{eq}), \mathrm{MeCN}$, reflux, 3-4 $\mathrm{h}$.

Scheme 70. Ag(I)-mediated synthesis of oxazoles $\mathbf{2 4 5}$

The synthesis of vinyloxazoles 247 through the $\mathrm{Ag}(\mathrm{I})$-catalysed cyclisation of allenylamides 246 was reported by Wan (Scheme 71). ${ }^{68}$ The reaction proceeds through intramolecular cyclisation of 248 to give

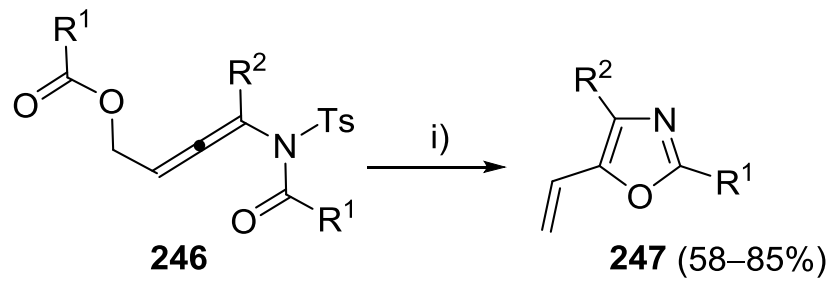

$\mathrm{R}^{1}=\mathrm{Ph}, \mathrm{Me}, 3-\mathrm{BrC}_{6} \mathrm{H}_{4}, 3-\mathrm{MeOC}_{6} \mathrm{H}_{4}, 4-\mathrm{MeC}_{6} \mathrm{H}_{4}, 4-\mathrm{FC}_{6} \mathrm{H}_{4}$, furan-2-yl, cyclopentyl;

$\mathrm{R}^{2}=\mathrm{Ph}, 2-\mathrm{FC}_{6} \mathrm{H}_{4}, 3-\mathrm{FC}_{6} \mathrm{H}_{4}, 4-\mathrm{BrC}_{6} \mathrm{H}_{4}$, furan-2-yl, naphthalen-2-yl

Proposed reaction mechanism

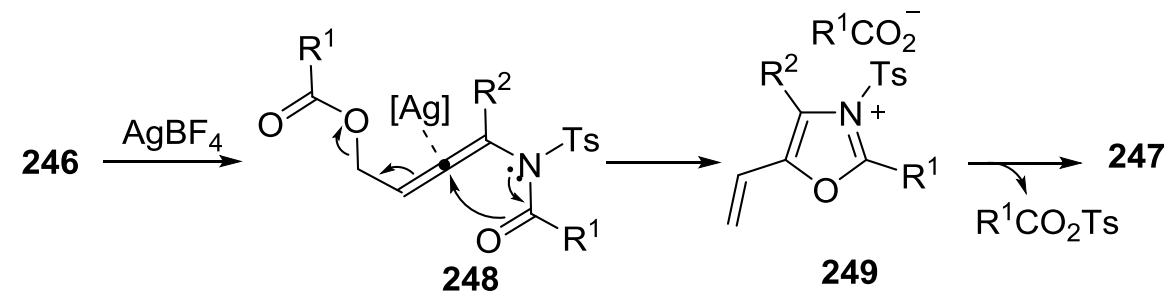

i) $\mathrm{AgBF}_{4}(10 \mathrm{~mol} \%), \mathrm{PhMe}, 80^{\circ} \mathrm{C}, 16-20 \mathrm{~h}$.

Scheme 71. Ag(II)-catalysed cyclisation of allenylamides 246 
249, followed by elimination of the sulfonyl and acyloxy groups. Substrates bearing a range of aryl and alkyl $\mathrm{R}^{1}$ substituents and aryl $\mathrm{R}^{2}$ groups successfully generated the corresponding oxazoles $\mathbf{2 4 7}$ in moderate to high yields.

More recently, Sueda reported the synthesis of 2,5-disubstituted oxazoles 252 (and 254) through the $\mathrm{Ag}(\mathrm{I})$-catalysed cyclisation of ynimides $\mathbf{2 5 0}$ (and 253) in the presence of alcohols 251 (Scheme 72). ${ }^{91}$ The reaction proceeds via activation of the carbonyl group of the ynimide $\mathbf{2 5 0}$ by the silver catalyst, followed by addition of the alcohol 251 generating the $N$-alkynyl amide 258. Cyclisation of 258 gives the oxazole 252 and regenerates the catalyst. Ynimides bearing sterically demanding and aromatic substituents $\left(\mathrm{R}^{1}\right)$ required harsh reaction conditions to bring about the transformation.

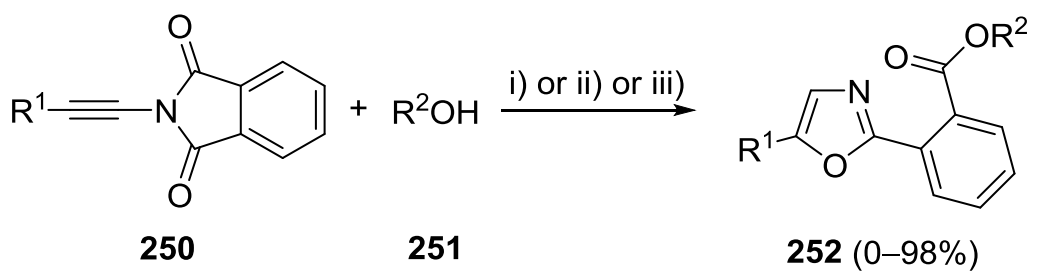<smiles>[R]#CN(C(C)=O)C(C)=O</smiles>

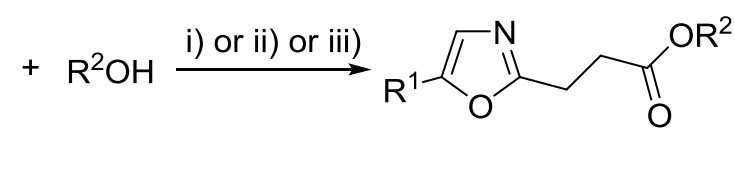

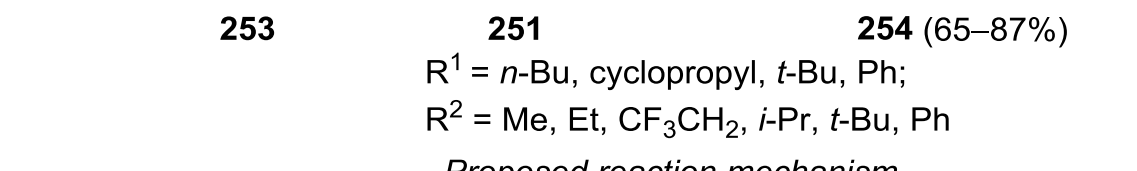<smiles>[R]C#CN1C(=O)c2ccccc2C1=O</smiles><smiles>C1=C[BiH2]1</smiles><smiles></smiles><smiles>[R]C1(O)c2ccc(C)cc2C(=O)N1C#C[R]#[Te]</smiles><smiles>[R6]O/C(=N/C#[R])c1cc(C)ccc1C([R20])=O</smiles><smiles>[R]OC(=O)c1ccccc1-c1nc([AlH2])c([R])o1</smiles>

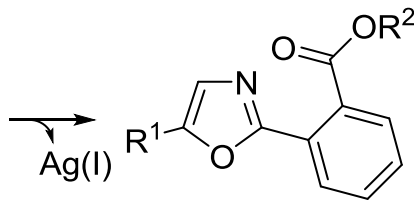

258

259

252

i) 250 or 253 (1.0 eq), 251 (2.5 eq), $\mathrm{Ag}_{2} \mathrm{O}$ (30 mol\%), $\mathrm{CH}_{2} \mathrm{Cl}_{2}, \mathrm{rt}, 24 \mathrm{~h}$; ii) 250 or 253 (1.0 eq), 251 (50.0 eq), $\mathrm{Ag}_{2} \mathrm{O}$ (30 mol\%), $\mathrm{CH}_{2} \mathrm{Cl}_{2}, 80^{\circ} \mathrm{C}, 1-24 \mathrm{~h}$; iii) 250 or 253 (1.0 eq), 251 (solvent), $\mathrm{Ag}_{2} \mathrm{O}$ (30 mol\%), $\mathrm{CH}_{2} \mathrm{Cl}_{2}, 80{ }^{\circ} \mathrm{C}, 1-24 \mathrm{~h}$.

Scheme 72. $\operatorname{Ag}(\mathrm{I})$-catalysed cyclisation of ynimides $\mathbf{2 5 0}$ (and 253) in the presence of alcohols 251 
Each of these silver(I) catalysed processes represent effective methods for the preparation of oxazoles. The requirement to prepare highly specific substrates to bring about the transformation provides significant opportunities for developing this area of research further.

\section{COPPER(I), COPPER(II)}

In 1992, Das described a synthesis of trisubstituted oxazole 262 through the $\mathrm{Cu}(\mathrm{II})$-mediated cyclisation of vinyl bromide 260 (and vinyl dibromide 261) in the presence of a base (Scheme 73). ${ }^{92}$ The proposed reaction mechanism involves the formation of a common intermediate followed by cyclisation to generate the oxazole 262 in good yield.

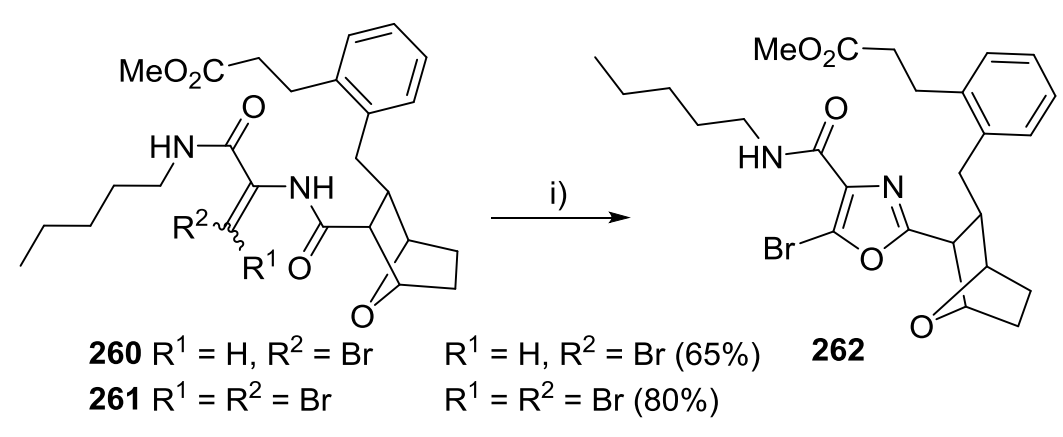

Proposed reaction mechanism
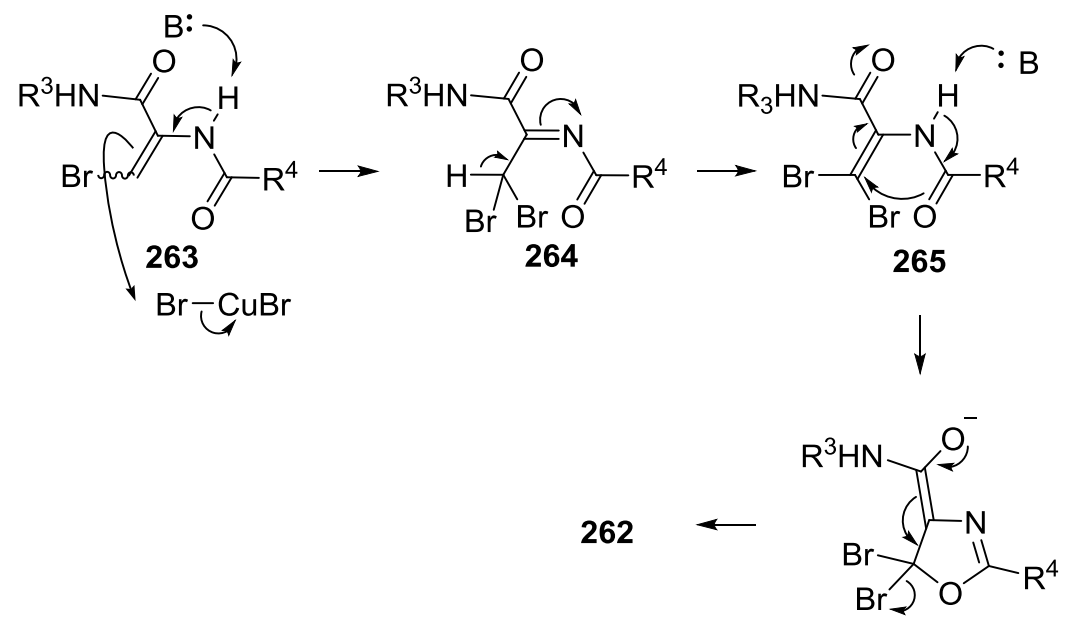

266

i) $\mathrm{CuBr}_{2}(4.0 \mathrm{eq}), \mathrm{DBU}(8.0 \mathrm{eq}), \mathrm{CH}_{2} \mathrm{Cl}_{2}, \mathrm{rt}, 24 \mathrm{~h}$.

Scheme 73. $\mathrm{Cu}(\mathrm{II})$-mediated synthesis of oxazoles $\mathbf{2 6 2}$

Stahl described a synthesis of 2,5-disubstituted oxazoles 125 through a $\mathrm{Cu}(\mathrm{II})$-mediated oxidative cyclisation of enamides 267 (Scheme 74). ${ }^{93}$ It was proposed the reaction proceeded via a radical pathway involving the single-electron oxidation of $\mathbf{2 6 7}$ by $\mathrm{CuCl}_{2}$, generating a radical-cation intermediate $\mathbf{2 6 8}$, followed by cyclisation to give 270. A second single-electron oxidation of $\mathbf{2 7 0}$ gives the observed oxazole 125. Oxygen re-oxidises the resulting $\mathrm{Cu}(\mathrm{I})$ species to $\mathrm{Cu}(\mathrm{II})$ completing the catalytic cycle. The best yields 
were obtained with enamides $\mathbf{2 6 7}$ bearing electron-rich aromatic substituents, whereas their alkyl-substituted counterparts provided $\mathbf{1 2 5}$ in poor yield.

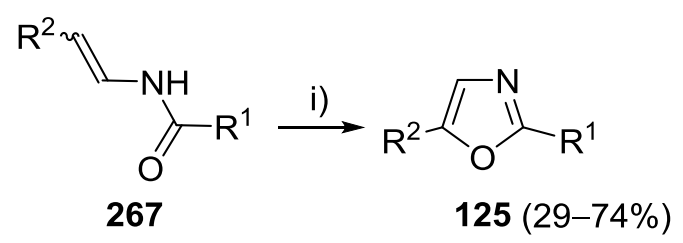

$\mathrm{R}^{1}=\mathrm{Ph}, 4-\mathrm{MeOC}_{6} \mathrm{H}_{4}, 4-\mathrm{NO}_{2} \mathrm{C}_{6} \mathrm{H}_{4}, t-\mathrm{Bu}, \mathrm{PhCH}=\mathrm{CH}$;

$\mathrm{R}^{2}=\mathrm{Ph}, 4-\mathrm{MeOC}_{6} \mathrm{H}_{4}, 3-4-(\mathrm{MeO})_{2} \mathrm{C}_{6} \mathrm{H}_{3}, 4-\mathrm{ClC}_{6} \mathrm{H}_{4}, 4-\mathrm{MeC}_{6} \mathrm{H}_{4}, 4-t-\mathrm{BuC}_{6} \mathrm{H}_{4}, n-\mathrm{Bu}$

Proposed reaction mechanism

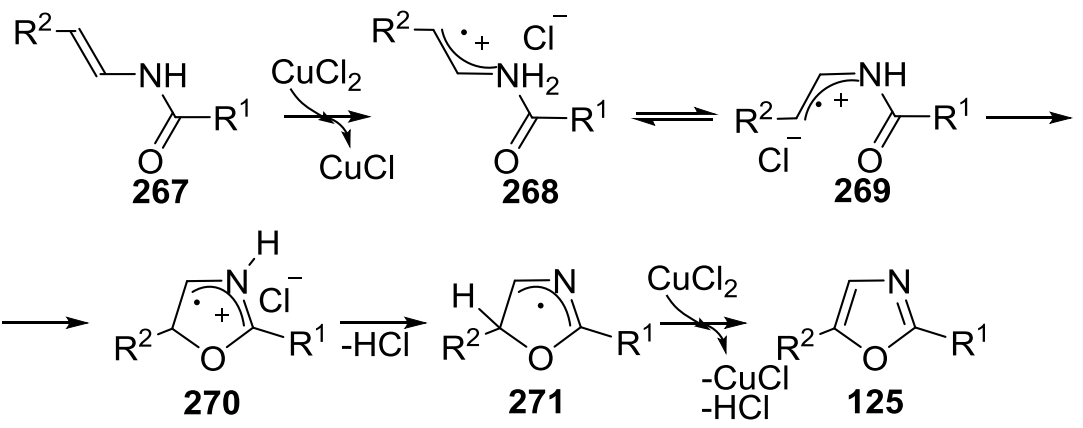

i) $\mathrm{CuCl}_{2}(2.0 \mathrm{eq}), \mathrm{N}$-methylimidazole $(2.0 \mathrm{eq})$, air, 1,4-dioxane, $140^{\circ} \mathrm{C}, 20 \mathrm{~h}$.

Scheme 74. $\mathrm{Cu}(\mathrm{II})$-mediated oxidative cyclisation of enamides $\mathbf{2 6 7}$

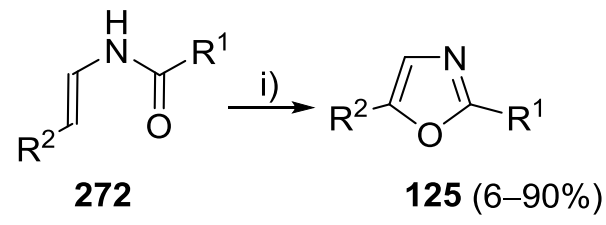

$\mathrm{R}^{1}=\mathrm{Ph}, 4-\mathrm{MeOC}_{6} \mathrm{H}_{4}, 4-\mathrm{MeC}_{6} \mathrm{H}_{4}, 4-\mathrm{ClC}_{6} \mathrm{H}_{4}, 4-\mathrm{FC}_{6} \mathrm{H}_{4}, 4-\mathrm{F}_{3} \mathrm{CC}_{6} \mathrm{H}_{4}, 4-\mathrm{NO}_{2} \mathrm{C}_{6} \mathrm{H}_{4}, 3-\mathrm{NO}_{2} \mathrm{C}_{6} \mathrm{H}_{4}$, 4- $\mathrm{BrC}_{6} \mathrm{H}_{4}, 4-t-\mathrm{BuC}_{6} \mathrm{H}_{4}, t-\mathrm{Bu}, 3,4,5-(\mathrm{MeO})_{3} \mathrm{C}_{6} \mathrm{H}_{2}$, cyclohexyl, 1-cyclohexenyl, thiophen-2-yl, thiophen-3-yl, furan-2-yl, 3,4-(MeO $)_{2} \mathrm{C}_{6} \mathrm{H}_{3} \mathrm{CH}=\mathrm{CH}, 2-\mathrm{MeC}_{6} \mathrm{H}_{4}$, naphthalen-2-yl, $\mathrm{PhCH}=\mathrm{CH}$; $\mathrm{R}^{2}=\mathrm{Ph}, 4-\mathrm{MeOC}_{6} \mathrm{H}_{4}, 4-\mathrm{MeCOC}_{6} \mathrm{H}_{4}, 4-\mathrm{MeC}_{6} \mathrm{H}_{4}, 4-\mathrm{ClC}_{6} \mathrm{H}_{4}, 4-\mathrm{BrC}_{6} \mathrm{H}_{4}, 4-\mathrm{FC}_{6} \mathrm{H}_{4}$, 3,4- $\mathrm{F}_{2} \mathrm{C}_{6} \mathrm{H}_{3}, 2-\mathrm{MeC}_{6} \mathrm{H}_{4}, \mathrm{PhCH}=\mathrm{CH}, n$-octyl, thiophen-3-yl , $N$-benzoyl-5-indolyl

Proposed reaction mechanism

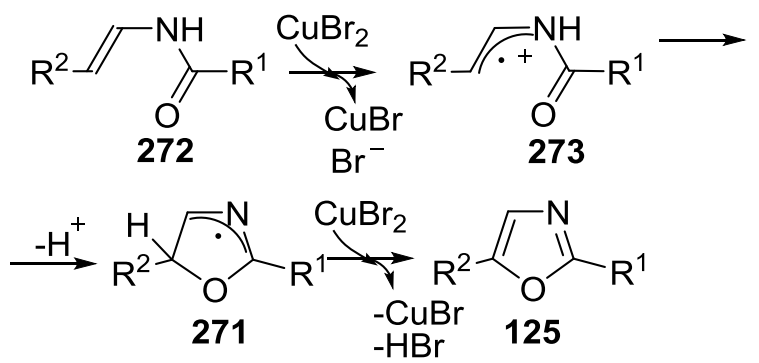

i) $\mathrm{CuBr}_{2}(7.5-15 \mathrm{~mol} \%)$, ethyl nicotinate (15-30 mol\%), TBAB (1.2 eq), $\mathrm{K}_{2} \mathrm{~S}_{2} \mathrm{O}_{8}(1.3 \mathrm{eq}), \mathrm{MeCN}, \mathrm{rt}, 24 \mathrm{~h}$.

Scheme 75. $\mathrm{Cu}(\mathrm{II})$-catalysed oxidative cyclisation of enamides $\mathbf{2 7 2}$ 
The substrate scope for this class of transformation was expanded by Buchwald, who described the preparation of 2,5-disubstituted oxazoles 125 through the $\mathrm{Cu}(\mathrm{II})$-catalysed oxidative cyclisation of enamides 272 (Scheme 75). ${ }^{94}$ In a similar manner to the vinylic $\mathrm{C}-\mathrm{H}$ functionalization developed by Stahl, ${ }^{93}$ the reaction involves the single-electron oxidation of 272 by $\mathrm{CuCl}_{2}$, generating a radical-cation $\mathbf{2 7 3}$, which undergoes cyclisation. A second single-electron oxidation of 271 leads to $\mathbf{1 2 5}$. The reduced $\mathrm{Cu}(\mathrm{I})$ species generated is re-oxidised to $\mathrm{Cu}$ (II) by potassium persulfate completing the catalytic cycle. A wide variety of enamides 272 underwent oxidative cyclisation to yield 2,5-disubstituted oxazoles 125 in moderate to excellent yields under exceptionally mild reaction conditions.

The synthetic application of this class of transformation was expanded to include the preparation of 2,4,5-trisubstituted oxazoles $\mathbf{2 7 5}$ through the $\mathrm{Cu}(\mathrm{I})$-catalysed 5-endo-trig cyclisation of $\beta$-(methylthio)enamides 274 (Scheme 76). ${ }^{95}$ This protocol provides considerable advantages over the previous $\mathrm{Ag}(\mathrm{I})$-mediated cyclisation described above (Scheme 70), ${ }^{89}$ including the use of catalytic amounts of copper and the ability to introduce carbon based substituents at the 5-position.

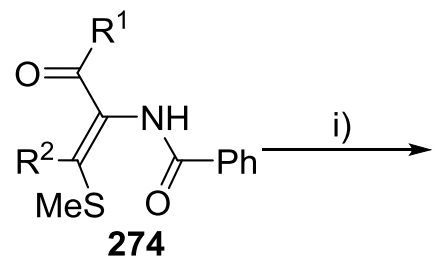

274

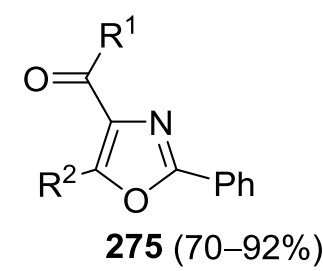

$275(70-92 \%)$

$\mathrm{R}^{1}=4-\mathrm{MeOC}_{6} \mathrm{H}_{4}, n-\mathrm{Bu}, \mathrm{EtO}, \mathrm{C}_{4} \mathrm{H}_{9} \mathrm{O}, \mathrm{PhCH}_{2} \mathrm{O}, t-\mathrm{BuO}, 3,4-(\mathrm{MeO})_{2} \mathrm{C}_{6} \mathrm{H}_{3} \mathrm{CH}_{2} \mathrm{CH}_{2} \mathrm{NH}$, indol-3-yl- $\left(\mathrm{CH}_{2}\right)_{2} \mathrm{NH}$, morpholin-4-yl, 4-benzylpiperazin-1-yl, 3,4,5-( $\mathrm{MeO})_{3} \mathrm{C}_{6} \mathrm{H}_{2} \mathrm{NH}$, 4- $\mathrm{FC}_{6} \mathrm{H}_{4} \mathrm{NH}$, 4- $\mathrm{CF}_{3} \mathrm{C}_{6} \mathrm{H}_{4} \mathrm{NH}, \mathrm{Bn}(\mathrm{CH}) \mathrm{CO}_{2} \mathrm{EtNH}$, indol-3-yl- $\mathrm{CH}_{2}(\mathrm{CH}) \mathrm{CO}_{2} \mathrm{EtNH}, \mathrm{HOCH}_{2}(\mathrm{CH}) \mathrm{CO}_{2} \mathrm{EtNH}$, benzo[d][1,3]dioxol-5-yl, thiophen-2-yl;

$\mathrm{R}^{2}=4-\mathrm{MeOC}_{6} \mathrm{H}_{4}, 3,4-(\mathrm{MeO})_{2} \mathrm{C}_{6} \mathrm{H}_{3}$, benzo[d][1,3]dioxol-5-yl, furan-2-yl, 1-Me-1H-indol-3-yl, pyridin-3-yl, Ph, 1-Me-1H-pyrrol-2-yl, thiophen-2-yl

i) $\mathrm{Cs}_{2} \mathrm{CO}_{3}(1.0 \mathrm{eq})$, Cul (10 mol\%), 1,10-phenanthroline (20 mol\%), DMF, $90^{\circ} \mathrm{C}, 3-4 \mathrm{~h}$.

Scheme 76. $\mathrm{Cu}(\mathrm{I})$-catalysed synthesis of oxazoles 275 Modified scheme 76: added 4-MeOC6H4 and n-Bu and modified substituents

Overall the copper catalysed processes described deliver high functional group tolerance and good structural diversity in the oxazole products. Although commercial availability of substrates is limited, challenges to prepare these compound are less significant than with alternative approaches.

\section{PALLADIUM(0) AND PALLADIUM(II)}

Cacchi described the synthesis of 2,5-disubstituted oxazoles 277 through the $\operatorname{Pd}(0)$-catalysed reaction of $N$-propargylamides 194 and aryl iodides 276 (Scheme 77). ${ }^{96}$ The reaction appears to proceed through a palladium catalysed coupling followed by intramolecular cyclisation to give the observed oxazoles 277 . Although little mechanistic evidence was provided in this study a competing base-mediated cyclisation to 
generate 195 was also noted. A more detailed understanding of this protocol will render this simple methodology very attractive.

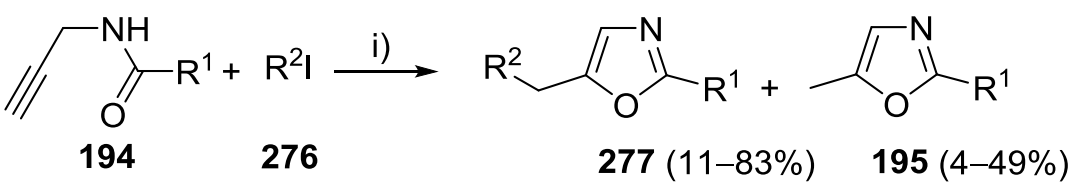

$\mathrm{R}^{1}=\mathrm{Ph}, 4-\mathrm{MeOC}_{6} \mathrm{H}_{4}, 3-\mathrm{CF}_{3} \mathrm{C}_{6} \mathrm{H}_{4}, \mathrm{CF}_{3}, 4-\mathrm{MeC}_{6} \mathrm{H}_{4}$;

$\mathrm{R}^{2}=2-\mathrm{MeC}_{6} \mathrm{H}_{4}, 3-\mathrm{MeC}_{6} \mathrm{H}_{4}, 4-\mathrm{MeC}_{6} \mathrm{H}_{4}, 3,5-\mathrm{Me}_{2} \mathrm{C}_{6} \mathrm{H}_{3}, 3-\mathrm{MeOC}_{6} \mathrm{H}_{4}, 4-\mathrm{MeOC}_{6} \mathrm{H}_{4}$,

$\mathrm{Ph}, 4-\mathrm{ClC}_{6} \mathrm{H}_{4}, 3-\mathrm{CF}_{3} \mathrm{C}_{6} \mathrm{H}_{4}, 3-\mathrm{FC}_{6} \mathrm{H}_{4}, 4-\mathrm{FC}_{6} \mathrm{H}_{4}, 4-\mathrm{MeCOC}_{6} \mathrm{H}_{4}$

i) 194 (1.0 eq), 276 (1.2 eq), NaOt-Bu (2.0 eq), $\mathrm{Pd}_{2}(\mathrm{dba})_{3}$ (2.5 mol\%), P(2-furyl) ${ }_{3}(10 \mathrm{~mol} \%), \mathrm{MeCN}, 40^{\circ} \mathrm{C}, 4-20 \mathrm{~h}$.

Scheme 77. $\operatorname{Pd}(0)$-catalysed/base-mediated synthesis of oxazoles 277

Saito and Hanzawa expanded the substrate scope of this class of transformation to encompass the coupling of terminal and internal $N$-propargylamides 278 with allyl ethyl carbonate 279 (Scheme 78 ). ${ }^{97}$ Although a number of allyl carbonate derivatives were successfully employed for this transformation, competing reaction pathways detract from this method. ${ }^{96}$

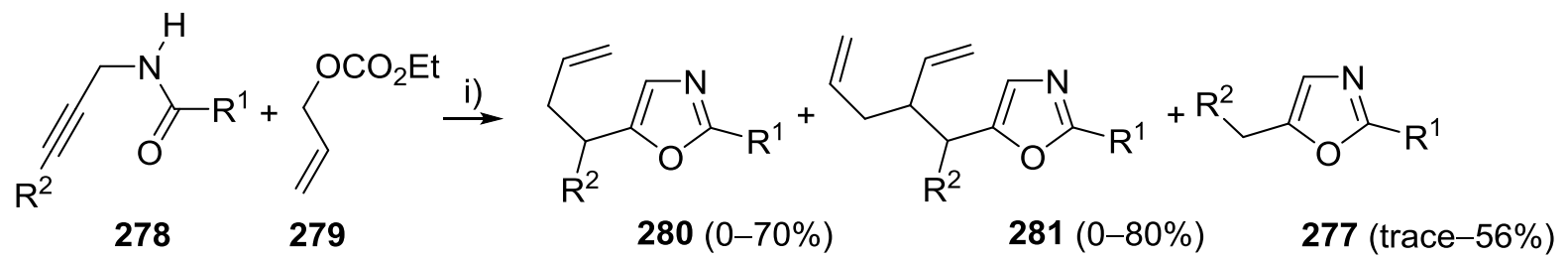

$\mathrm{R}^{1}=\mathrm{Ph}, \mathrm{H}, 4-\mathrm{MeOC}_{6} \mathrm{H}_{4}, 4-\mathrm{MeC}_{6} \mathrm{H}_{4}, 4-\mathrm{ClC}_{6} \mathrm{H}_{4}, 4-\mathrm{NO}_{2} \mathrm{C}_{6} \mathrm{H}_{4}$, 2-thienyl, 2-furyl, $\mathrm{CH}=\mathrm{CH}_{2} \mathrm{Ph}, \mathrm{CH}_{2} \mathrm{Ch}_{2} \mathrm{Ph}$; $\mathrm{R}^{2}=\mathrm{H}, \mathrm{Et}, t-\mathrm{Bu}, \mathrm{Ph}, 4-\mathrm{MeOC}_{6} \mathrm{H}_{4}, 4-\mathrm{NO}_{2} \mathrm{C}_{6} \mathrm{H}_{4}$

i) 278 (1.0 eq), 279 (3.0 or 6.0 eq), $\mathrm{Pd}_{2}(\mathrm{dba})_{3}$ (2.5 or $5 \mathrm{~mol} \%$ ), IPr $\cdot \mathrm{HCl}$ (6 or $\left.12 \mathrm{~mol} \%\right), \mathrm{Cy}_{3} \mathrm{P}(10$ or 20 $\mathrm{mol} \%), \mathrm{Cs}_{2} \mathrm{CO}_{3}$ (3.0 or $6.0 \mathrm{eq}$ ), $\mathrm{MeCN}, 90^{\circ} \mathrm{C}, 21 \mathrm{~h}$.

Scheme 78. $\operatorname{Pd}(0)$-catalysed cycloisomerisation-allylation reaction of $N$-propargylamides $\mathbf{2 7 8}$ and allyl ethyl carbonate $\mathbf{2 7 9}$

The synthesis of 2,5-disubstituted oxazoles 282 through the $\mathrm{Pd}(\mathrm{II})$-catalysed oxidative cyclisation of $N$-propargylamides 194 in the presence of an oxidant 317 was reported by Broggini (Scheme 79). ${ }^{98}$ The reaction proceeds via the intramolecular nucleophilic attack of the carbonyl oxygen at the Pd(II)-activated triple bond to give $\mathbf{2 8 4}$. Reaction of $\mathbf{2 8 4}$ with water generates $\mathbf{2 8 5}$, which undergoes reductive elimination to form 286 and a $\operatorname{Pd}(0)$ species. Tautomerisation of $\mathbf{2 5 6}$ furnishes oxazoline $\mathbf{2 8 7}$. Subsequent oxidation of 287 and the $\operatorname{Pd}(0)$ species gives the desired oxazoles 282 and regenerates the catalyst. A variety of $N$-propargylamides 194 bearing aliphatic and aromatic substituents were successfully employed in this transformation, affording 5-oxazolecarboxaldehydes $\mathbf{2 8 2}$ in moderate to good yields. 


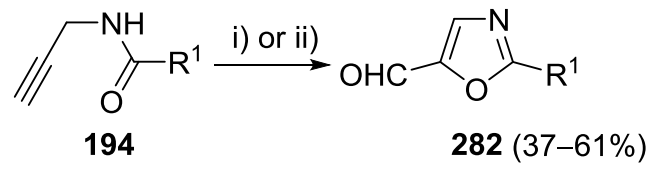

$\mathrm{R}^{1}=4-\mathrm{MeOC}_{6} \mathrm{H}_{4}, 4-\mathrm{NO}_{2} \mathrm{C}_{6} \mathrm{H}_{4}, \mathrm{Bn}, \mathrm{Ph}\left(\mathrm{CH}_{2}\right)_{2}, \mathrm{~N}$-Me-pyrrol-2-yl, pyrrol-2-yl, thiophen-2-yl, furan-2-yl, $\mathrm{Me}(\mathrm{CH}) \mathrm{NHBoc},(\mathrm{Me})_{2} \mathrm{CH}(\mathrm{CH}) \mathrm{NHBoc}$

Proposed reaction mechanism
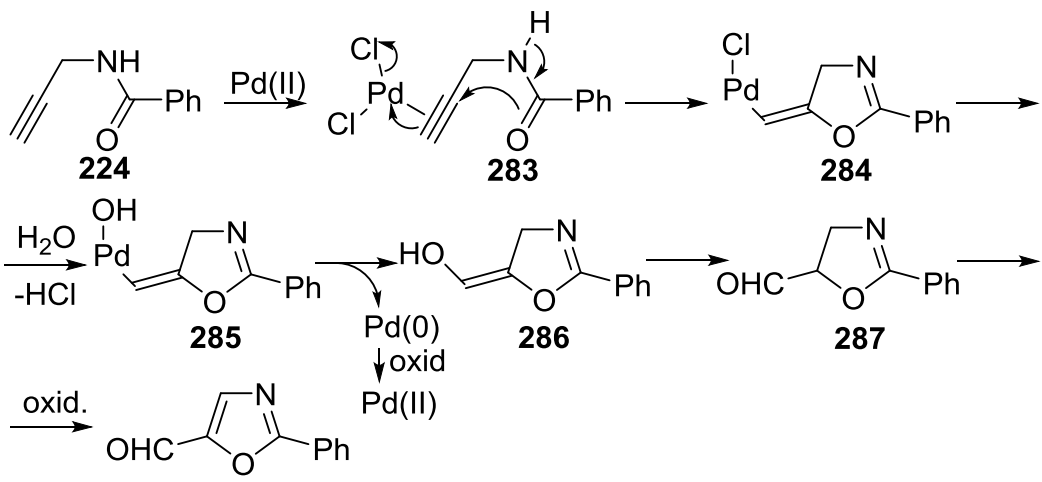

282

i) 194 (1.0 eq), $\mathrm{PdCl}_{2}(\mathrm{MeCN})_{2}(5 \mathrm{~mol} \%)$, benzoquinone (1.0 eq), DMF/THF, $60^{\circ} \mathrm{C}, 3 \mathrm{~h}$;

ii) $\mathrm{PdCl}_{2}(\mathrm{MeCN})_{2}(5 \mathrm{~mol} \%), \mathrm{CuCl}_{2}(10 \mathrm{~mol} \%), \mathrm{DMF}, \mathrm{rt}, 30 \mathrm{~min}$ then $194(1.0 \mathrm{eq}), \mathrm{O}_{2}, \mathrm{DMF}, 100{ }^{\circ} \mathrm{C}, 2 \mathrm{~h}$.

Scheme 79. $\mathrm{Pd}(\mathrm{II})$-catalysed oxidative cyclisation of $N$-propargylamides 194

The accessibility of $N$-propargyl amides makes the palladium catalysed synthetic strategy to prepare oxazoles very attractive. Focus on rendering the subsequent functionalisation of the $\mathrm{Pd}(\mathrm{II})$ intermediate selective will undoubtedly increase the uptake of this work.

\section{MERCURY(II)}

The first example of $\mathrm{Hg}(\mathrm{II})$-mediated cycloisomerisation of $\mathrm{N}$-propargylamides 194 to oxazoles was reported by Deryckere in 1973 (Scheme 80).${ }^{99}$ Reaction of 194 with $\mathrm{Hg}(\mathrm{OAc})_{2}$ in the presence of acetic acid provided moderate to good yields of oxazole 195 (50-74\%). This protocol has found a number of applications in the synthesis of bioactive oxazole-containing compounds. ${ }^{100}$

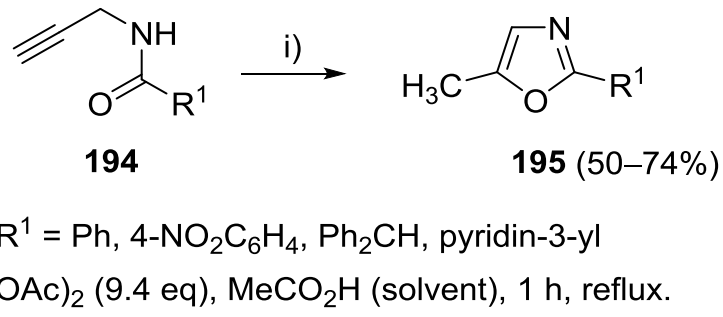

Scheme 80. Hg(II)-mediated cycloisomerisation of $N$-propargylamides 194

Kim used this protocol to develop a ratiometric chemodosimeter for the selective detection of mercuric ions based on the cyclisation of $\mathbf{2 8 8}$ in aqueous ethanol (Scheme 81). ${ }^{101} \mathrm{Hg}$ (II)-promoted intramolecular cyclisation of $\mathbf{2 8 8}$ generates $\mathbf{2 9 2}$, which reacts with water and a second $\mathrm{Hg}(\mathrm{II})$ ion to form the dimercurate 
intermediate 293. Loss of mercury leads to oxazole $\mathbf{2 8 9} .^{102}$<smiles>C#CCNC(=O)c1cc2ccc(NCC)cc2oc1=O</smiles>

288

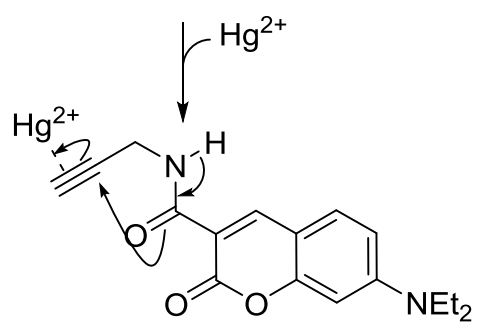

290

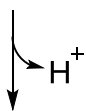<smiles>CCNc1ccc2cc(C3=NCC(C)(CO)C3(C)C[SeH2+])c(=O)oc2c1</smiles>

292

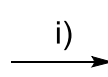<smiles>CCNc1ccc2cc(-c3ncc(C=O)o3)c(=O)oc2c1</smiles>

289<smiles>CCNc1ccc2cc(-c3ncc(C(C)(O)O)o3)c(=O)oc2c1</smiles>

291

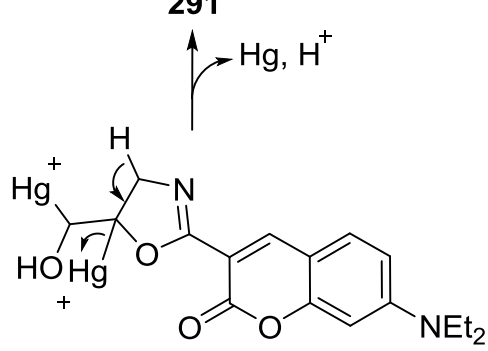

293

i) $\mathrm{Hg}(\mathrm{II})$ ions, EtOH/HEPES, $\mathrm{pH}=7.4, \lambda_{\mathrm{ex}}=438 \mathrm{~nm}$.

Scheme 81 . $\mathrm{Hg}(\mathrm{II})$-mediated synthesis of oxazole $\mathbf{2 8 9}$

\section{TUNGSTEN(0)}

Kim has also shown that the W(0)-catalysed cyclisation of terminal $N$-propargylamides $\mathbf{1 7 5}$ in the presence of trimethylamine $\mathrm{N}$-oxide as an oxidant leads to a mixture of oxazoline 294 and oxazole 174 with low levels of selectivity (Scheme 82$){ }^{103}$

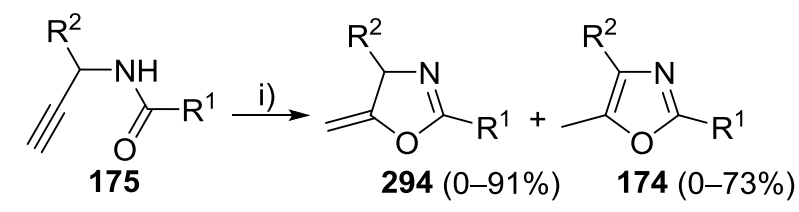

$\mathrm{R}^{1}=\mathrm{Ph}, \mathrm{Bn}, 2-\mathrm{BrC}_{6} \mathrm{H}_{4}, 2-\mathrm{MeOC}_{6} \mathrm{H}_{4}, 4-\mathrm{NO}_{2} \mathrm{C}_{6} \mathrm{H}_{4}, n$-heptyl;

$\mathrm{R}^{2}=\mathrm{H}, \mathrm{Me}$

i) $175(1.0 \mathrm{eq}), \mathrm{W}(\mathrm{CO})_{6}(20 \mathrm{~mol} \%), \mathrm{DABCO}(1.0 \mathrm{eq}), 350 \mathrm{~nm}, \mathrm{PhMe}, \mathrm{rt}, 20 \mathrm{~h}$ then $(\mathrm{Me})_{3} \mathrm{NO}, \mathrm{THF}$.

Scheme 82. W(0)-catalysed cyclisation of $N$-propargylamides 175

The O1-C5 bond disconnection represents a simple and versatile method for the preparation of mono-, diand tri-substituted oxazole products using a broad range of transition metal catalysts. Improving access to the appropriate starting materials for many of these transformations would enhance the applicability of this strategy. 


\section{O1-C2 BOND DISCONNECTION}

\section{ZINC(II)}

Ganem reported the synthesis of 2,5-disubstituted oxazoles 298 through the Zn(II)-promoted three-component condensation of ethyl isocyanoacetate 295, carbonyl compounds 296 and trimethylsilyl chloride 297 in the presence of a base (Scheme 83). ${ }^{104}$ The reaction proceeds via the nucleophilic attack of 295 on 296 to give a nitrilium ion 299. Intramolecular cyclisation of 299 generates 300, which upon deprotonation leads to 298. A range of aliphatic and aromatic carbonyl compounds $\mathbf{2 9 6}$ could efficiently be employed in this transformation. This metal-promoted variant of the Passerini reaction ${ }^{105}$ provides a mild protocol for the synthesis of a range of 2-substituted-5-alkoxyoxazoles in moderate yield.

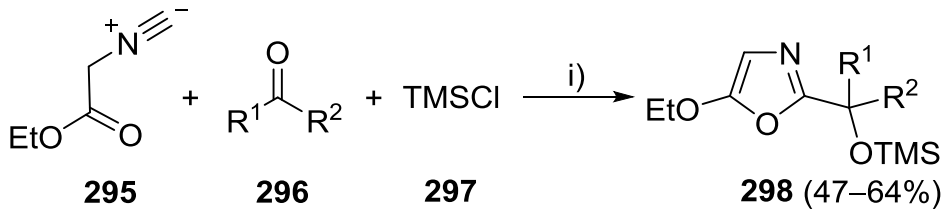

$\mathrm{R}^{1}, \mathrm{R}^{2}=\mathrm{H}, \mathrm{Ph}, \mathrm{Me}, \mathrm{Ph}\left(\mathrm{CH}_{2}\right)_{2}, n$-heptyl, $\left(\mathrm{CH}_{2}\right)_{5}, \mathrm{PhCH}=\mathrm{CH}$

Proposed reaction mechanism

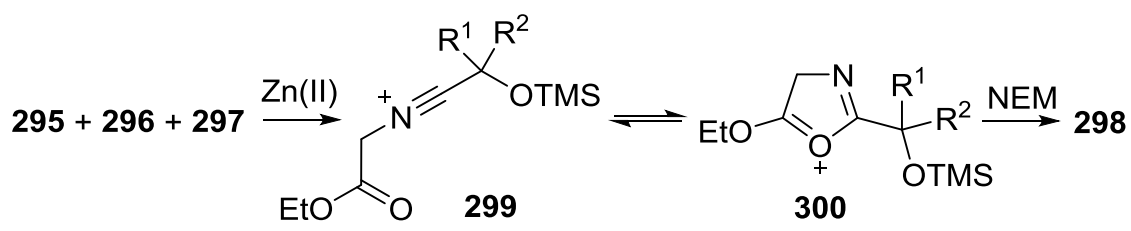

i) 295 (1.2 eq), 296 (1.0 eq), Zn(OTf) 2 (0.5 eq), TMSCl (3.0 eq), $N$-ethylmorpholine (3.0 eq), $\mathrm{CH}_{2} \mathrm{Cl}_{2}, 0^{\circ} \mathrm{C}$ then rt, $24 \mathrm{~h}$.

Scheme 83. Zn(II)-promoted synthesis of oxazoles 298

The substrate scope of this transformation was expanded to the condensation of isocyanoacetamides $\mathbf{3 0 1}$ and carbonyl compounds 302 in the presence of silyl chlorides 303 (Scheme 84). ${ }^{106}$ A number of

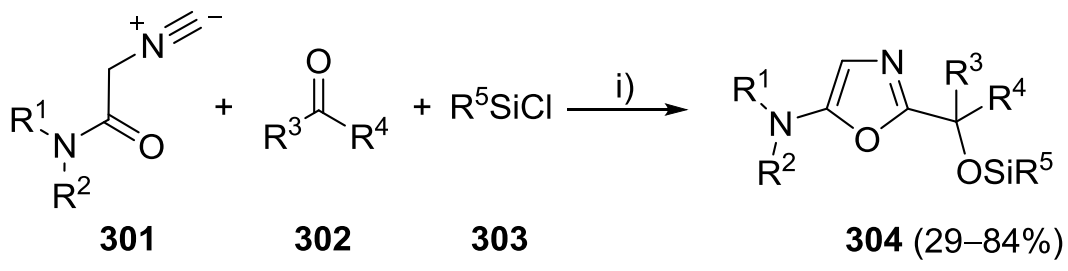

$N R^{1} R^{2}=$ morpholino, $\mathrm{NMe}_{2}$;

$\mathrm{R}^{3}, \mathrm{R}^{4}=\mathrm{H}, \mathrm{Ph}, t-\mathrm{Bu},\left(\mathrm{CH}_{2}\right)_{5}, \mathrm{Ph}\left(\mathrm{CH}_{2}\right)_{2}, n$-nonyl;

$\mathrm{R}^{5}=\mathrm{Me}_{3}, \mathrm{Et}_{3}$

i) $\mathrm{Zn}(\mathrm{OTf})_{2}(0.3 \mathrm{eq}), 301$ (1.0 eq), 302 (1.3 eq), $\mathrm{R}^{5} \mathrm{SiCl}$ (1.6 or $\left.2.0 \mathrm{eq}\right), \mathrm{N}$-ethylmorpholine (2.1 eq), $\mathrm{CH}_{2} \mathrm{Cl}_{2}, \mathrm{rt}, 12 \mathrm{~h}$. 
Scheme 84. Zn(II)-promoted synthesis of oxazoles 304

2-substituted 5-aminooxazoles could be obtained in good yields via this method. 2,4,5-Trisubstituted oxazoles can also be accessed through the $\mathrm{Zn}(\mathrm{II})$-promoted four-component condensation of isocyanoacetamides, carbonyl compounds and silyl chlorides. ${ }^{107}$ 

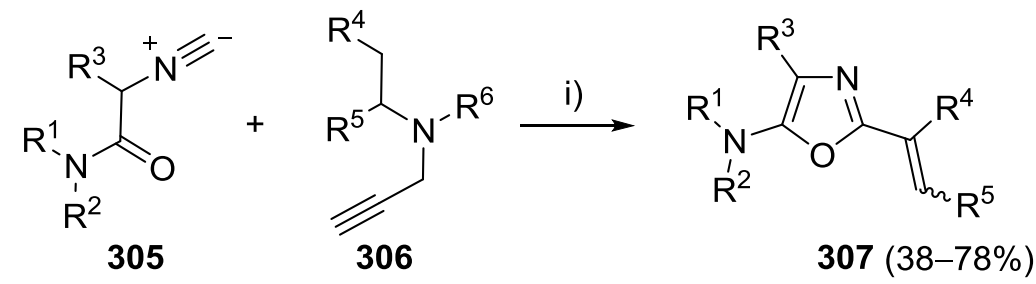

$N R^{1} R^{2}=$ morpholin-4-yl, pyrrolidin-1-yl;

$\mathrm{R}^{3}=4-\mathrm{MeC}_{6} \mathrm{H}_{4} \mathrm{CH}_{2}, 4-\mathrm{MeOC}_{6} \mathrm{H}_{4} \mathrm{CH}_{2}, 4-\mathrm{FC}_{6} \mathrm{H}_{4} \mathrm{CH}_{2}, 4-\mathrm{BrC}_{6} \mathrm{H}_{4} \mathrm{CH}_{2}, 3-\mathrm{BrC}_{6} \mathrm{H}_{4} \mathrm{CH}_{2}$,

2- $\mathrm{BrC}_{6} \mathrm{H}_{4} \mathrm{CH}_{2}, n$-hexyl, $\mathrm{Ph}, \mathrm{Bn}$;

$\mathrm{R}^{4} \mathrm{CH}_{2} \mathrm{CHR}^{5}=i-\mathrm{Pr},\left(\mathrm{MeCH}_{2}\right)_{2} \mathrm{CH}, \mathrm{MeCH}_{2} \mathrm{CHMe}$, cyclopentyl, cyclohexyl,

cycloheptyl, cyclooctyl, bicyclo[2.2.1]heptan-1-yl;

$\mathrm{R}^{6}=i-\mathrm{Pr},\left(\mathrm{MeCH}_{2}\right)_{2} \mathrm{CH}, \mathrm{MeCH}_{2} \mathrm{CHMe}$, cyclopentyl, cyclohexyl, cycloheptyl,

cyclooctyl, Me

Proposed reaction mechanism<smiles>[R]CC([R])N([R7])CC#C</smiles>

306

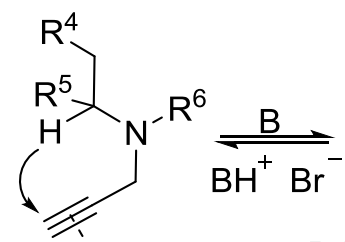
$\mathrm{ZnBr}_{2}$ 308<smiles>[R]CC([R])N([R])CC#CCBr</smiles>

309<smiles>[R]CC([R7])=[N+](Br)CC(=C)Br</smiles>

310

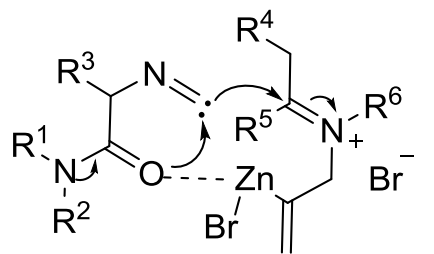

311

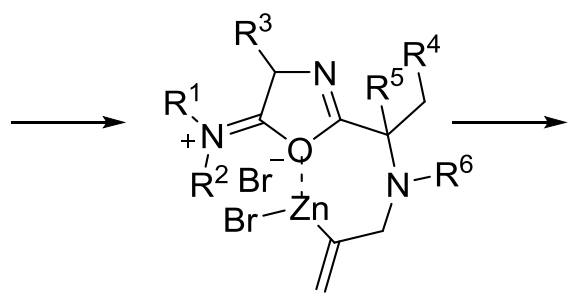

312

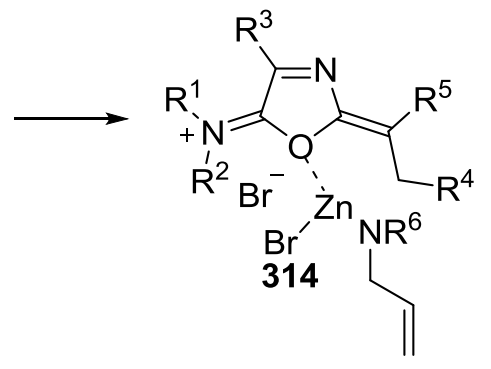

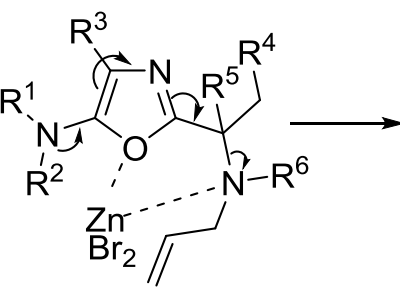

313

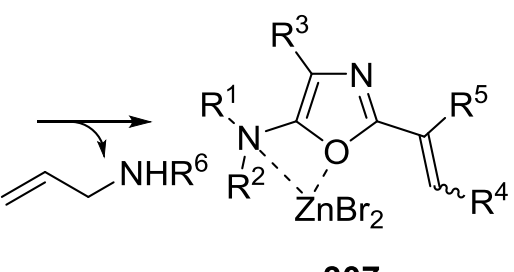

307

i) 305 (2.0 or 3.0 or 5.0 eq), 306 (1.0 eq), $\mathrm{ZnBr}_{2}$ (1.5 or $\left.5.0 \mathrm{eq}\right), \mathrm{PhMe}, 100^{\circ} \mathrm{C}, 2 \mathrm{~h}$.

Scheme 85. Zn(II)-mediated synthesis of oxazoles $\mathbf{3 0 7}$

Trisubstituted oxazoles 307 have also been prepared through the $\mathrm{Zn}$ (II)-mediated reaction of $\alpha$-isocyanoacetamidates 305 and propargylamines 306 (Scheme 85). ${ }^{108}$ The reaction proceeds via the formation of an alkyne- $\mathrm{ZnBr}_{2} \pi$-complex $\mathbf{3 0 8}$, which undergoes 1,5-hydride shift to generate iminium ion 
310. Interaction of $\mathbf{3 0 5}$ and $\mathbf{3 1 0}$ leads to 311, which undergoes cyclisation to form $\mathbf{3 1 2}$. Aromatisation of 312 generates 313, which upon 1,6-elimination of an allylamine and subsequent isomerisation gives 307. A range of isocyanoacetamidates $\mathbf{3 0 5}$ bearing benzyl, alkyl and aryl substituents and a series of alkyl-substituted propargylamines $\mathbf{3 0 6}$ were successfully employed in this transformation.

\section{TIN(II)}

Oxazoles 316 can be prepared through the Sn(II)-catalysed condensation of $\alpha$-isocyanoacetamides $\mathbf{3 0 5}$ and aldehydes 315 under very mild reaction conditions (Scheme 86). ${ }^{109}$ This transformation works well with a range of aliphatic linear and $\alpha$-branched aldehydes 315 , whereas aromatic aldehydes were generally less effective substrates and required extended reaction times. Use of a chiral supporting ligand gave the product with up to $80 \%$ ee.
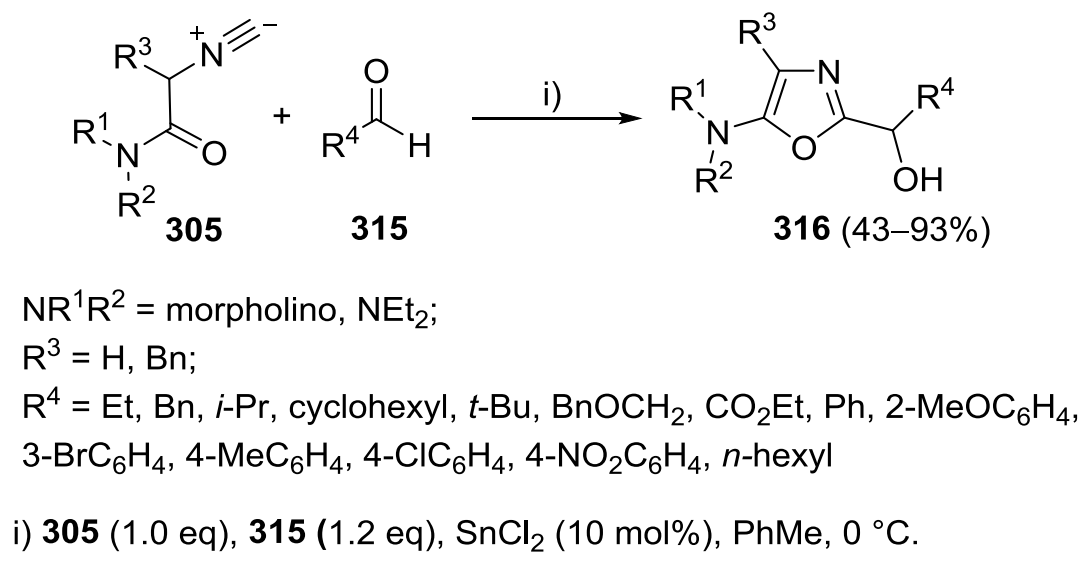

Scheme 86. Sn(II)-catalysed synthesis of oxazoles 316

The O1-C2 bond disconnection for the preparation of oxazoles is substantially less explored than alternative disconnections due to the challenges associated with preparation of the required isonitriles. However, functional group tolerance and mild conditions provide significant opportunities for the preparation of richly functionalised oxazole products.

\section{O1-C2, O1-C5 AND N3-C4 BOND DISCONNECTION}

\section{COPPER(II)}

Jiang described an intriguing $\mathrm{Cu}(\mathrm{II})$-catalysed [2+2+1] cycloaddition of internal alkynes 145, nitriles 2 and water (Scheme 87). ${ }^{110}$ The transformation proceeds via the regioselective nucleophilic addition of a nitrile 2 to a Lewis acid activated alkyne 145 leading to 317. Addition of water followed by isomerisation and reductive elimination gives 75. Dioxygen oxidises the reduced copper species completing the catalytic cycle. Importantly, the reaction of unsymmetrical alkynes proceeds with predictable regioselectivity based 
upon electronic effects. The transformation showed good compatibility with a range of functional groups, providing a rapid and convenient access to the trisubstituted oxazole core.

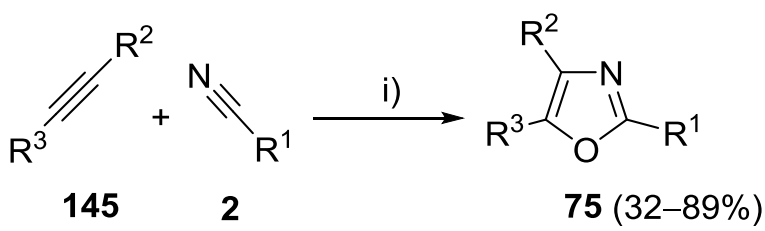

$\mathrm{R}^{1}=\mathrm{Me}, \mathrm{CH}_{2}=\mathrm{CH}, \mathrm{Ph}, \mathrm{CN}\left(\mathrm{CH}_{2}\right)_{4}, n-\mathrm{Bu}$, cyclopropyl, 4- $\mathrm{FC}_{6} \mathrm{H}_{4}, 4-\mathrm{ClC}_{6} \mathrm{H}_{4}, 4-\mathrm{BrC}_{6} \mathrm{H}_{4}, 4-\mathrm{MeC}_{6} \mathrm{H}_{4}$;

$\mathrm{R}^{2}=\mathrm{Ph}, 4-\mathrm{ClC}_{6} \mathrm{H}_{4}, 4-\mathrm{MeC}_{6} \mathrm{H}_{4}, 4-t-\mathrm{BuC}_{6} \mathrm{H}_{4}, 4-\mathrm{EtC}_{6} \mathrm{H}_{4}, 4-\mathrm{FC}_{6} \mathrm{H}_{4}, 2-\mathrm{FC}_{6} \mathrm{H}_{4}, 3-\mathrm{FC}_{6} \mathrm{H}_{4}$, naphthalen-1-yl, thiophen-2-yl, $\mathrm{Me}, n-\mathrm{Pr}, 4-\mathrm{MeOC}_{6} \mathrm{H}_{4}, \mathrm{PhC} \equiv \mathrm{C}$;

$\mathrm{R}^{3}=\mathrm{Ph}, 4-\mathrm{ClC}_{6} \mathrm{H}_{4}, 4-\mathrm{MeC}_{6} \mathrm{H}_{4}, 4-t-\mathrm{BuC}_{6} \mathrm{H}_{4}, 4-\mathrm{EtC}_{6} \mathrm{H}_{4}, 4-\mathrm{FC}_{6} \mathrm{H}_{4}, 2-\mathrm{FC}_{6} \mathrm{H}_{4}, 3-\mathrm{FC}_{6} \mathrm{H}_{4}$, naphthalen-1-yl, thiophen-2-yl, $\mathrm{Me}, n-\mathrm{Pr}, 2-\mathrm{CNC}_{6} \mathrm{H}_{4}, 4-\mathrm{NO}_{2} \mathrm{C}_{6} \mathrm{H}_{4}, \mathrm{Me}, \mathrm{Et}, \mathrm{CO}_{2} \mathrm{Et}$

Proposed reaction mechanism

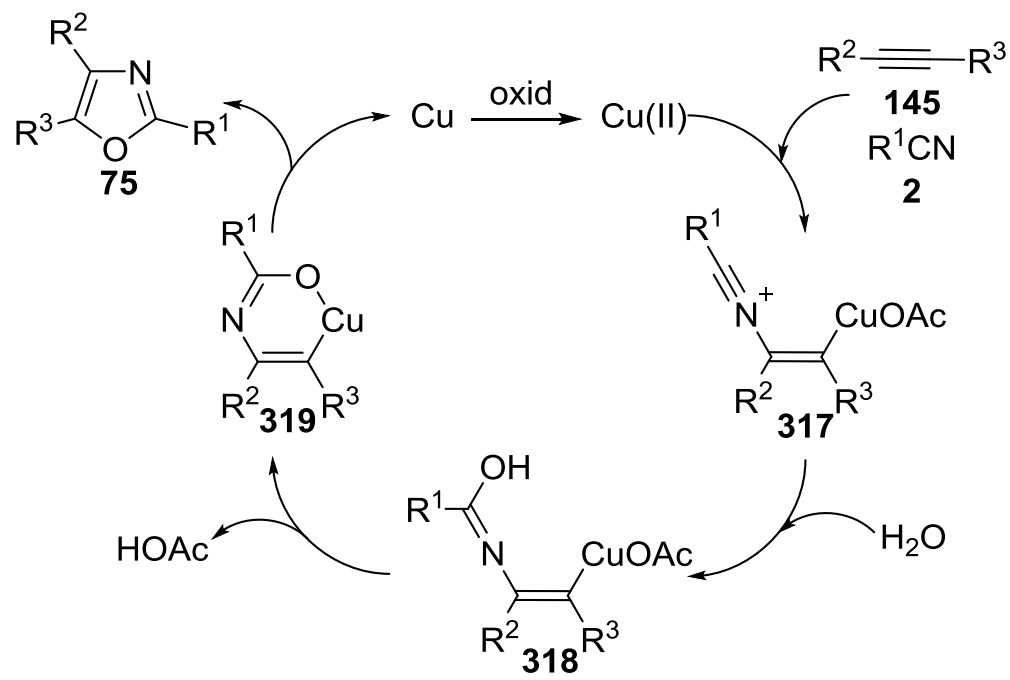

i) 2 (2.5 or 3.0 eq), 145 (1.0 eq), $\mathrm{Cu}(\mathrm{OAc})_{2}$ (5 or $\left.10 \mathrm{~mol} \%\right), \mathrm{BF}_{3} \cdot \mathrm{OEt}_{2}(1.0 \mathrm{eq}), \mathrm{H}_{2} \mathrm{O}$ (5.0 eq), $\mathrm{O}_{2}(1 \mathrm{~atm}), \mathrm{MeNO}_{2}$ (solvent), 80 or $100^{\circ} \mathrm{C}, 12 \mathrm{~h}$.

Scheme 87. $\mathrm{Cu}(\mathrm{II})$-catalysed [2+2+1] annulation for the synthesis of oxazoles $\mathbf{7 5}$

Jiao described a highly efficient synthesis of disubstituted oxazoles $\mathbf{1 2 5}$ through the $\mathrm{Cu}$ (II)-mediated aerobic oxidative dehydrogenative annulation of aldehydes 320 and amines $\mathbf{3 2 1}$ (Scheme 88). ${ }^{111}$ The proposed mechanism involves the oxidation of an imine 322 to give a radical 323, which undergoes 1,5-hydrogen atom abstraction and subsequent intramolecular radical coupling leading to an oxazoline 325 . Oxidation of 325 with molecular oxygen provides the oxazole 125. A broad variety of readily available aryl and aliphatic amines 321 could efficiently be converted to the corresponding oxazoles 125 using this method. The ability to form the oxazole core with specific substitution from such simple starting materials renders this a powerful piece of methodology. 


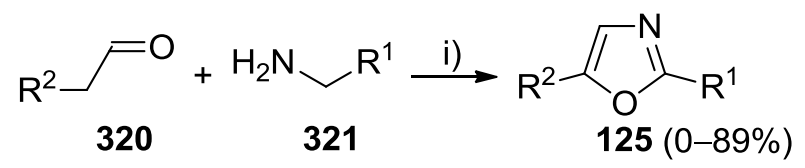

$\mathrm{R}^{1}=2-\mathrm{MeC}_{6} \mathrm{H}_{4}, 3-\mathrm{MeC}_{6} \mathrm{H}_{4}, 4-\mathrm{MeC}_{6} \mathrm{H}_{4}, 2,4-\mathrm{Me}_{2} \mathrm{C}_{6} \mathrm{H}_{3}, 4-\mathrm{MeOC}_{6} \mathrm{H}_{4}, 4-\mathrm{CF}_{3} \mathrm{C}_{6} \mathrm{H}_{4}, 4-\mathrm{FC}_{6} \mathrm{H}_{4}, 2,5-\mathrm{F}_{2} \mathrm{C}_{6} \mathrm{H}_{3}$, 4- $\mathrm{ClC}_{6} \mathrm{H}_{4}, 3-\mathrm{BrC}_{6} \mathrm{H}_{4}$, 4-t-BuC $\mathrm{H}_{4}$, naphthalen-1-yl, $\mathrm{Bn}, 2-\mathrm{MeC}_{6} \mathrm{H}_{4} \mathrm{CH}_{2}, 4-\mathrm{FC}_{6} \mathrm{H}_{4} \mathrm{CH}_{2}, \mathrm{PhCHCH}_{3}, \mathrm{Ph}\left(\mathrm{CH}_{2}\right)_{2}$, $\mathrm{Ph}\left(\mathrm{CH}_{2}\right)_{3}, n$-Bu, $n$-pentyl, $n$-heptyl, $i$-Bu, $\mathrm{Ph}$; $\mathrm{R}^{2}=\mathrm{Ph}, 2-\mathrm{MeC}_{6} \mathrm{H}_{4}, 3-\mathrm{MeC}_{6} \mathrm{H}_{4}, \mathrm{Me}, 4-\mathrm{MeC}_{6} \mathrm{H}_{4}, 4-\mathrm{FC}_{6} \mathrm{H}_{4}, 4-\mathrm{MeOC}_{6} \mathrm{H}_{4}, 4-\mathrm{EtOC}_{6} \mathrm{H}_{4}$

Proposed reaction mechanism

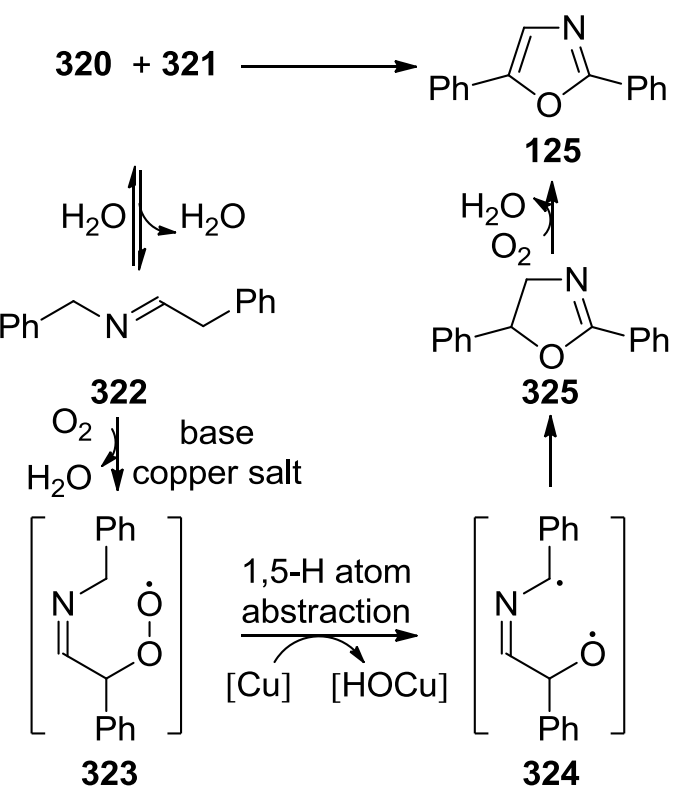

i) 320 (1.0 eq), 321 (1.5), $\mathrm{CuBr}_{2}$ (1.5 eq), pyridine (20 mol\%), $\mathrm{K}_{2} \mathrm{CO}_{3}(2.0 \mathrm{eq}), \mathrm{PhMe}_{2} \mathrm{O}_{2}(1 \mathrm{~atm}), 80^{\circ} \mathrm{C}, 11 \mathrm{or} 16 \mathrm{~h}$.

Scheme 88. Cu(II)-catalysed synthesis of oxazoles $\mathbf{1 2 5}$

\section{GOLD(I)}

$\mathrm{Au}(\mathrm{I})$-catalysed [2+2+1] annulation of alkynes 123, nitriles 2 and an $N$-oxide also leads to the corresponding oxazole (Scheme 89). ${ }^{112}$ The reaction proceeds via the Au(I)-catalysed oxidation of alkyne 123, to give the gold carbene intermediate 326. In situ reaction of $\mathbf{3 2 6}$ with a nitrile $\mathbf{2}$ leads to the oxazole product 125. A broad variety of functional groups are tolerated using this method giving the oxazole in good to excellent isolated yields (59-93\%). The method provides an attractive alternative to the use of hazardous $\alpha$-diazoketones, generating an $\alpha$-oxo gold carbene in situ. Due to the high reactivity of gold carbenes it was necessary to use the nitrile as the solvent to bring about an efficient transformation. This drawback can be circumvented by the use of the more expensive catalyst BrettPhosAuNTf ${ }_{2}$ which allows the use of three equivalents of the nitrile substrate to achieve acceptable yields. The mild reaction conditions and functional group tolerance make this a particularly attractive convergent method for the preparation of 2,5-substituted oxazoles. 


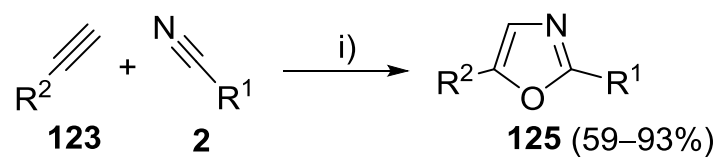

$\mathrm{R}^{1}=\mathrm{Me}, i-\mathrm{Pr}, \mathrm{Et}, \mathrm{Ph}, \mathrm{PhCH}_{2}, \mathrm{NC}\left(\mathrm{CH}_{2}\right)_{4}$

$\mathrm{R}^{2}=\mathrm{Ph}\left(\mathrm{CH}_{2}\right)_{2}, \mathrm{HO}\left(\mathrm{CH}_{2}\right)_{4}, \mathrm{TBSO}\left(\mathrm{CH}_{2}\right)_{3}, \mathrm{THPO}\left(\mathrm{CH}_{2}\right)_{2}, \mathrm{HO}_{2} \mathrm{C}\left(\mathrm{CH}_{2}\right)_{4}, \mathrm{PhS}\left(\mathrm{CH}_{2}\right)_{2}, \mathrm{BocNH}\left(\mathrm{CH}_{2}\right)_{4}, \mathrm{Cl}\left(\mathrm{CH}_{2}\right)_{4}$, cyclohexyl, cyclopentyl, $t-\mathrm{Bu}, \mathrm{MeC}=\mathrm{CH}_{2}$, cyclopropyl, $\mathrm{Me}, \mathrm{Ph}, 4-\mathrm{MeOC}_{6} \mathrm{H}_{4}, 4-\mathrm{HOCC}_{6} \mathrm{H}_{4}, 2-\mathrm{MeC}_{6} \mathrm{H}_{4}$

Proposed reaction mechanism

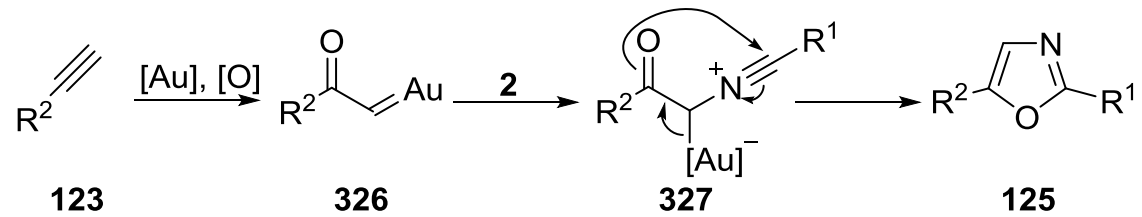

i) 123 (1.0 eq), 2 (solvent), $\mathrm{Ph}_{3} \mathrm{PAuNTf}_{2}$ ( 5 or $10 \mathrm{~mol} \%$ ), 8-methylquinoline- $N$-oxide (1.3 or 2.6 eq), $60^{\circ} \mathrm{C}, 3 \mathrm{~h}$ or on.

Scheme 89. $\mathrm{Au}(\mathrm{I})$-catalysed $[2+2+1]$ annulation for the synthesis of oxazoles $\mathbf{1 2 5}$

\section{MERCURY(II)}

Lee reported a rapid microwave-assisted synthesis of 2,4- and 2,4,5-substituted oxazoles 328 through the $\mathrm{Hg}(\mathrm{II})$-mediated reaction of aromatic ketones 61 and benzonitrile 13 (Scheme 90). ${ }^{113}$ The reaction proceeds

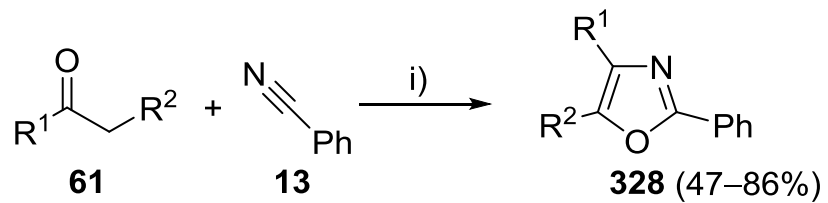

$\mathrm{R}^{1}=\mathrm{Ph}, 4-\mathrm{ClC}_{6} \mathrm{H}_{4}, 4-\mathrm{MeC}_{6} \mathrm{H}_{4}, 4-\mathrm{FC}_{6} \mathrm{H}_{4}, \mathrm{CO}_{2} \mathrm{Et} ;$

$\mathrm{R}^{2}=\mathrm{H}, \mathrm{Me}, \mathrm{CH}_{2} \mathrm{Me}$

Proposed reaction mechanism

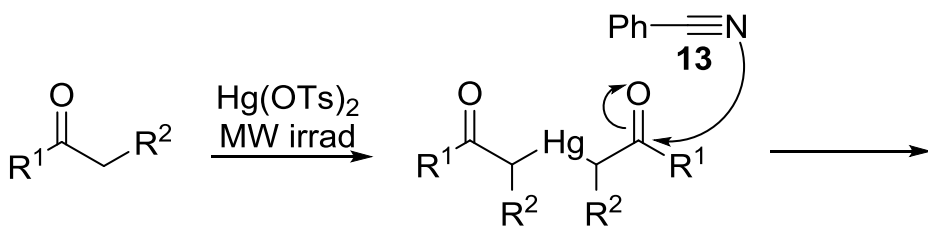

61

329
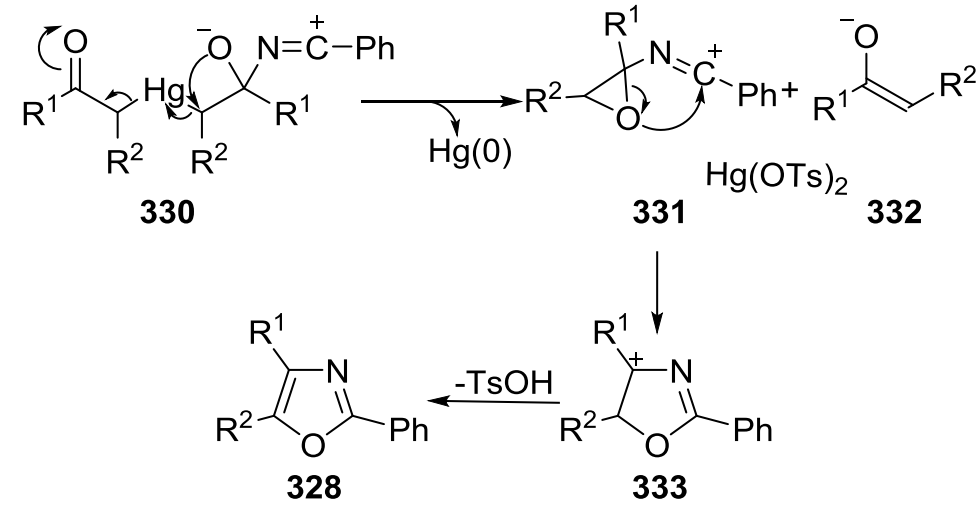

i) 61 (1.0 eq), 13 (5.0 eq), Hg(OTs) $)_{2}(1.0$ eq), MW irrad, 2-4 min.

Scheme 90. $\mathrm{Hg}(\mathrm{II})$-mediated synthesis of oxazoles $\mathbf{3 2 8}$ 
via the enolisation of $\mathbf{6 1}$ to generate $\mathbf{3 2 9}$, reaction of $\mathbf{3 2 9}$ with the nitrile to give $\mathbf{3 3 3}$, which upon aromatisation gives the observed oxazole 328. Ketones bearing a more acidic methylene group $\alpha$ - to the carbonyl functionality proved to be more effective substrates for this transformation, potentially due to a higher enol content.

The ability to construct three bonds in one-pot provides an attractive, versatile and diversity oriented method for the preparation of oxazoles. Of particular note is the combination of alkynes and nitriles or ketones and nitriles. Construction of oxazoles from each of these combinations of monomers provides excellent opportunity for significant structural diversity in the heterocyclic products.

\section{O1-C5 AND C2-N3 BOND DISCONNECTION}

\section{PALLADIUM(II) AND COPPER(I)}

An interesting one-pot three-component synthesis of oxazoles 336 using both $\mathrm{Cu}(\mathrm{I})$ - and $\mathrm{Pd}(\mathrm{II})$-catalysis was reported by Müller (Scheme 91). ${ }^{114,115}$ The reaction proceeds via a proposed amidation-coupling-cycloisomerisation sequence (ACCI). Reaction of 335 with 173 generates amide 194, which undergoes coupling with 334 under modified Sonogashira conditions to give 337. Brønsted acid-mediated cycloisomerization of 337 yields oxazoles 336. A range of acid chlorides 334 and 173 were employed in this protocol, providing the corresponding oxazoles 336 in moderate to good yields. Müller also exploited this transformation in a four-component procedure. ${ }^{14,115}$

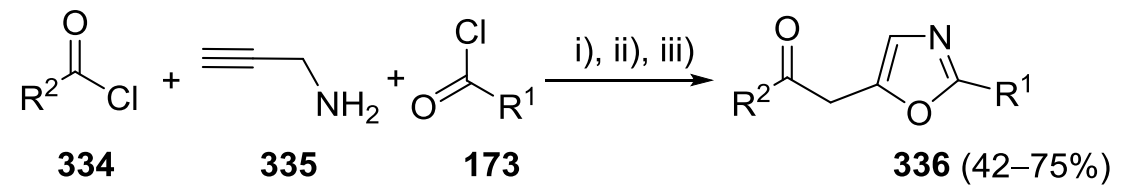

$\mathrm{R}^{1}=\mathrm{Ph}, 4-\mathrm{MeOC}_{6} \mathrm{H}_{4}, 4-\mathrm{MeC}_{6} \mathrm{H}_{4}, 2-\mathrm{FC}_{6} \mathrm{H}_{4}, 4-\mathrm{ClC}_{6} \mathrm{H}_{4}, 4-\mathrm{NO}_{2} \mathrm{C}_{6} \mathrm{H}_{4}, 2-\mathrm{NO}_{2} \mathrm{C}_{6} \mathrm{H}_{4}$, thiophen-2-yl, cyclohexen-1-yl, $\mathrm{PhCH}=\mathrm{CH}_{2}, \mathrm{CH}_{2}=\mathrm{CH}$; $\mathrm{R}^{2}=\mathrm{Ph}, 4-\mathrm{MeC}_{6} \mathrm{H}_{4}$, thiophen-2-yl, $\mathrm{PhCH}=\mathrm{CH}_{2}, 4-\mathrm{MeOC}_{6} \mathrm{H}_{4}, 4-\mathrm{ClC}_{6} \mathrm{H}_{4}, 2-\mathrm{BrC}_{6} \mathrm{H}_{4}, \mathrm{PhCH}=\mathrm{CH}_{2}$

Proposed reaction mechanism

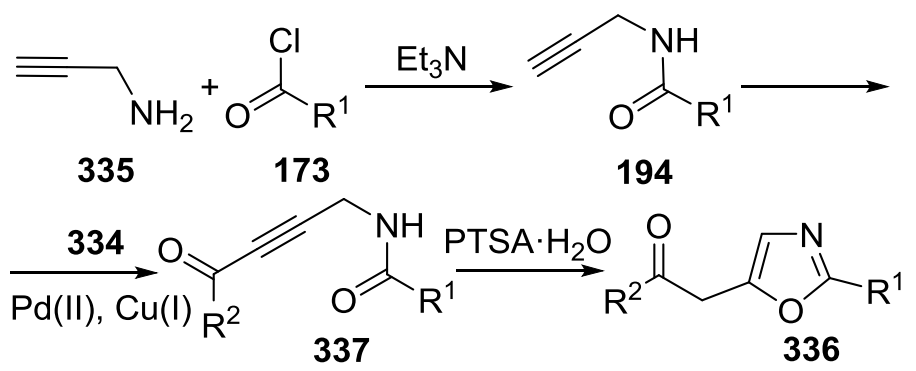

i) 335 (1.0 eq), 173 (1.0 eq), $\mathrm{Et}_{3} \mathrm{~N}(1.0 \mathrm{eq}), \mathrm{THF}, 0^{\circ} \mathrm{C}$ then rt, $1 \mathrm{~h}$; ii) 334 (1.0 eq), $\mathrm{PdCl}_{2}\left(\mathrm{PPh}_{3}\right)_{2}(2 \mathrm{~mol} \%), \mathrm{Cul}$ (4 mol\%), Et ${ }_{3} \mathrm{~N}$ (1.0 eq), rt, $1 \mathrm{~h}$; iii) PTSA, $\mathrm{H}_{2} \mathrm{O}$ (1.0 eq), $\mathrm{BuOH}, 60^{\circ} \mathrm{C}, 1 \mathrm{~h}$.

Scheme 91. One-pot three-component synthesis of oxazoles 336 


\section{ZINC(II)}

Trisubstituted oxazoles 340 can also be prepared through the $\mathrm{Zn}(\mathrm{II})$-mediated coupling of isonitriles $\mathbf{3 3 8}$ with carboxylic acids 339 (Scheme 92). ${ }^{116}$ Addition of the carboxylic acid 339 to a Lewis acid activated isonitrile followed by migratory insertion leads to $\mathbf{3 4 3}$. Coordination of 343 with a second isonitrile leads to 344, which undergoes a second migratory insertion leading to 346. The resulting ketenimine 346 undergoes rearrangement to give 347. Intramolecular cyclisation of $\mathbf{3 4 7}$ followed by dealkylation provides the observed oxazole 340. A stoichiometric amount of $\mathrm{ZnBr}_{2}$ is required for this protocol, due to the oxazole's ability to chelate $\mathrm{Zn}^{2+}$ ions, however, a broad scope of isonitriles $\mathbf{3 3 8}$ as well as a wide range of carboxylic acids 339 bearing aromatic, heteroaromatic, aliphatic and $\alpha$ - $\beta$-unsaturated substituents could effectively be used in this process.

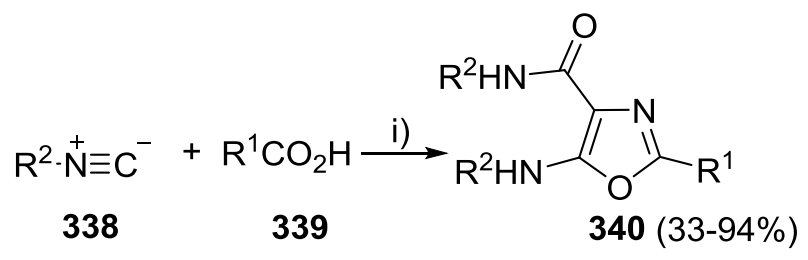

$\mathrm{R}^{1}=\mathrm{Ph}, 4-\mathrm{CNC}_{6} \mathrm{H}_{4}, 4-\mathrm{MeO}_{2} \mathrm{C}, 4-\mathrm{NO}_{2} \mathrm{C}_{6} \mathrm{H}_{4}, 4-\mathrm{CF}_{3} \mathrm{C}_{6} \mathrm{H}_{4}, 3-\mathrm{MeOC}_{6} \mathrm{H}_{4}, 2-\mathrm{Br}-4,5-(\mathrm{MeO})_{2} \mathrm{C}_{6} \mathrm{H}_{2}$, indol-2-yl, furan-2-yl, thiophen-2-yl, $\mathrm{PhCH}=\mathrm{CH}, \mathrm{C}_{6} \mathrm{~F}_{5} \mathrm{CH}=\mathrm{CH}, 4-\mathrm{NO}_{2} \mathrm{C}_{6} \mathrm{H}_{4} \mathrm{CH}_{2}$, 2,2-dimethyl-1,3-dioxolan-4-one-5-yl, 4- $\mathrm{MeC}_{6} \mathrm{H}_{4}, t-\mathrm{Bu}, \mathrm{Cl}\left(\mathrm{CH}_{2}\right)_{3}$;

$\mathrm{R}^{2}=\mathrm{MeCH}_{2} \mathrm{C}\left(\mathrm{CH}_{3}\right)_{2}, t-\mathrm{Bu},(\mathrm{Me})_{3} \mathrm{CCH}_{2} \mathrm{C}(\mathrm{Me})_{2}$, adamantan-1-yl, $\mathrm{MeO}_{2} \mathrm{COCH}_{2} \mathrm{C}(\mathrm{Me})_{2}$, benzo[d][1,3]dioxol-5-yl
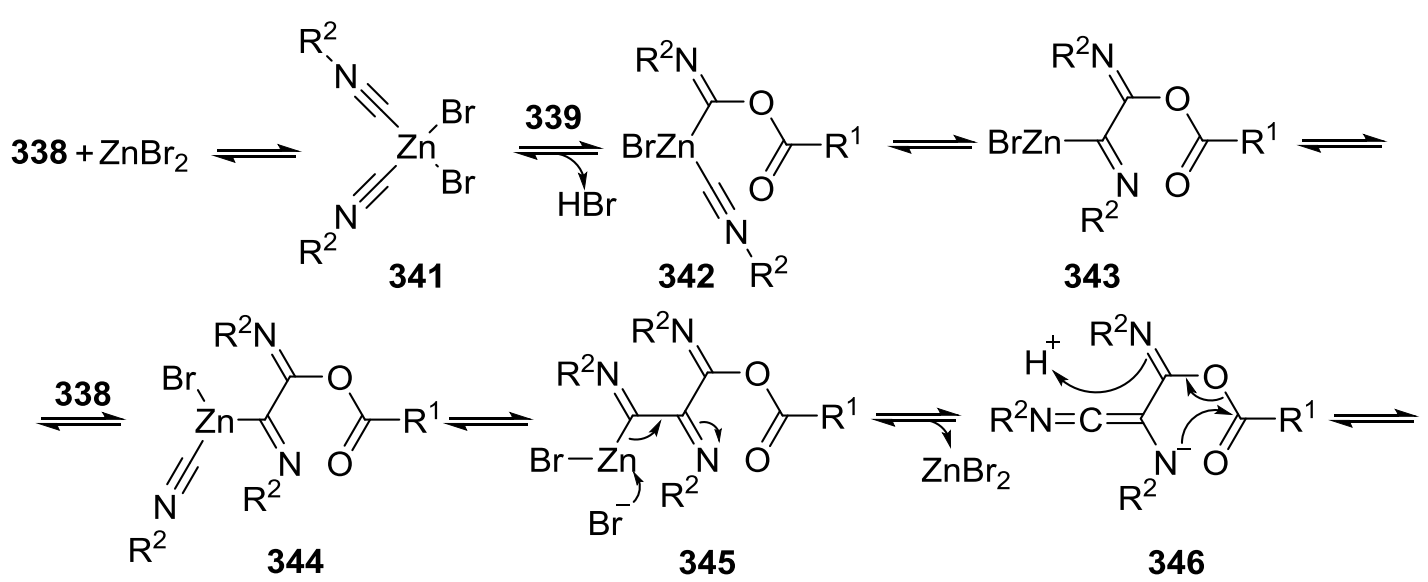

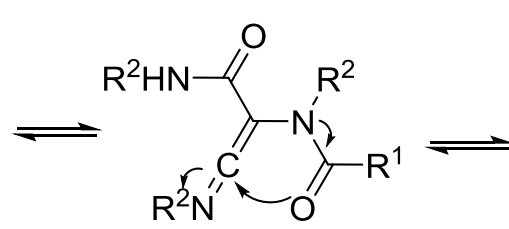

347<smiles>[R]NC(=O)c1c([NH2+][R])oc([R])[n+]1[R]</smiles>

348

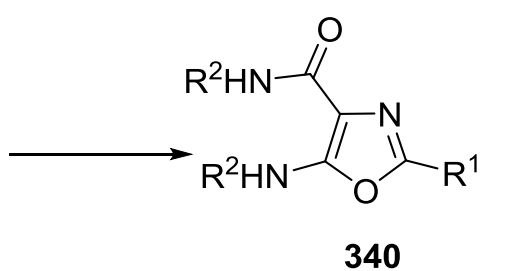

340

i) 338 (1.7 eq), 339 (1.0 eq), $\mathrm{ZnBr}_{2}$ (1.5 eq), PhMe, 60 or $100^{\circ} \mathrm{C}, 5 \mathrm{~min}-2 \mathrm{~h}$.

Scheme 92. Zn(II)-mediated synthesis of oxazoles $\mathbf{3 4 0}$ 
There has been significant progress in developing multi-component methods using simple starting materials in recent years providing accessible and versatile methods for the preparation of the core oxazole structure which should find good applicability in the field of medicinal chemistry.

\section{O1-C5 AND C4-C5 BOND DISCONNECTION}

\section{TIN(IV)}

Bisoxazoles 350 are available through the Sn(IV)-mediated reaction of diamides $\mathbf{3 4 9}$ and acetic anhydride (Scheme 93). ${ }^{117}$ Although this protocol furnished bisoxazoles $\mathbf{3 5 0}$ in good to excellent yields, the substrate scope reported was limited to 4,4'-pyridyl and 5,5'-methyl substituents. Further exploration and understanding of this scope would be useful.

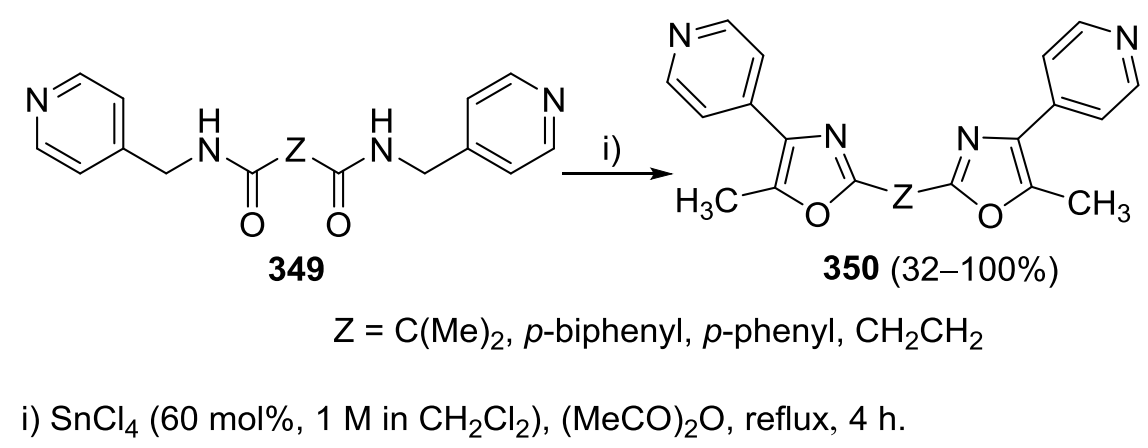

Scheme 93. Sn(IV)-mediated synthesis of bis-oxazoles $\mathbf{3 5 0}$

\section{ZINC(II)}

Ciufolini described an automated parallel synthesis of 2,4,5-trisubstituted oxazoles 352 through the $\mathrm{Zn}(\mathrm{II})$-mediated cyclisation of isonitriles 338 and $\alpha$-chloroglycinates 351 (Scheme 94). ${ }^{118}$ Although $\mathrm{Me}_{2} \mathrm{AlCl}$ proved to be a superior Lewis acid promoter for this transformation, automated parallel reactions were conducted using $\mathrm{ZnCl}_{2}$ due to the convenience of handling this reagent.

$$
\begin{aligned}
& 338 \\
& \mathrm{R}^{1}=\mathrm{Ph}, \mathrm{Me} \text {, cyclohexyl, 2- } \mathrm{MeC}_{6} \mathrm{H}_{4}, 2,6-\mathrm{F}_{2} \mathrm{C}_{6} \mathrm{H}_{3} ; \\
& \mathrm{R}^{2}=t-\mathrm{Bu}, n-\mathrm{Bu} \text {, cyclohexyl, } \mathrm{Bn}, 2,6-\mathrm{Me}_{2} \mathrm{C}_{6} \mathrm{H}_{3} \\
& \text { i) Chemspeed Robot, } \mathrm{ZnCl}_{2}(1.0-3.0 \text { eq), THF, rt. }
\end{aligned}
$$

Scheme 94. Zn(II)-mediated synthesis of oxazoles 352 


\section{N3-C4 BOND DISCONNECTION}

\section{GOLD(III)}

The $\mathrm{Au}(\mathrm{III})$-catalysed synthesis of oxazoles 354 through the cycloisomerisation of propargyl trichloroacetimidates 353 was disclosed by Hashmi (Scheme 95). ${ }^{119,120}$ Only two substrates $(\mathbf{3 5 3} ; \mathrm{R}=\mathrm{H}$ or $\mathrm{Me}$ ) were reported to be successful under these conditions, which provides significant opportunity to expand the functional group tolerance and substrate scope of this promising procedure. Interestingly, when using $\mathrm{Au}(\mathrm{I})$ catalysts the intermediate 355 could be isolated in good yield $\left(81 \%, \mathrm{R}^{1}=\mathrm{H}\right)$.

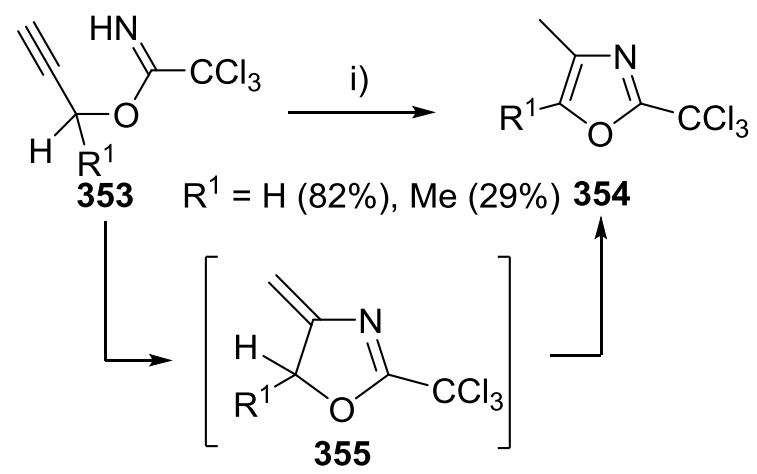

i) $\mathrm{AuCl}_{3}\left(3 \mathrm{~mol} \%, 10 \mathrm{w} / \mathrm{w} \%\right.$ in $\left.\mathrm{CD}_{3} \mathrm{CN}\right), \mathrm{CDCl}_{3}, \mathrm{rt}$., $3 \mathrm{~d}$.

Scheme 95. Au(III)-catalysed cycloisomerisation of propargyl trichloroacetimidates $\mathbf{3 5 3}$

It is interesting that the corresponding intermolecular reaction of propargylic alcohols with nitriles has yet to be described to access the oxazole core suggesting this procedure is challenging to bring about.

\section{O1-C2 AND C4-C5 BOND DISCONNECTION}

\section{COPPER(I)}

Ila reported a novel synthesis of bis-oxazole 358 through the $\mathrm{Cu}(\mathrm{I})$-catalysed reaction of oxazolone $\mathbf{3 5 6}$ and isocyanides 357 (Scheme 96). ${ }^{121}$ The reaction proceeds via the nucleophilic ring opening of $\mathbf{3 5 6}$ by the organo copper species 365 generating the copper enolate 360, which undergoes cyclisation to intermediate 361. Protonation of $\mathbf{3 6 1}$ gives oxazole 362 and regenerates the active catalyst. The resulting oxazole 362 undergoes formation of the copper chelated intermediate $\mathbf{3 6 3}$, which leads to bis-oxazole 358 via a 5-endo cyclisation. This protocol provides additional flexibility for access to a trisubstituted oxazole core when compared to the related methods developed by the same group. ${ }^{89,95}$ 


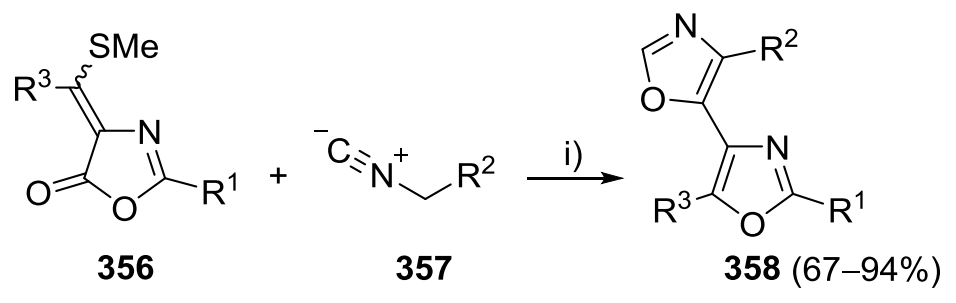

$\mathrm{R}^{1}=$ thiophen-2-yl, $\mathrm{Ph}$

$\mathrm{R}^{2}=\mathrm{CO}_{2}$ Et, pyridin-4-yl, 4- $\mathrm{ClC}_{6} \mathrm{H}_{4}, 1$-morpholinoformyl, Ts;

$\mathrm{R}^{3}=4-\mathrm{MeOC}_{6} \mathrm{H}_{4}, 3,4-\mathrm{MeO}_{2} \mathrm{C}_{6} \mathrm{H}_{3}$, thiophen-2-yl, 1-methyl-1H-pyrrol-2-yl,

1-methyl-1H-indol-3-yl, pyridin-3-yl, benzo[d][1,3]dioxol-5-yl

Proposed reaction mechanism

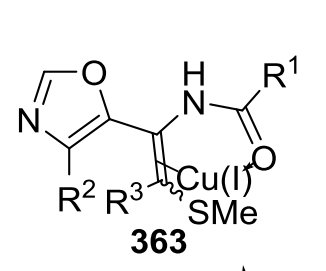<smiles>CCCCCC</smiles>

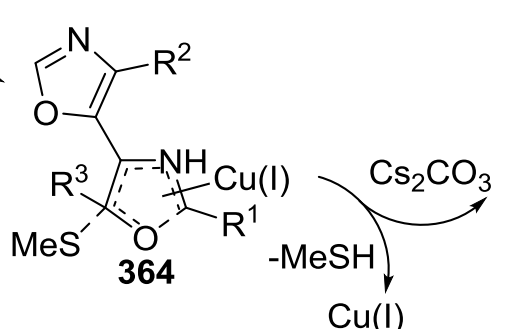<smiles>[R]c1nc(-c2ocnc2[R])c([R15])o1</smiles>

$\mathrm{Cu}(\mathrm{I})$

$\mathrm{Cu}(\mathrm{I})$<smiles>[R]C(=O)NC(=C([R])C([R])C)c1ocnc1[R]</smiles>

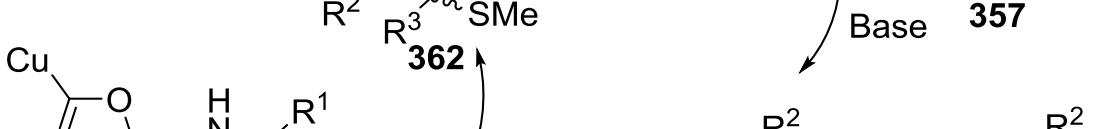

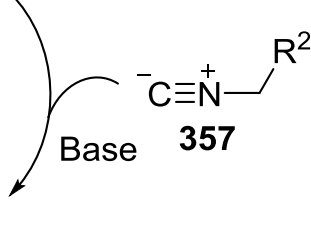

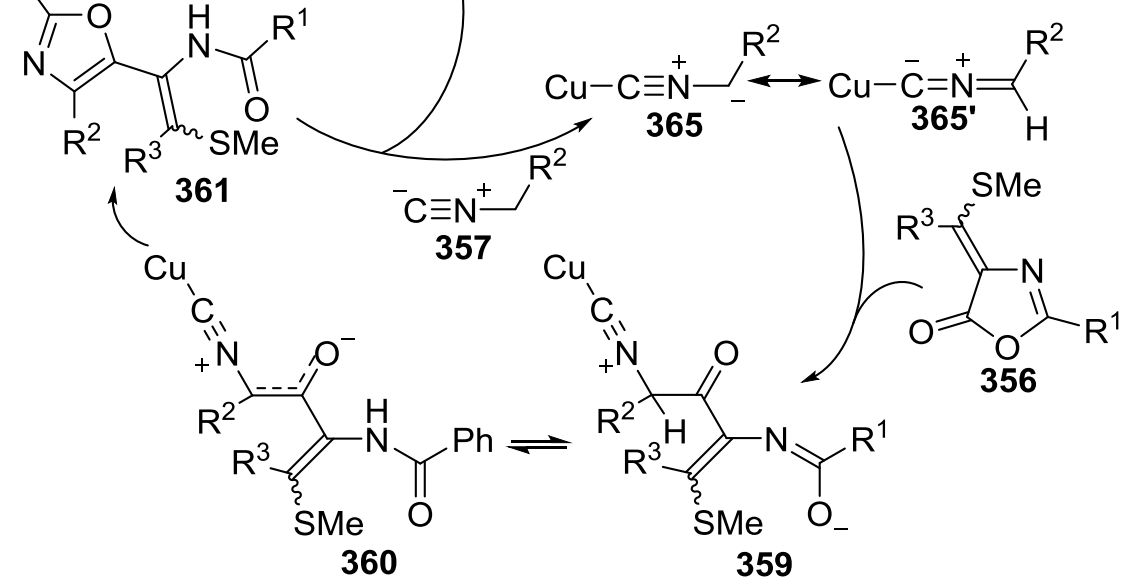

i) $\mathrm{Cul}(10 \mathrm{~mol} \%), \mathrm{Cs}_{2} \mathrm{CO}_{3}(1.0 \mathrm{eq}), \mathrm{DMF}, 90^{\circ} \mathrm{C}, 4-6 \mathrm{~h}$.

Scheme 96. Cu(I)-catalysed synthesis of oxazoles $\mathbf{3 5 8}$

\section{O1-C5, C2-N3 AND C4-C5 BOND DISCONNECTION}

\section{GOLD(III)}

A one-pot three-component $\mathrm{Au}(\mathrm{III})$-catalysed synthesis of trisubstituted oxazoles 368 from $N$-benzylimines 366, acid chlorides 367 and alkynes 123 was recently described by Strand (Scheme 97). ${ }^{122}$ The reaction proceeds via coupling of a copper acetylide 370 with an iminium species 369 to give a propargylamide 371 . Cyclisation of $\mathbf{3 7 1}$ by acid catalysis followed by debenzylation generates $\mathbf{3 7 3}$. Isomerisation of $\mathbf{3 7 3}$ forms 
375, which upon proto-demetallation furnishes oxazole 368. Substrate scope encompassed aliphatic, aryl and heteroaryl substituents. The method allows for preparation of a range of trisubstituted oxazoles 368 in moderate to excellent yields. The same transformation was performed in a seven-component fashion, which provided a tris-oxazole product in modest yield. ${ }^{122}$

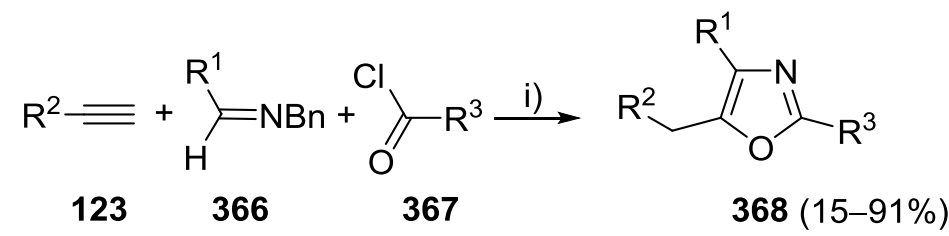

$\mathrm{R}^{1}=$ adamantan-1-yl, $t$ - $\mathrm{Bu}, \mathrm{MeO}_{2} \mathrm{CC}(\mathrm{Me})_{2}, \mathrm{H}, \mathrm{Ph}, \mathrm{BnOCH}_{2} \mathrm{C}(\mathrm{Me})_{2}, \mathrm{CH}_{2}=\mathrm{CHCH}_{2} \mathrm{C}(\mathrm{Me})_{2}$;

$\mathrm{R}^{2}=4-\mathrm{FC}_{6} \mathrm{H}_{4}, t-\mathrm{BuSiMe}_{2}, \mathrm{ClCH}_{2} \mathrm{CH}_{2} \mathrm{CH}_{2}$;

$\mathrm{R}^{3}=4-\mathrm{FC}_{6} \mathrm{H}_{4}$, thiophen-2-yl, $i-\mathrm{Bu}, 4-\mathrm{MeOC}_{6} \mathrm{H}_{4}, t-\mathrm{Bu}, \mathrm{Ph}$

Proposed reaction mechanism

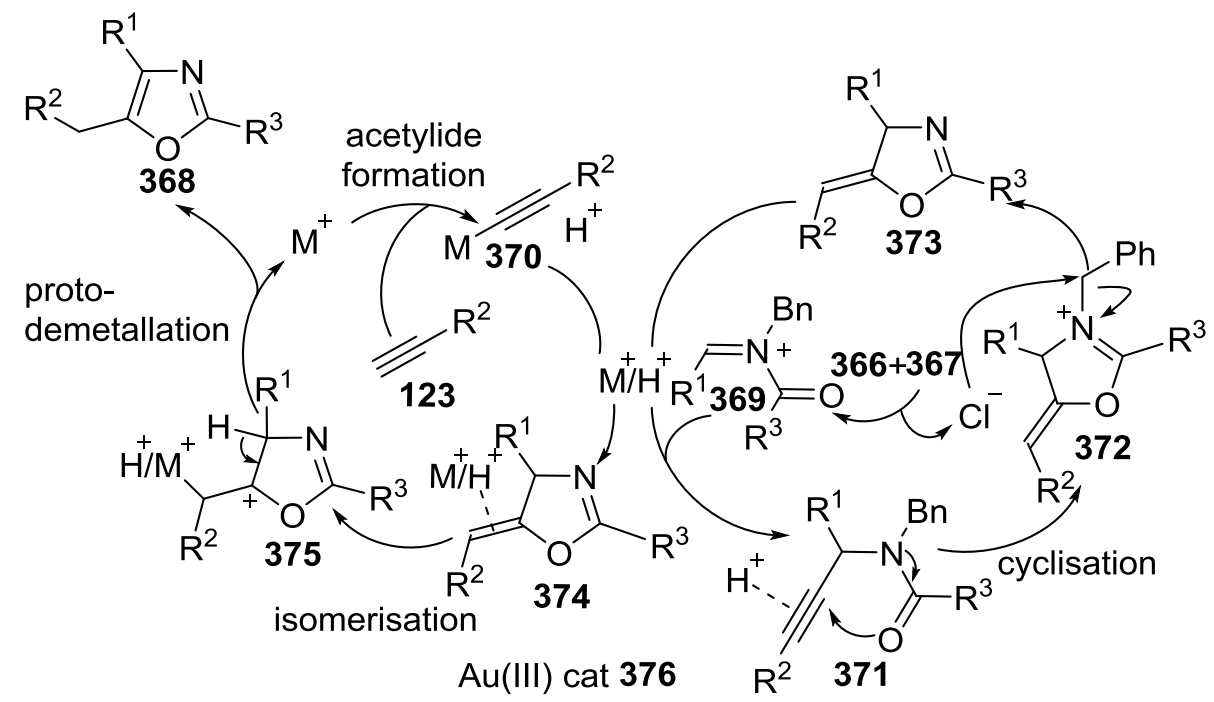

i) 123 (2.0 eq), 366 (1.0 eq), 367 (1.0 eq), Au-(salen) $\mathrm{PF}_{6} 376$ (1 or 5 mol\%), MW irrad, MeCN, $170{ }^{\circ} \mathrm{C}, 15 \mathrm{~min}$.

Scheme 97. Three-component $\mathrm{Au}(\mathrm{III})$-catalysed domino reaction

\section{O1-C5, C2-N3, N3-C4 AND C4-C5 BOND DISCONNECTION}

\section{COPPER(I)}

A one-pot four-component $\mathrm{Cu}(\mathrm{I})$-catalysed synthesis of oxazoles 368 from an alkyne 123, aldehyde 377, acid chlorides 367 and silylamide 378 has been described (Scheme 98). ${ }^{123}$ The reaction proceeds via imine formation followed by acylation to generate an iminium species $\mathbf{3 8 0}$. Coupling of $\mathbf{3 8 0}$ with a copper acetylide 382 generates a secondary propargylamide 381, which undergoes cycloisomerisation in the presence of a base to provide oxazole 368. This transformation can also be performed using $\mathrm{Zn}(\mathrm{II})$-catalysis. ${ }^{123}$ The protocol allows for the rapid assembly of trisubstituted oxazoles from simple building blocks. 


$$
\begin{aligned}
\mathrm{R}^{2} \equiv+\overbrace{377} & { }_{367}^{\mathrm{O}^{1}} \\
\mathrm{R}^{1} & =\mathrm{Ph}, 4-\mathrm{MeC}_{6} \mathrm{H}_{4}, 4-\mathrm{MeOC}_{6} \mathrm{H}_{4} ; \\
\mathrm{R}^{2} & =\mathrm{Ph} ; \\
\mathrm{R}^{3} & =\mathrm{Ph}, i-\mathrm{Pr}, i-\mathrm{Bu} ;
\end{aligned}
$$

Proposed reaction mechanism

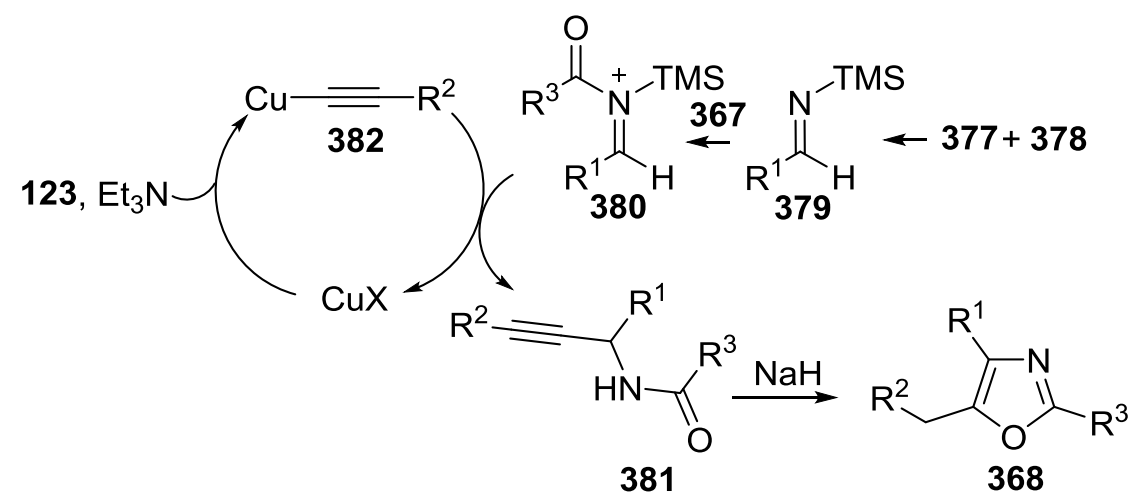

i) $\mathrm{HN}(\mathrm{TMS})_{2}(1.1 \mathrm{eq})$, BuLi (1.1 eq), hexanes, $0^{\circ} \mathrm{C}, 10 \mathrm{~min}$ then $377(1.0 \mathrm{eq}), 1 \mathrm{~h}, 0^{\circ} \mathrm{C}$ then $367(1.3 \mathrm{eq})$, rt, $30 \mathrm{~min}$ then 123 (1.0 eq), MeCN, Cul (10 mol\%), $\mathrm{BF}_{3} \cdot \mathrm{Et}_{2} \mathrm{O}(20 \mathrm{~mol} \%),(i-\mathrm{Pr})_{2} \mathrm{NH}(1.0 \mathrm{eq}), 65^{\circ} \mathrm{C}, 14 \mathrm{~h}$ then $\mathrm{NaH}(0.5 \mathrm{eq}), \mathrm{MeCN}, \mathrm{rt}, 30 \mathrm{~min}$.

Scheme 98. Stepwise one-pot four-component $\mathrm{Cu}(\mathrm{I})$-catalysed synthesis of oxazole $\mathbf{3 6 8}$

This ambitious process proceeds in remarkably high yields and provides an exceptionally effective way of preparing densely functionalised tri-substituted oxazole products 368. Although the strongly basic reaction conditions limit functional group tolerance, the ability to combine four components in a controlled and reliable manner is testament to understanding and knowledge of mechanism and reactivity applied in the development of this transformation.

\section{CONCLUSIONS}

The repertoire of chemical transformations developed for assembly of the oxazole ring is extensive. This is particularly the case for transition metal catalysed processes. In recent years significant progress has been made in developing simple and effective methods for the preparation of this important heterocycle. Of note is the emerging trend to develop protocols which have applicability to medicinal chemistry through the use of starting materials for which diverse monomer sets exist. Efforts to combine multi-step sequences into one-pot procedures have proved successful in this field circumventing the challenges associated with preparation of complex or unstable starting materials. This review has highlighted this progress and revealed further opportunities to develop additional oxazole-ring forming protocols. Notwithstanding the 
considerable advances achieved in this field, synthetic applications of transition metals have not yet been fully exploited. A more detailed understanding of reactivity and selectivity will be essential to create a platform for further development.

\section{ACKNOWLEDGEMENTS}

We thank the EPSRC for financial support.

\section{REFERENCES}

1. G. V. Boyd, 'Comprehensive Heterocyclic Chemistry', Vol. 6, ed. by A. R. Katritzky, and C. W. Rees, Pergamon, Oxford, 1984, 177; F. W. Hartner Jr., 'Comprehensive Heterocyclic Chemistry II', Vol. 3, ed. by A. R. Katritzky, C. W. Rees, and E. F. V. Scriven, Elsevier, Oxford, 1996, 261; V. Yeh, and R. Iyengar, 'Comprehensive Heterocyclic Chemistry III', Vol. 4, ed. by A. R. Katritzky, C.A. Ramsden, E. F. V. Scriven, and R. J. K. Taylor, Elsevier, Oxford, 2008, 487; D. W. Knight, 'Heterocycles in natural product synthesis', ed. by K. C. Majumdar, and S. K. Chattopadhyay, Wiley-VCH, Weinheim, 2011, 403; J. Revuelta, F. Machetti, and S. Cicchi, 'Modern Heterocyclic Chemistry', Vol. 2, ed. by J. Alvarez-Builla, J. J. Vaquero, and J. Barluenga, Wiley-VCH, Weinheim, 2011, 809; Z. Jin, Nat. Prod. Rep., 2011, 28, 1143; G. V. Boyd, 'Science of Synthesis', Vol. 11, ed. by E. Schaumann, 2001, 383; A. Khartulyari, and M. E. Maier, 'Science of Synthesis Knowledge Updates', Vol. 3, 2010, 57; A. V. Gulevich, A. S. Dudnik, N. Chernyak, and V. Gevorgyan, Chem. Rev., 2013, 113, 3084.

2. R. D. Connell, F. Scavo, P. Helquist, and B, Akermark, Tetrahedron Lett., 1986, $27,5559$.

3. R. D. Connell, M. Tebbe, A. R. Gangloff, P. Helquist, and B. Akermark, Tetrahedron, 1993, 49, 5445.

4. J. S. Tullis, and P. Helquist, Org. Synth., 1997, 74, 229.

5. R. D. Connell, M. Tebbe, P. Helquist, and B. Akermark, Tetrahedron Lett., 1991, 32, 17.

6. $\quad$ K. J. Doyle, and C. J. Moody, Tetrahedron Lett., 1992, 33, 7769.

7. K. J. Doyle, and C. J. Moody, Tetrahedron, 1994, 50, 3761.

8. D. Gong, L. Zhang, and C. Yuan, Synth. Commun., 2004, 34, 3259.

9. $\quad$ S.-K. Yoo, Tetrahedron Lett., 1992, 33, 2159.

10. T. Ibata, and K. Fukushima, Chem. Lett., 1992, 2197.

11. K. J. Doyle, and C. J. Moody, Synthesis, 1994, 1021.

12. C. J. Moody, K. J. Doyle, M. C. Elliot, and T. J. Mowlem, Pure Appl. Chem., 1994, 66, 2107.

13. P. Wolbers, A. M. Misske, and H. M. R. Hoffmann, Tetrahedron Lett., 1999, 40, 4527.

14. J. Linder, A. J. Blake, and C. J. Moody, Org. Biomol. Chem., 2008, 6, 3908.

15. Y. Wang, J. Janjic, and S. A. Kozmin, J. Am. Chem. Soc., 2002, 124, 13670; Y. Wang, J. Janjic, and S. A. Kozmin, Pure Appl. Chem., 2005, 77, 1161. 
16. J. Linder, T. P. Garner, H. E. L. Williams, M. S. Searle, and C. J. Moody, J. Am. Chem. Soc., 2011, 133, 1044.

17. J. C. Banks, and C. J. Moody, Tetrahedron Lett., 2009, 50, 3371.

18. H.-S. Kim, S. H. Kim, and J.-Y. Lee, J. Korean Chem. Soc., 1996, 40, 692.

19. G. Shi, and Y. Xu, J. Chem. Soc., Chem. Commun., 1989, 607.

20. K. Fukushima, and T. Ibata, Heterocycles, 1995, 40, 149.

21. Y. Wang, and S. Zhu, J. Fluorine Chem., 2000, 103, 139.

22. P. C. Ducept, and S. P. Marsden, Synlett, 2000, 692.

23. E. P. Gogonas, and L. P. Hadjìarapoglou, Tetrahedron Lett., 2000, 41, 9299.

24. Y. R. Lee, S. H. Yoon, Y. Seo, and B. S. Kim, Synthesis, 2004, 2787.

25. C. Batsila, G. Kostakis, and L. P. Hadjìarapoglou, Tetrahedron Lett., 2002, 43, 5997.

26. I. F. Clémençon, and B. Ganem, Tetrahedron, 2007, 63, 8665.

27. X. Xu, P. Y. Zavalij, W. Hu, and M. P. Doyle, Chem. Commun., 2012, 48, 11522.

28. R. Huisgen, H. König, G. Binsch, and H. J. Sturm, Angew. Chem., Int. Ed. Engl., 1961, 73, 368.

29. M. E. Alonso, and P. Jano, J. Heterocyclic Chem., 1980, 17, 721.

30. L. P. Hadjìarapoglou, Tetrahedron Lett., 1987, 28, 4449.

31. K. Nagayoshi, and T. Sato, Chem. Lett., 1983, 1355.

32. C. Wan, J. Zhang, S. Wang, J. Fan, and Z. Wang, Org. Lett., 2010, 12, 2338.

33. R. Paulissen, Ph. Moniotte, A. J. Hubert, and Ph. Teyssié, Tetrahedron Lett., 1974, 37, 3311.

34. P. Moniotte, A. J. Hubert, and Ph. Teyssié, J. Organomet. Chem., 1975, 88, 115.

35. K. Kitatani, T. Hiyama, and H. Nozaki, Tetrahedron Lett., 1974, 16, 1531.

36. K. Kitatani, T. Hiyama, and H. Nozaki, Bull. Chem. Soc. Jpn., 1977, 50, 1647.

37. R. Huisgen, G. Binsch, and L. Ghosez, Chem. Ber., 1964, 97, 2628.

38. M. Austeri, D. Rix, W. Zeghida, and J. Lacour, Org. Lett., 2011, 13, 1394.

39. M. V. Marques, M. M. Ruthner, L. A. M. Fontoura, and D. Russowsky, J. Braz. Chem. Soc., 2012, 23, 171.

40. M. P. Doyle, W. E. Buhro, J. G. Davidson, R. C. Elliot, J. W. Hoekstra, and M. Oppenhuizen, J. Org. Chem., 1980, 45, 3657.

41. M. C. Bagley, R. T. Buck, S. L. Hind, C. J. Moody, and A. M. Z. Slawin, Synlett, 1996, 825.

42. M. C. Bagley, R. T. Buck, S. L. Hind, and C. J. Moody, J. Chem. Soc., Perkin Trans. 1, 1998, 591.

43. P. Wipf and C. P. Miller, J. Org. Chem., 1993, 58, 3604.

44. M. Falorni, G. Dettori, and G. Giacomelli, Tetrahedron: Asymmetry, 1998, 9, 1419.

45. J. R. Davies, P. D. Kane, and C. J. Moody, Tetrahedron, 2004, 60, 3967.

46. B. Clapham, C. Spanka, and K. D. Janda, Org. Lett., 2001, 3, 2173. 
47. J. R. Davies, P. D. Kane, C. J. Moody, and A. M. Z. Slawin, J. Org. Chem., 2005, 70, 5840.

48. B. Shi, A. J. Blake, I. B. Campbell, B. D. Judkins, and C. J. Moody, Chem. Commun., 2009, 3291.

49. B. Shi, A. J. Blake, W. Lewis, I. B. Campbell, B. D. Judkins, and C. J. Moody, J. Org. Chem., 2010, 75, 152.

50. M. A. Honey, R. Pasceri, W. Lewis, and C. J. Moody, J. Org. Chem., 2012, 77, 1396.

51. M. C. Bagley, C. J. Moody, and A. G. Pepper, Tetrahedron Lett., 2000, 41, 6901.

52. M. C. Bagley, S. L. Hind, and C. J. Moody, Tetrahedron Lett., 2000, 41, 6897.

53. F. N. Palmer, F. Lach, C. Poriel, A. G. Pepper, M. C. Bagley, A. M. Z. Slawin, and C. J. Moody, Org. Biomol. Chem., 2005, 3, 3805.

54. J. R. Davies, P. D. Kane, and C. J. Moody, J. Org. Chem., 2005, 70, 7305.

55. C. J. Moody and M. C. Bagley, J. Chem. Soc., Perkin Trans. 1, 1998, 601.

56. M. C. Bagley, K. E. Bashford, C. L. Hesketh, and C. J. Moody, J. Am. Chem. Soc., 2000, 122, 3301.

57. K. Schuh and F. Glorious, Synthesis, 2007, 2297.

58. R. Martín, A. Cuenca, and S. L. Buchwald, Org. Lett., 2007, 9, 5521.

59. I. Cano, E. Álvarez, M. C. Nicasio, and P. J. Pérez, J. Am. Chem. Soc., 2011, 133, 191.

60. P. W. Davies, A. Cremonesi, and L. Dumitrescu, Angew. Chem. Int. Ed., 2011, 50, 8931.

61. E. Chatzopoulou and P. W. Davies, Chem. Commun., 2013, 49, 8617.

62. Y. Luo, K. Ji, Y. Li, and L. Zhang, J. Am. Chem. Soc., 2012, 134, 17412.

63. W. He, C. Li, and L. Zhang, J. Am. Chem. Soc., 2011, 133, 8482.

64. R. J. Lundgren, B. D. Peters, P. G. Alsabeh, and M. Stradiotto, Angew. Chem. Int. Ed., 2010, 49, 4071; K. D. Hesp, M. Stradiotto, J. Am. Chem. Soc., 2010, 132, 18026.

65. D. J. Ritson, C. Spiteri, and J. E. Moses, J. Org. Chem., 2011, 76, 3519.

66. F. O. Blümlein, Ber., 1884, 17, 2578; M. Lewy, Ber., 1887, 20, 2576.

67. C. Spiteri, D. J. Ritson, A. Awaad, and J. E. Moses, J. Saudi Chem. Soc., 2011, 15, 375.

68. Y. Hu, R. Yi, F. Wu, and B. Wan, J. Org. Chem., 2013, 78, 7714.

69. W.-W. Xu, M. Lin, Y. Huang, L. Chen, and Z.-P. Zhan, Lett. Org. Chem., 2009, 664.

70. G. C. Senadi, W.-P. Hu, J.-S. Hsiao, J. K. Vandavasi, C.-Y. Chen, and J.-J. Wang, Org. Lett., 2012, 14, 4478.

71. M. D. Milton, Y. Inada, Y. Nishibayashi, and S. Uemura, Chem. Commun., 2004, 2712.

72. M. P. Kumar, and R.-S. Liu, J. Org. Chem., 2006, 71, 4951.

73. C. L. Zhong, B. Y. Tang, P. Yin, Y. Chen, and L. He, J. Org. Chem., 2012, 77, 4271.

74. A. S. K. Hashmi, J. P. Weyrauch, W. Frey, and J. W. Bats, Org. Lett., 2004, 6, 4391.

75. J. P. Weyrauch, A. S. K. Hashmi, A. Schuster, T. Hengst, S. Schetter, A. Littmann, M. Rudolph, M. Hamzic, J. Visus, F. Rominger, W. Frey, and J. W. Bats, Chem. Eur. J., 2010, 16, 956. 
76. C. L. Paradise, P. R. Sarkar, M. Razzak, and J. K. De Brabander, Org. Biomol. Chem., 2011, 9, 4017.

77. G. Verniest, D. England, N. De Kimpe, and A. Padwa, Tetrahedron, 2010, 66, 1496.

78. G. Verniest, and A. Padwa, Org. Lett., 2008, 10, 4379.

79. A. S. K. Hashmi, A. M. Schuster, and F. Rominger, Angew. Chem. Int. Ed., 2009, 48, 8247.

80. A. S. K. Hashmi, A. M. Schuster, M. Schmuck, and F. Rominger, Eur. J. Org. Chem., 2011, 4595.

81. D. Aguilar, M. Contel, R. Navarro, T. Soler, and E. P. Urriolabeitia, J. Organomet. Chem., 2009, 694, 486.

82. M. J. Jou, X. Chen, K. M. K. Swamy, H. N. Kim, H.-J. Kim, S.-G. Lee, and J. Yoon, Chem. Commun., $2009,7218$.

83. O. A. Egorova, H. Seo, A. Chatterjee, and K. H. Ahn, Org. Lett., 2010, 12, 401.

84. O. A. Egorova, H. Seo, Y. Kim, D. Moon, Y. M. Rhee, and K. H. Ahn, Angew. Chem. Int. Ed., 2011, 50, 11446.

85. A. S. K. Hashmi and A. Littmann, Chem. Asian J., 2012, 7, 1435.

86. S. Orbisaglia, B. Jaques, P. Braunstein, D. Hueber, P. Pale, A. Blanc, and P. De Frémont, Organometallics, 2013, 32, 4153.

87. M. Tran-Dubé, S. Johnson, and I. McAlpine, Tetrahedron Lett., 2013, 54, 259.

88. N. Elders, E. Ruijter, F. J. J. De Kanter, M. B. Groen, and R. V. A. Orru, Chem. Eur. J., 2008, 14, 4961.

89. N. C. Misra, and H. Ila, J. Org. Chem., 2010, 75, 5195.

90. V. Amareshwar, N. C. Misra, and H. Ila, Org. Biomol. Chem., 2011, 9, 5793.

91. T. Sueda, A. Kawada, Y. Urashi, and N. Teno, Org. Lett., 2013, 15, 1560.

92. J. Das, J. A. Reid, D. R. Kronenthal, J. Singh, P. D. Pansegrau, and R. H. Mueller, Tetrahedron Lett., $1992,33,7835$.

93. A. E. Wendlandt, and S. S. Stahl, Org. Biomol. Chem., 2012, 10, 3866.

94. C. W. Cheung, and S. L. Buchwald, J. Org. Chem., 2012, 77, 7526.

95. S. V. Kumar, B. Saraiah, N. C. Misra, and H. Ila, J. Org. Chem., 2012, 77, 10752.

96. A. Arcadi, S. Cacchi, L. Cascia, G. Fabrizi, and F. Marinelli, Org. Lett., 2001, 3, 2501.

97. A. Saito, K. Limura, and Y. Hanzawa, Tetrahedron Lett., 2010, 51, 1471.

98. E. M. Beccalli, E. Borsini, G. Broggini, G. Palmisano, and S. Sottocornola, J. Org. Chem., 2008, 73, 4746.

99. F. Eloy, and A. Deryckere, Chim. Ter., 1973, 4, 437.

100. F. Micheli, G. Bonanomi, F. E. Blaney, S. Braggio, A. M. Capelli, A. Checchia, O. Curcuruto, F. Damiani, R. Di Fabio, D. Donati, G. Gentile, A. Gribble, D. Hamprecht, G. Tedesco, S. Terreni, L. Tarsi, A. Lightfoot, G. Stemp, G. MacDonald, A. Smith, M. Pecoraro, M. Petrone, O. Perini, J. Piner, 
T. Rossi, A. Worby, M. Pilla, E. Valerio, C. Griffante, M. Mugnaini, M. Wood, C. Scott, M. Andreoli, L. Lacroix, A. Schwarz, A. Gozzi, A. Bifone, C. R. Ashby, J. J. Hagan, and C. Heidbreder, J. Med. Chem., 2007, 50, 5076; A. Petrocchi, P. Jones, M. Rowley, F. Fiore, and V. Summa, Bioorg. Med. Chem., 2009, 19, 4245; J. Saunders, M. Cassidy, S. B. Freedman, E. A. Harley, L. L. Iverse, C. Kneen, A. M. MacLeod, K. J. Merchant, R. J. Snow, and R. Baker, J. Med. Chem., 1990, 33, 1128; L. J. Street, R. Baker, J. L. Castro, M. S. Chambers, A. R. Guiblin, S. C. Hobbs, V. G. Matassa, A. J. Reeve, M. S. Beer, D. N. Middlemiss, A. J. Noble, J. A. Stanton, K. Scholey, and R. J. Hargreaves, J. Med. Chem., 1993, 36, 1529.

101. H. Lee, and H.-J. Kim, Tetrahedron Lett., 2011, 52, 4775.

102. H. Lee, and H.-J. Kim, Bull. Korean Chem. Soc., 2011, 32, 3959.

103. X. Meng, and S. Kim, Org. Biomol. Chem., 2011, 9, 4429.

104. Q. Xia, and B. Ganem, Org. Lett., 2002, 4, 1631.

105. M. Passerini, and L. Simone, Gazz. Chim. Ital., 1921, 51, 126; M. Passerini and G. Ragni, Gazz. Chim. Ital., 1931, 61, 964.

106. Q. Wang, Q. Xia, and B. Ganem, Tetrahedron Lett., 2003, 44, 6825.

107. Q. Wang and B. Ganem, Tetrahedron Lett., 2003, 44, 6829.

108. Y. Odabachian, Q. Wang, and J. Zhu, Chem. Eur. J., 2013, 19, 12229.

109. S. Wang, M.-X. Wang, D.-X. Wang, and J. Zhu, Eur. J. Org. Chem., 2007, 4076.

110. X. Li, L. Huang, H. Chen, W. Wu, H. Huang, and H. Jiang, Chem. Sci., 2012, 3, 3463.

111. Z. Xu, C. Zhang, and N. Jiao, Angew. Chem. Int. Ed., 2012, 51, 11367.

112. W. He, C. Li, and L. Zhang, J. Am. Chem. Soc., 2011, 133, 8482.

113. J. C. Lee and I.-G. Song, Tetrahedron Lett., 2000, 41, 5891.

114. E. Merkul and T. J. J. Müller, Chem. Commun., 2006, 4817.

115. E. Merkul, O. Grotkopp, and T. J. J. Müller, Synthesis, 2009, 502.

116. Y. Odabachian, S. Tong, Q. Wang, M.-X. Wang, and J. Zhu, Angew. Chem. Int. Ed., 2013, 52, 10878. 117. Y. Martín-Cantalejo, B. Sáez, J. Soto, M. J. Villa, and M. F. Braña, Synthesis, 2003, 2211.

118. J. Zhang, P.-Y. Coqueron, J.-P. Vors, and M. A. Ciufolini, Org. Lett., 2010, 12, 3942; J. Zhang, P.-Y. Coqueron, and M. A. Ciufolini, Heterocycles, 2011, 82, 949.

119. A. S. K. Hashmi, M. Rudolph, S. Schymura, J. Visus, and W. Frey, Eur. J. Org. Chem., 2006, 4905.

120. A. S. K. Hashmi, Chem. Rev., 2007, 107, 3180.

121. S. Yugandar, A. Acharya, and H. Ila, J. Org. Chem., 2013, 78, 3948.

122. H. V. Wachenfeldt, P. se, F. Paulsen, N. Loganathan, and D. Strand, Chem.Eur. J., 2013, 19, 7982.

123. D. A. Black and B. Arndtsen, Tetrahedron, 2005, 61, 11317; M. Regitz, 'Diazo Compounds. Properties and Synthesis', Academic Press, Inc., London, 1986. 


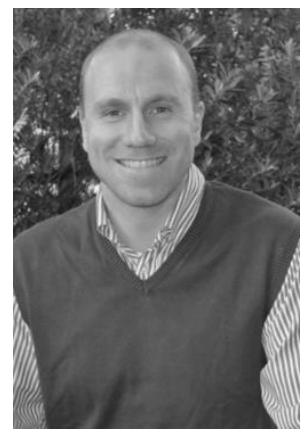

Stefano Bresciani Stefano Bresciani was born in Viadana, Italy, in 1979. He received his M.Sc. in Chemistry and Pharmaceutical Technologies (2004) from the University of Parma. After around two years in industry, he moved to the University of St Andrews in 2007, where he received his $\mathrm{PhD}$ (2010) in organofluorine chemistry under the supervision of Professor David O'Hagan. In 2011 he joined the research group of Professor Nicholas Tomkinson for a postdoctoral position in synthetic organic and medicinal chemistry. This included an initial period at the University of Strathclyde, Glasgow, UK. He is currently completing his postdoctoral contract (2011-present) at GlaxoSmithKline, Stevenage, UK.

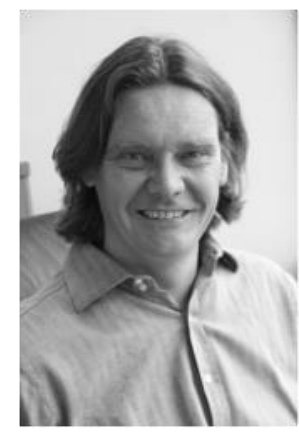

Nick Tomkinson was born in St Andrews, Scotland in 1969. He studied Chemistry at The University of Sheffield and received his PhD in 1996 under the supervision of Dr D. Neville Jones and Professor Jim Anderson. After postdoctoral studies with Dr Tim Willson at GlaxoSmithKline, North Carolina (1996-1998), he was appointed to the staff at Cardiff University in 1999. In June 2011 he took up a position in the Department of Pure and Applied Chemistry at the University of Strathclyde. His research interests are centred on the development of practical synthetic methodology and the preparation of tool compounds of biological relevance. 